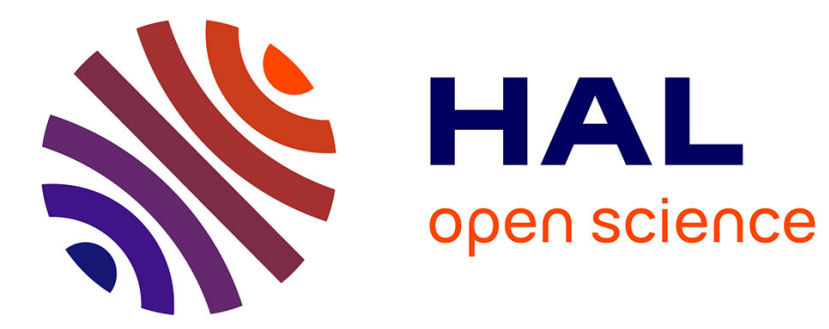

\title{
"L'église romane de Croute à Lasserrade (Gers) : un édifice inachevé de Gascogne centrale autour de 1125"
}

Christophe Balagna

\section{To cite this version:}

Christophe Balagna. "L'église romane de Croute à Lasserrade (Gers) : un édifice inachevé de Gascogne centrale autour de 1125". Archéologie du Midi Médiéval, 2008, 26, pp. 59-91. hal-02427364

\section{HAL Id: hal-02427364 \\ https://hal.science/hal-02427364}

Submitted on 3 Jan 2020

HAL is a multi-disciplinary open access archive for the deposit and dissemination of scientific research documents, whether they are published or not. The documents may come from teaching and research institutions in France or abroad, or from public or private research centers.
L'archive ouverte pluridisciplinaire HAL, est destinée au dépôt et à la diffusion de documents scientifiques de niveau recherche, publiés ou non, émanant des établissements d'enseignement et de recherche français ou étrangers, des laboratoires publics ou privés. 


\section{L'église romane de Croute à Lasserrade (Gers) : Un édifice inachevé de Gascogne centrale autour de $1125^{1}$}

\section{Christophe BALAGNA*}

L'église romane Sainte-Christine de Croute, anciennement dédiée à saint Barthélemy, est un édifice peu connu, complexe, mais particulièrement intéressant. Si un très petit nombre de chercheurs s'est penché sur ce bâtiment à la structure désordonnée et à l'aspect extérieur modeste, l'étude de son architecture, par le biais des vestiges des élévations intérieure et extérieure, et l'analyse de son décor sculpté révèlent un monument digne des grands édifices romans régionaux. L'étude de l'église de Croute renouvelle également nos connaissances sur la place qu'occupe la Gascogne gersoise dans le domaine de la commande religieuse à l'époque romane et l'élaboration de son décor démontre la parfaite connaissance des ensembles sculptés contemporains dont la diffusion des motifs et des images est assurée par les artistes eux-mêmes à travers leurs pérégrinations.

Mots clefs: Lasserrade, Croute, Crota, Gascogne centrale, architecture romane, sculpture romane, sculpture hispano-languedocienne.

\section{Une histoire énigmatique :}

L'historiographie de l'église Saint-Barthélemy² de Croute est assez récente et comporte très peu de titres. En effet, seuls Paul Mesplé et l'abbé Jean Cabanot ont rédigé une courte notice de cette construction. Paul Mesplé, dans un article fondateur (Mesplé 1971, 75-130), a reconnu l'importance du plan de l'édifice qu'il a associé à celui d'autres monuments religieux de Gascogne centrale. Sa courte présentation pose les jalons d'une étude plus complète qu'il restait à accomplir ${ }^{3}$, rendue difficile par l'indigence des sources dont rendait compte sa bibliographie succincte. Dans le volume de la collection «La Nuit des Temps » consacré à la Gascogne, l'abbé Jean Cabanot résume assez bien tout l'intérêt de l'édifice qui réside en deux thèmes majeurs : la qualité de la construction et l'élégance du décor sculpté encore en place (Cabanot 1978, 34-35). L'auteur tente même quelques comparaisons stylistiques qui ne demandent qu'à être complétées, approfondies et élargies. Enfin, l'aspect historique reste à nouveau bien mince, du fait de l'absence de véritables documents.

Effectivement, il nous est bien difficile aujourd'hui de faire jaillir de l'ombre l'histoire de l'église qui, parmi les très nombreux monuments gersois encore mal connus, occupe sans doute parmi eux une place éminente. Tout d'abord, nous ne savons rien des origines de l'église, bien que deux légendes circulent, transmises par certaines sources modernes et les érudits locaux du XIXe siècle.

\footnotetext{
* 14, rue de la Porte de Rieux 31310 Montesquieu-Volvestre.

1. Les pièces graphiques qui accompagnent cet article ont été en grande partie réalisées grâce à l'aide précieuse de Stéphane Abadie. Sa disponibilité, ses remarques pertinentes et ses compétences techniques sont pour beaucoup dans l'élaboration de cette étude. Qu'il trouve ici l'expression de ma plus vive reconnaissance.

2. Pour des raisons de commodités, on conservera au cours de cette étude le vocable primitif.

${ }^{3}$. Mesplé 1971, 121 : «Église très mutilée, sur laquelle on est très mal informé, mais dont les restes témoignent d'un grand et bel édifice, à trois absides semi-circulaires et trois nefs. Il en reste l'abside centrale, la plus importante, mais sans son cul-de-four ; l'absidiole sud, qui l'a conservé, et une petite partie de l'absidiole nord (dans la sacristie). De la nef, il n'est demeuré que des fragments de trois grosses piles rondes. Peut-être faut-il lui rattacher les restes de substruction de mur que l'on voit dans le jardin, à l'ouest [au sud]. Abside et absidioles sont décorées intérieurement d'une arcature à beaux chapiteaux. L'appareil des murs est constitué de blocs bien taillés, mais irréguliers ».
} 
La première mentionne l'existence, vers 600, d'un certain Auditus ou Auditius, issu d'une famille noble et chrétienne de Toulouse et obligé de quitter la région pour fuir les persécutions ariennes. Il se retira sur les coteaux de l'Arros. Devenu Ausit, il propagea la foi chrétienne et s'installa dans un petit ermitage. Lors d'une fête païenne, il aurait été poursuivi par des adorateurs du soleil et mis à mort. Ses disciples auraient recueilli son corps et l'auraient enseveli dans sa petite chapelle. Plus tard, on reconstruisit près de cet ermitage l'église de Croute ${ }^{4}$. La deuxième, sans doute aussi peu crédible, mentionne un certain Ausit ${ }^{5}$, saint évêque d'Auch, qui aurait accompagné Sénoc, l'un des derniers évêques d'Éauze, au concile de Reims. Il aurait été égorgé, près de l'Arros, par une horde barbare, devant laquelle il avait fui. Il aurait existé vers $634^{6}$. Il fit ainsi l'objet d'un pèlerinage local et on l'invoquait principalement contre la surdité. Son corps aurait été placé dans l'église de Croute, dans une crypte, située sous le maître-autel ${ }^{7}$. Malheureusement, nous ne savons presque rien de ces deux prélats, mis à part ce que nous en disent dom Brugèles ${ }^{8}$ et J.-J. Monlezun ${ }^{9}$. Quant à la crypte, qui pourrait également être une simple confession, ou un caveau voûté, il n'en existe aucune trace, ni dans les sources, ni à travers l'analyse archéologique de l'édifice. Nous en sommes donc réduits à de simples conjectures.

En ce qui concerne l'époque médiévale, nous ne savons là non plus pratiquement rien ${ }^{10}$. Le cartulaire de Saint-Mont cite une charte du XIe siècle où l'on trouve la mention de l'église Sainte-Christine de Lasserrade $^{11}: s^{\prime} i l$ ne s'agit pas de notre édifice, on peut penser que l'église de Croute n'appartenait pas à Saint-Mont. Au plan religieux, aux XIVe et XVe siècles, l'église de Croute ou Crota fait partie de l'archidiaconé de Pardiac ${ }^{12}$. Elle semble alors être une simple chapelle rurale desservie par un

4. Cet épisode de la vie du saint a la vie dure puisque Monlezun 1846, 225, raconte qu' «à l'extrémité du porche, se voyaient naguère les restes d'une chapelle dont la voûte bien proportionnée a longtemps survécu à une partie de l'édifice. On croit communément que les reliques de saint Ausit furent d'abord déposées dans cette chapelle et qu'elles furent depuis transférées dans l'église actuelle ». Il n'y a aucune trace d'une construction supplémentaire près de l'église de Croute. Cette chapelle est vraisemblablement l'absidiole est, dont la voûte est la seule conservée de l'église.

${ }^{5}$. Ausit était fêté le 24 août. Monlezun, 1846, 225, relate que dans un ancien calendrier, on pouvait lire à la date du 24 août : «Festum Sancti Bartolomei Apostoli et Sancti Auditii episcopi et martyris». Malheureusement, et comme souvent, Monlezun ne cite pas ses sources. Quant aux Bollandistes des Acta Sanctorum, ils ne disent rien d'un saint Auditus, ou Auditius, ou Ausit, fêté au 24 août. Je remercie Patrice Cabau de m’avoir communiqué cette dernière information.

${ }^{6}$. En ce qui concerne les évêques d'Éauze, la liste s'interrompt en 627 avec Sidocus, pour reprendre vers 673 avec l'évêque Scupilio. Pour les prélats auscitains, Auderic est évêque de 625 à 634, suivi entre 635 et 646 par Domnin. Pour certains, Auderic ou Aulderic pourrait être saint Ausit. A nouveau, les Acta Sanctorum ne mentionnent pas l'existence d'un saint Audericus.

${ }^{7}$. On raconte qu'on « voyait à la face nord d'un bel autel roman, une profonde excavation où ceux qui sollicitaient leur guérison passaient la tête et se frottaient les oreilles. Quand cet autel fut remplacé par un autel moderne, on détruisit ces reliques, et peutêtre même le tombeau ». La présence d'une crypte ou d'un espace plus modeste situé sous le chœur pourrait être attestée par l'étymologie même du nom de Crota : le terme serait issu du latin crypta. Enfin, depuis le XIXe siècle, on relate qu'en frappant le sol du sanctuaire, on obtient des résonances qui permettent de croire en l'existence de cavités sous le sanctuaire. Tout cela demande à être vérifié d'un point de vue archéologique. Rappelons qu'en Béarn, plus précisément en Vic-Bilh, on découvrit dans l'église paroissiale Saint-Julien-de-Lescar de Sedze-Maubecq un caveau voûté, situé sous le chœur. Large et haut de 1,80 m, on y accédait par un escalier. Cette découverte a été faite en 1895 par le curé. Peut-être avons-nous le même système à Croute ? Cela est d'autant plus plausible quand on évoque les relations artistiques entre certaines églises béarnaises et nos constructions de Gascogne centrale : Cabanot 1978, 42-43 et Lassère 1989 dir., 566-568.

8. Brugèles 1746, 65 : «XXXI - Auderic, autrement Audic ou Audit, assista au 1er concile de Reims avec son métropolitain Senoc, l'an 625. Il vivait encore en $634 »$.

9. Monlezun 1846, 225-226 : «Senoc, métropolitain d'Éauze, assiste au concile de Reims en 630 » (sic). L'auteur donne la liste des évêques d'Auch, qu'il emprunte notamment à la Gallia Christiana: "Cithoire, Titoine, Dracoald, puis Auderic ou Audit qui accompagna Senoc à Reims. Ses reliques sont sous le maître-autel de Croute ».

10. En 1308, Gaston, comte de Foix, aurait brûlé Lasserrade après avoir massacré 40 personnes : Breuils 1915, 110-128. C'est l'un des rares événements historiques antérieurs à l'époque moderne qui pourrait concerner l'église de Croute.

11. Samaran 1953, 43-44, charte 47. Le vocable de sainte Christine à Croute paraît assez récent, sans qu'il soit possible d'en préciser la date exacte. Tous les documents conservés, notamment les plus anciens, mentionnent le vocable de saint Barthélemy. Il faut donc chercher ailleurs qu'à Croute l'église dédiée à sainte Christine mentionnée dans le cartulaire.

12. Breuils 1901, 185 et Saint-Blanquat 1972 : en 1383-1384, est cité le capellanus de Crota comme faisant partie de l'archidiaconé de Pardiac (p. 288), en 1405, le capellanus de Crota, qui dessert également les églises de Arteni et de Podio Draguino est à nouveau mentionné (p. 309). Enfin, toujours au XVe siècle, l'ecclesia de Crota est signalée comme appartenant à l'archidiaconé de Pardiac (p. 330), puis comme relevant de l'archidiaconé d'Armagnac. A ce moment-là, elle est unita ad ecclesiam de Artheys [alias de Podio Draguino] (p. 334). Je remercie à nouveau Patrice Cabau de ces éclaircissements concernant le statut de l'église de Croute à l'époque médiévale. 
chapelain ou un curé. Pourtant, de nombreux auteurs évoquent les liens qui auraient uni l'église de Croute à l'abbaye de Tasque (Monlezun 1846, 225-226, texte repris par d'Ayrens 1911). En effet, jusqu'en 1793, l'abbé de Tasque se rendait chaque année à Croute lors de la fête du saint, accompagné par des moines. Ce jour-là, il percevait toutes les offrandes faites par les fidèles, se contentant d'en donner une partie, non au desservant de Croute, mais au seigneur de Lasserrade dont l'église dépendait ${ }^{13}$. Ce seigneur était lui-même obligé $d^{\prime} y$ aller faire le guet avec ses vassaux, la veille et le jour de la fête ${ }^{14}$. Depuis le XII siècle, de nombreux seigneurs ont possédé cet ancien castelnau qui domine la plaine de l'Arros. Parmi eux, on peut citer Sanche de Lados qui vend ses terres de Lasserrade à l'abbé de La Case-Dieu en 1292 (Laclaverie 2005, 360-361). Est-il possible qu'à ce moment-là l'église de Croute ait été donnée à La Case-Dieu en même temps que le village, ou bien l'église dépendait-elle encore d'une communauté religieuse plus importante, ce qui voudrait dire que l'union de l'église à la seigneurie de Lasserrade est postérieure ? C'est malheureusement impossible à vérifier. Puis, de la fin du XIVe siècle jusqu'en 1573, Lasserrade appartint à la famille de Lupé, avant de passer successivement aux mains des familles de Lacassagne, de Pins, d'Andouins, de Mont et de Sérignac en 1634 (Laclaverie 2005, 360-361). Nous reviendrons plus loin sur les liens qui unissaient l'église de Croute à certains seigneurs de Lasserrade.

Les sources modernes signalent l'église de Croute mais ne nous offrent que très peu d'indications pertinentes. C'est le cas en 1546, lors d'une visite faite le 19 novembre, ayant pour objet de vérifier si l'ecclesia de Crota a besoin de réparations (Breuils 1889, 74 note 2). Malheureusement, nous n'apprenons rien de particulier, ce qui pourrait être l'indice d'un édifice en bon état. Cela pourrait donc dire que la destruction de la partie sud ${ }^{15}$ de l'église - $\mathrm{s}^{\prime} \mathrm{il}$ y a bien eu destruction - a pu intervenir pendant les guerres de Religion, à la fin du siècle. En effet, entre 1568 et 1569, Gabriel de Lorges, comte de Montgomery, met en coupe réglée une grande partie de la Gascogne. Durant l'automne 1569 et une partie de l'hiver 1569-1570, il est en Astarac, en Pardiac, en Rivière-Basse, avant de remonter vers $1^{\prime}$ Armagnac ${ }^{16}$. Auparavant, en 1564, dans un recueil des dîmes du chapitre d'Auch, on apprend que l'abbé de Tasque, ainsi que les moines, se partagent les revenus de l'église ${ }^{17}$. Devonsnous à nouveau en conclure que l'église de Croute a appartenu à l'abbaye de Tasque ? L'hypothèse est tentante mais ne repose sur aucun texte avéré.

Dans un pouillé de 1672, Croute est citée comme une annexe de Pouydraguin (Bourgeat 1934, 279). La même remarque apparaît chez Dom Brugèles, un siècle plus tard (Brugèles 1746, 389). L'auteur, qui, d'ordinaire, se montre disert sur les édifices réguliers, abbayes, prieurés, chapelles desservies par des moines, est particulièrement discret sur Croute. Il mentionne simplement que

13. Ce texte apparaît d'ailleurs chez Louis Daignan du Sendat (1680-1764), curé de Samatan, puis de Saint-Orens d'Auch, chanoine métropolitain puis vicaire général. Docteur en théologie, féru d'histoire, il rédigea au cours de sa vie 12 volumes actuellement conservés à la Bibliothèque municipale $\mathrm{d}$ 'Auch, dans lesquels il copia et compila un grand nombre de documents, dont certains sont aujourd'hui disparus. C'est donc une inestimable source de renseignements. Au sujet de Croute, cf. Bibliothèque municipale d'Auch, ms. 72, p. 325.

14. Certains auteurs arguent du fait que Tasque dépendait à ce moment-là du diocèse de Tarbes, ce qui aurait empêché l'abbé de percevoir quoi que ce soit de Croute. Cette affirmation ne tient pas. Pourtant le père Lamazouade, qui a écrit au début du $X X^{e}$ siècle une histoire de Croute restée à l'état de manuscrit, rapporte l'existence, dans des archives privées, d'un document daté de 1666, déclarant que «si depuis quelques années le curé de Pouydraguin qui faisait le service religieux de la paroisse de Croute, avait autorisé la présence de religieux de Tasque dans l'église de Croute, le jour de la fête de saint Ausit, cela devait cesser car s'il leur avait permis de prélever les dons faits par les fidèles, c'était uniquement par tolérance ». Je n'ai pas pu retrouver la trace de ce document.

15. L'église n'est pas correctement orientée, puisque le chœur est construit en direction du nord. La partie située habituellement à l'ouest, dans le cas d'un édifice orienté, est donc ici au sud.

16. On a pu reconstituer une partie du périple destructeur des protestants : le 23 octobre 1569, Montgomery et ses troupes s'acharnent sur l'église de Nogaro, le 28 octobre, ils s'en prennent à Madiran, Tasque, Saint-Mont, Castelnau Rivière-Basse, dont ils détruisent une partie des édifices religieux. On le voit, ils sont donc tout près de Croute. On peut dès lors envisager que cette proie facile, isolée sur sa colline, a pu être en grande partie dévastée.

17. Archives Départementales du Gers (désormais cité A.D.G.), série V. 223, 1564, f $73-74$ : « Au dit Lasserrade, se trouve une annexe qu'on appelle Croute et en l'église Saint-Barthélemy, le recteur de Pouydraguin et de l'annexe de Saint-Barthélemy prend la 4 e partie desdites dîmes et les 3 restantes se partent par moitié entre ledit archevêque d'Auch et l'abbé et religieux de Tasque». 
« l'église est d'une structure belle et antique. Il y a un grand tombeau de pierre qu'on dit être de saint Ausit (Auditus), qui est invoqué contre la surdité, et dont on fait la fête le 25 août ». A nouveau, nous retrouvons la mention d'un tombeau dans l'église, mais il est impossible d'en préciser l'emplacement exact. Enfin, celle-ci est à nouveau nommée dans un document de 1687 sans doute consécutif à des travaux de réfection dont l'église a fait l'objet ${ }^{18}$. En 1790, le territoire de Croute fut englobé dans celui de Lasserrade, canton de Plaisance. Au plan religieux, et jusqu'en 1853, Croute appartint à la paroisse de Pouydraguin, canton d'Aignan. Depuis 1853, l'église est rattachée à la commune de Lasserrade et elle est desservie par le curé de cette paroisse.

En ce qui concerne les restaurations, on note que l'édifice a subi peu de travaux importants, la plupart au XIXe siècle (A.D.G., série V. 201) : en 1839, un devis estimatif concerne quelques réparations au clocher, plus précisément à la flèche ${ }^{19}$. En 1855 et 1856, on projette de construire une sacristie, une grange, une écurie et une remise pour le presbytère, lequel comprend une salle à manger dont on fait le plancher et un galetas accessible par un escalier ${ }^{20}$. Pour la sacristie, un devis est proposé, tandis que les travaux au presbytère nécessitent 27 journées de maçon. En 1858, on construit un porche à l'entrée, sans doute un simple auvent, qui fut enlevé pour raisons esthétiques au cours du siècle dernier. En 1860, les travaux de construction de la sacristie démarrent après avoir été retardés depuis 1858. Elle occupe désormais l'emplacement de l'absidiole ouest.

Enfin, notons que l'église a fait récemment l'objet de sondages dans le chœur, afin de faire apparaître les vestiges de peintures murales qui semblent recouvrir tout l'intérieur du sanctuaire. Le rapport fait apparaître plusieurs éléments intéressants ${ }^{21}$ : on a pu déceler 3 couches de badigeon de chaux sur les chapiteaux, les arcs, les colonnes et les murs. Dessous, un décor polychrome ancien, à base de rouge et de bleu, se voit notamment sur les chapiteaux. Dans la première arcade à droite, un détail montre une peinture sur fine couche de badigeon de chaux, parfois à même la pierre. Dans la deuxième arcade à gauche, on aperçoit une bande décorative, à croisillons rouge et bleu, comportant aussi du rose. Dans l'arcade suivante, on trouve de l'ocre jaune. Mais surtout, en février 2006, on a procédé au dégagement du décor peint situé dans la première arcade de droite de l'abside d'axe. Un grand personnage en pied, bien conservé, a ainsi été révélé. Il s'agit d'un saint Christophe portant sur ses épaules l'Enfant Jésus au nimbe crucifère. Cette figure pourrait appartenir à l'époque gothique, tout comme les traces de peintures relevées sur les murs et sur les éléments sculptés, notamment les chapiteaux et les tailloirs. Mentionnons aussi les quadrilobes ornant l'intrados de l'arc triomphal de l'absidiole est, exemple intéressant du vocabulaire décoratif gothique utilisé lors de l'embellissement pictural de l'édifice, probablement au XIVe siècle.

En conclusion, que peut-on dire des circonstances qui ont présidé à la fondation de l'église de Croute? Tout d'abord, nous ne savons rien sur les origines de l'église. La présence supposée de reliques attribuées à un saint évêque d'Auch du VIIe siècle paraît la plus plausible. On aurait donc construit un édifice religieux, peut-être pourvu d'une crypte, plus vraisemblablement d'une confession, située sous l'autel. Seule une campagne de fouilles dans le sol du chœur ou bien des sondages nous permettraient de confirmer ou d'infirmer cette supposition. En ce qui concerne la communauté religieuse rattachée à l'église, c'est là aussi le mystère le plus complet. Comme nous le verrons plus loin, on avait prévu de construire l'édifice roman sur un plan particulièrement ambitieux. Il s'agissait sans doute de donner aux reliques conservées un cadre élégant et de pourvoir la

\footnotetext{
18. Cf. A.D.G., série G. 482, Procès-verbal de réception des réparations des églises du diocèse d'Auch, 1687 : « Le 20 e du mois de décembre, nous experts, nous sommes transportés en l'église de Croute laquelle nous avons visitée et parcouru les réparations qui ont été faites en icelle par Bavoyme entrepreneur. Nous avons vérifié qu'elles étaient conformes au devis qui en avait esté dressé par nous... ». Malheureusement, nous ne connaissons pas la teneur de ce devis.

19. D'autres réparations plus récentes furent effectuées en 1994-1995.

${ }^{20}$. Le presbytère occupe la partie sud de l'église et est construit entre le chœur aujourd'hui conservé et le ravin.

21. Auch, Service départemental de l'Architecture, dossier Lasserrade, église de Croute, sondage effectué le 5 juillet 1994.
} 
communauté d'une église en rapport avec les grands édifices locaux contemporains. L'église étant éloignée de tout bourg, village ou centre urbain, on peut alors envisager qu'il s'agissait d'une communauté monastique, sans doute bénédictine, desservant l'église. A quelle communauté était-elle rattachée ? C'est aujourd'hui impossible à dire. D'ailleurs, il n'existe absolument aucune trace de bâtiments religieux autour de l'église (fig. 1) ${ }^{22}$. En revanche, nous pouvons procéder par élimination pour évoquer les hypothèses envisageables :

- Croute n'appartint sans doute pas à la cathédrale d'Auch car ni le cartulaire noir, ni les cartulaires blancs, ni le Livre rouge de la cathédrale ne nomment la possession de cet établissement (A.D.G., séries G. 16, G. 17, G. 18, G. 19 ou Lacave-Laplagne-Barris 1899).

- Parmi les proches communautés religieuses, même constat: le cartulaire de l'abbaye de La CaseDieu ne mentionne jamais Croute ${ }^{23}$, ni même le nécrologe ${ }^{24}$. Dans le cartulaire de Saint-Mont, l'église de Croute n'apparaît pas non plus.

- Parmi ces édifices religieux situés près de notre église, le seul qui semble être en rapport plus ou moins étroit avec l'église est l'ancienne abbatiale de Tasque (Maroix 2004). Malheureusement, le cartulaire de l'abbaye a disparu. En tous cas, la mention de la visite annuelle de l'abbé de Tasque à Croute peut être considérée comme un élément pertinent. L'étude de l'architecture et du décor pourrait, seule, apporter quelques informations à ce sujet. Nous verrons d'ailleurs un peu plus loin que l'église de Croute semble entretenir des rapports précis sur le plan structurel avec l'ancienne abbatiale Saint-Pierre de Tasque. Cela renforce donc l'hypothèse d'un lien, dont il reste à définir la teneur, entre Tasque et Croute.

\section{Un programme architectural ambitieux mais avorté :}

Le chevet de l'édifice religieux étant dirigé vers le nord, sans doute pour des raisons topographiques ${ }^{25}$, l'actuelle église de Croute se laisse appréhender par sa modeste façade est. Le nouveau plan ${ }^{26}$ dressé spécialement dans le cadre de cette étude laisse apparaître, de prime abord, une construction tronquée, dont ne subsistent qu'un chevet tripartite, et plus précisément, l'abside d'axe et l'absidiole orientale en totalité, c'est-à-dire avec leur travée droite, ainsi qu'une petite partie de l'absidiole occidentale. Toute la partie sud a disparu; seules quelques traces de supports massifs sont visibles à certains endroits (fig. 2). Nous y reviendrons plus loin.

Tout d'abord, nous avons un chœur à trois absides, formule particulièrement courante dans le Midi de la France aux XI et $\mathrm{XII}$ e siècles. En Gascogne centrale, cette organisation architecturale est bien représentée, tant pour des édifices possédant une nef à vaisseau unique qu'une nef à trois vaisseaux (fig. 3).

Le premier type était notamment visible dans l'ancienne église de Saint-Orens d'Auch, aujourd'hui presque entièrement disparue (Mesplé 1971, 116-117 et Rouja 1995-1997) ou à Notre-Dame d'Estang (Cabanot 1978, 32-33 et Mesplé 1971, 119), à l'ouest d'Éauze, en Armagnac27. Plus près de Croute, quelques édifices intéressants dépendent aussi de ce schéma : les églises de Saint-Mamet de

\footnotetext{
22. L'unique indice visible est la plate-forme en terre talutée et fossoyée qui supporte l'église et qui forme sans doute la superficie initiale de l'enclos religieux. En effet, une vue aérienne du site montre que l'église est posée sur un large rectangle fossoyé. Je remercie Stéphane Abadie pour cette précision.

23. Nous attendons avec impatience la publication du cartulaire par le professeur Xavier Ravier. Au sujet des aspects architecturaux et décoratifs de cet édifice disparu : Balagna 2004, 63-78.

24. Il vient d'être tout récemment étudié par X. Ravier et $\mathrm{S}$. Abadie.

25. L'église, qui a donc été construite sur cette plate-forme, est elle-même surmontée, au nord, d'un tumulus ou d'une motte castrale de grande superficie qui n’a pas encore livré tous ses secrets. D'après S. Abadie, cette motte était peut-être déjà abandonnée lors de la construction de l'édifice. La configuration de l'espace disponible a donc conduit les constructeurs à en utiliser la portion la plus étirée pour accueillir les fidèles dans la nef et les religieux dans le chœur, suivant un axe sud-nord, et non ouest-est.

26. Auparavant, il fallait s'en tenir au plan insuffisamment précis de Mesplé 1971, pl. XI. On fera donc désormais référence au plan relevé par $\mathrm{S}$. Abadie et moi-même ainsi qu'aux autres pièces graphiques.

27. Pour une mise au point incluant les parties gothiques, Balagna 2000, t. IV, 262-266. A paraître prochainement.
} 
Peyrusse-Grande (Durliat 1970 a, 43-54, Mesplé 1971, 117-118 et Cabanot 1978, 48-52), Sainte-Marie de Maubourguet (Mesplé 1966, 57-74 et Cabanot 1978, 54-60) et aussi Saint-Pierre de Tasque (Durliat 1970 b, 55-66, Mesplé 1971, 117 et Maroix 2004). Ce sont des constructions qui appartiennent, pour la plupart, au dernier quart du XIe siècle et au premier quart du XIIe siècle.

La deuxième série comprend elle aussi des constructions majeures, notamment deux, dans la proche région de Croute. Il s'agit de l'ancienne collégiale Saint-Nicolas de Nogaro (Durliat 1970 c, 91110, Mesplé 1971, 121-122 et Cabanot 1978, 236-242) et de l'église paroissiale Saint-Laurent d'Aignan (Mesplé 1971, 122 et Cabanot 1978, 26-27), bien que pour cette dernière, il semble que le collatéral nord et l'absidiole correspondante n'aient jamais été construits, du fait de la présence, de ce côté-ci, de la muraille de la ville. En tous les cas, ces deux églises, malgré l'ampleur de leur nef, sont tout à fait contemporaines des précédentes.

Quand on compare plus précisément le chœur de l'église de Croute avec ces édifices, on remarque tout de même quelques différences : à Saint-Orens d'Auch, le chœur de l'église auscitaine comportait deux chapelles rayonnantes et une chapelle d'axe greffées sur l'abside, formule complexe qui témoigne de l'influence des grands sanctuaires de pèlerinage méridionaux. A Peyrusse-Grande, les trois sanctuaires semi-circulaires s'inscrivent dans un chevet plat et à Estang, tout comme à Nogaro, les chapelles ne sont pas accolées. Finalement, le chœur qui ressemble le plus à celui de Croute est celui de Tasque, dans les profils intérieur et extérieur des masses, dans les proportions d'ensemble, dans l'utilisation d'un volume harmonieux et unifié puisque les deux absidioles latérales sont accolées à la partie droite de l'abside d'axe. Le chœur d'Aignan est aussi très proche de Croute, non seulement pour les raisons évoquées pour Tasque, mais aussi pour un élément très important, absent à Tasque mais visible également à Peyrusse-Grande, à Estang et à Nogaro : l'abside d'axe est rythmée intérieurement par une arcature aveugle reposant sur des colonnes adossées. Enfin, une particularité exceptionnelle dissocie le chœur de Croute de tous les autres puisque les trois sanctuaires y étaient décorés d'arcatures ${ }^{28}$.

Le deuxième caractère inhabituel réside dans l'ampleur des volumes encore en place, véritable témoignage de l'ambition des constructeurs, désireux de donner à l'édifice un aspect monumental. L'abside d'axe étonne par sa largeur extrême eu égard à l'ensemble des dimensions du chœur. Elle mesure en effet 9,10 m de large, ce qui est plus important que dans n'importe lequel des édifices cités précédemment ${ }^{29}$, sauf à Tasque ou l'abside d'axe, démesurée, présentait une largeur intérieure d'environ $11 \mathrm{~m}^{30}$. La largeur de l'absidiole orientale de Croute, seule conservée, est de 3,85 m. Là, nous sommes dans une fourchette moyenne puisque la largeur des chapelles secondaires des édifices concernés oscille entre $3 \mathrm{~m}$ et $4,50 \mathrm{~m}^{31}$. Enfin, il est plus difficile d'utiliser la profondeur de l'abside car il faut alors tenir compte d'un paramètre essentiel qui est la présence de la travée droite, importante à Auch, Peyrusse-Grande et Estang. A Croute, avec ses 8,50 m de profondeur, l'abside d'axe est plus profonde que le sanctuaire principal de Nogaro $(7 \mathrm{~m})$ mais elle est légèrement en deçà de Tasque et d'Aignan (environ $9 \mathrm{~m})^{32}$.

Que nous apprennent ces différentes dimensions prises à l'intérieur du chœur de l'église de Croute ? Tout d'abord, il s'agit d'un plan étiré, à la fois en largeur et en profondeur, notamment pour l'abside d'axe qui concentre le caractère sacré de l'édifice. Ces dimensions sont d'ailleurs plus

\footnotetext{
28. C'était en effet le cas dans l'absidiole ouest. Bien que remontée en tant que sacristie à partir de 1860, on y a conservé un fragment de cette arcature aveugle, complétée pour les éléments disparus par des ajouts en plâtre.

${ }^{29}$. Voici les dimensions en largeur de l'abside d'axe de ces édifices : à Saint-Orens d'Auch : $8 \mathrm{~m}$; à Estang : 7,50 m; à PeyrusseGrande : 6,70 m ; à Maubourguet : 5,20 m ; à Nogaro : 5,90 m ; à Aignan : $9 \mathrm{~m}$.

30. Il faut aussi comprendre dans cette liste d'édifices régionaux contemporains l'ancienne église abbatiale Sainte-Marie de Madiran. L'abside, particulièrement large et profonde, aurait été construite dans le deuxième quart du XIIe siècle : Cabanot 1978, 35-36.

31. Voici les dimensions en largeur de l'absidiole sud, prise pour référence, de ces édifices: à Saint-Orens d'Auch: $3 \mathrm{~m}$; à Estang : 4,50 m ; à Peyrusse-Grande : 4,20 m ; à Maubourguet : 3,70 m ; à Nogaro et à Aignan : 3,80 m.

32. Si l'on ne tient compte que du tracé semi-circulaire de l'abside de Peyrusse-Grande (6,20 m) et de la totalité du chœur central de Maubourguet $(7,50 \mathrm{~m})$, la profondeur de l'abside de Croute est à nouveau supérieure.
} 
importantes que dans la plupart des édifices contemporains construits dans la proche région de Croute. Parmi les grandes constructions religieuses du temps, arrêtons-nous par exemple sur l'église Saint-Nicolas de Nogaro. Elle fut fondée par saint Austinde, archevêque d'Auch au milieu du XI siècle et consacrée par lui en 1060. Cette église, dont il semble ne rester aucune trace, fut détruite et remplacée à la fin du XIe siècle et au début du XII e siècle par le monument visible aujourd'hui, sans doute agrandi pour mieux accueillir le collège de chanoines qui venait d'y être installé. Quant à l'église abbatiale de Tasque, c'est celle qui présente le chœur le plus développé, en rapport d'ailleurs avec la très longue nef à vaisseau unique qui se déployait vers l'ouest. On peut donc affirmer que les constructeurs de l'église de Croute se sont montrés très ambitieux en construisant un monument parmi les plus imposants de la région, seulement dépassé par l'église de Tasque, ce qui pourrait sembler logique si l'on considère l'hypothèse selon laquelle Croute appartenait à Tasque. En tous cas, il semble que les dimensions apportées au chœur de Croute puissent être mises en relation avec un changement de statut de l'édifice. Peut-être est-ce en rapport avec la présence supposée des reliques de saint Ausit et le développement de son culte?

En ce qui concerne les étapes de construction, l'examen précis des maçonneries du chevet permet d'affiner la chronologie de l'édifice et de mieux comprendre le déroulement du chantier. Il y a eu en effet deux campagnes bien distinctes quoique très rapprochées dans le temps et la seconde de ces campagnes peut se diviser elle-même en plusieurs phases.

Tout d'abord, les trois sanctuaires semi-circulaires ont été construits en même temps, l'abside d'axe élevée en premier, servant de point d'appui aux deux sanctuaires latéraux, ce que révèlent l'élévation d'ensemble du chevet ${ }^{33}$ et le plan au sol. Plus précisément, c'est l'extrémité semi-circulaire des deux chapelles latérales qui appartient à cette première campagne. On y retrouve le même appareil, constitué de moellons de grès bien équarris, soit de forme cubique, soit allongés et disposés en assises à peu près horizontales et liés par des joints de mortier de chaux et de sable qui débordent largement sur la tête du moellon ${ }^{34}$. Les dimensions des petits blocs, l'horizontalité et la hauteur des assises sur les trois sanctuaires, la régularité des parements, l'absence d'assises de réglage révèlent aussi l'unité de la conception et sa réalisation rapide (fig. 4).

Sur l'absidiole ouest, reconstruite à partir de 1860, le remaniement est particulièrement visible: l'élévation primitive en petit appareil cubique n'est conservée que sur une faible partie, correspondant à la moitié orientale de l'absidiole, les assises d'origine diminuant en surface à mesure que l'on monte, formant un triangle irrégulier à la base élargie et au sommet étroit. Ensuite, la modification du XIXe siècle a fait intervenir des matériaux plus médiocres, du tout-venant, dans lequel se devinent parfois quelques blocs de remploi, appartenant à la construction d'origine et récupérés sans doute aux abords ${ }^{35}$. A nouveau, on peut noter que le seul trou de boulin conservé sur l'absidiole est aligné avec ceux de la première rangée de l'abside d'axe. A droite et au-dessus, les trous de boulin correspondent au chantier de 1860 (fig. 5).

On remarque la même mise en œuvre au chevet de l'église Saint-Laurent d'Aignan, qui offre, on a pu le voir plus haut, de nombreuses ressemblances avec l'église de Croute. L'élévation primitive de l'église est encore bien visible sur le flanc sud de la nef, sur l'absidiole méridionale et sur une faible partie de l'abside d'axe. On y voit le même petit appareil cubique allongé et assisé de manière soignée $^{36}$. La nef de l'église abbatiale de Tasque, partie la plus ancienne du monument, présente elle

\footnotetext{
33. Au chevet, quelques trous de boulin sont conservés sur l'abside d'axe et sur l'absidiole est. On remarque qu'ils sont quasiment alignés à l'horizontale, ce qui pourrait dénoter une campagne de construction homogène.

34. Au XIe siècle, notamment dans les édifices de Gascogne, les joints sont généralement épais et même si les joints sont parfois tracés au fer, ils restent le plus souvent assez grossiers, comme à Croute et comme dans la nef de Tasque : Cabanot 1987, 32.

35. Contrairement à ce qu'affirme M. Gaborit 1979, t. I, 251, l'absidiole nord [ouest] ne fut pas reconstruite en moyen appareil régulier.

36. Le matériau utilisé est un grès rouge, légèrement rosé, parfois poreux et facile à tailler. On retrouve le même matériau dans l'élévation intérieure de l'abside de Saint-Nicolas de Nogaro : Pousthomis-Dalle 1996, 63-68.
} 
aussi aux deux tiers inférieurs le même petit appareil, alternant avec quelques moellons allongés. Le tiers supérieur, là où sont percées les fenêtres, ressemble dans son élévation au chantier de Croute. La nef de Tasque pourrait appartenir à la deuxième moitié du XIe siècle ${ }^{37}$. Enfin, l'utilisation de ce petit appareil cubique parfois allongé est aussi commune à un nombre considérable d'édifices religieux appartenant au XIe siècle et situés dans une vaste zone géographique, partant des Pyrénées à la région bordelaise (Gaborit 1979). On peut donc en conclure que la première phase d'édification du chevet de l'église de Croute s'inscrit dans les traditions constructives de la fin du XIe siècle.

A ce moment-là, on peut penser que les trois sanctuaires étaient charpentés ${ }^{38}$. Etait-ce la couverture définitive ou plutôt un simple plancher provisoire, pouvant correspondre à une courte interruption des travaux et à une mise hors d'eau des espaces déjà construits ${ }^{39}$ ?

Sans doute un plancher temporaire car c'est alors qu'intervient, très rapidement, la deuxième campagne de construction. Tout d'abord, on décida de prolonger l'édification de l'absidiole orientale, en direction du sud, au niveau de sa partie droite, par l'utilisation d'un moyen appareil de pierre de taille, composé essentiellement de grès ${ }^{40}$, parfaitement dressé, dont les joints de mortier très fins embellissent l'aspect (fig. 4). Cet aménagement révèle ici un changement technique ${ }^{41}$, et donc de l'arrivée de tailleurs de pierre, absents dans la campagne précédente, et d'un remaniement structurel puisque l'on décide de substituer à la charpente un couvrement de pierre - une voûte en cul-de-four encore en place sur l'absidiole est, mais soit disparue soit jamais construite sur l'abside d'axe et sur $l^{\prime}$ absidiole ouest ${ }^{42}$.

Considérant sans doute que les murs primitifs du chevet seraient trop fragiles, on décida alors, à l'extérieur, d'épauler les maçonneries par des contreforts rectangulaires, en moyen appareil de pierre de taille, visiblement postérieurs aux murs primitifs ${ }^{43}$. Seuls cinq de ces contreforts sont encore en place et deux d'entre eux ont été établis de manière très originale. En effet, ils on été construits aux angles que forme l'abside d'axe avec les chapelles latérales. C'est à cet endroit-là que les murs risquaient de s'effondrer, là où justement se raccordent les trois sanctuaires de façon irrégulière. Quant aux trois autres, ils ont été eux aussi judicieusement disposés : le premier, sur l'absidiole est, se trouve à l'angle opposé, au point de jonction entre la partie courbe et la partie droite de la chapelle ; les deux autres renforcent, de part et d'autre de l'axe central, l'abside d'axe au diamètre imposant. On voit très bien tout le caractère empirique de cette deuxième campagne puisque l'emplacement des différents contreforts ne correspond pas parfaitement à l'élévation intérieure des absides et plus précisément à la mise en place de l'arcature aveugle. Ce repentir signifie donc que l'on a, en cours de route, décidé de modifier le projet initial.

\footnotetext{
37. Durliat 1970 b, 58. Il faut noter à Peyrusse-Grande et à Tasque l'utilisation d'un appareil en arêtes de poisson, signe d'un certain archaïsme. A Croute et à Aignan, cette technique disparaît, ce qui pourrait faire admettre que ces deux derniers chantiers sont postérieurs.

38. Cette conception se retrouve aussi, près d'Aignan, et donc de Croute, à Bouzon, Gellenave, Loussous-Débat, mais aussi, plus loin, à Saint-Martin d'Armagnac, à Lamaguère, à Caillavet, ... : Mesplé 1971 et Gaborit 1979. Il est donc encore assez courant, en Gascogne, au XI siècle, de surmonter d'une simple charpente les sanctuaires des églises, soit de façon fixe, soit de façon temporaire.

39. La plupart des édifices mis en parallèle avec Croute étaient simplement charpentés. C'était, semble-t-il, le cas pour Aignan, Cabanot 1978, 26. On peut aussi penser à la nef de Tasque, ou à celle de Saint-Mont, elles aussi charpentées.

40. Les dimensions de certains blocs, autour de 0,60-0,65 m de large, témoignent aussi de la volonté de se rapprocher du grand appareil.

41. A l'extérieur de l'absidiole, la pierre de taille apparaît à droite du contrefort ; à l'intérieur, elle est utilisée au même niveau, juste après la première colonne de l'arcature aveugle, renforcée à l'extérieur par le contrefort. L'examen des maçonneries ne permet pas de le dire, mais il pourrait s'agir des mêmes blocs formant les parements intérieur et extérieur. En tous cas, cela renforce l'unité de cette phase de construction.

42. En effet, on peut présumer que cette phase de construction concernait aussi l'absidiole ouest, traitée de la même façon, mais la disparition presque complète de cette chapelle ne nous permet pas d'être plus catégorique.

43. Dès le XIe siècle, on peut utiliser un moyen appareil aux blocs taillés ou layés en biais, pour accroitre la cohésion des maçonneries menacées de déformation du fait des dimensions ou de la présence d'une voûte, ce qui a par exemple conduit à la multiplication des contreforts à la largeur considérable, comme à Tasque : Cabanot 1987, 33.
} 
L'élévation extérieure de l'absidiole orientale permet de mesurer toute l'ambition apportée à cette phase de construction : la petite fenêtre $\mathrm{d}^{\prime} \mathrm{axe}^{44}$, en plein cintre, a été agrémentée d'une arcature aveugle de même profil, surmontée par une archivolte de billettes ${ }^{45}$, le mur a été surhaussé de deux assises de pierre de taille correspondant à la surélévation du sanctuaire et à la pose de la voûte en culde-four, on a fait reposer la toiture primitive, aujourd'hui disparue, sur une corniche à modillons sculptés, agrémentée de trois rangées de billettes (fig. 6). Les modillons, de forme rectangulaire et traités de manière très sobre, possèdent un décor sur leur partie abattue. Ce décor est en grande partie endommagé, sauf pour un seul modillon, le premier à droite par rapport à la fenêtre ${ }^{46}$. Il est recouvert d'un tapis de petites feuilles épanouies, à quatre pétales, inscrites dans des médaillons, dans les écoinçons desquels on retrouve d'autres fleurs ${ }^{47}$. La composition, répétitive, évite la monotonie grâce à la précision de la taille en creux et à la fermeté du dessin. C'est un exemple parfait du type de décor qui a été exécuté à l'intérieur.

Qu'en est-il de l'abside d'axe ? Elle paraît avoir souffert de destructions et elle a perdu une partie de son élévation. En effet, on peut penser qu'elle avait été prévue pour être bien plus haute que sa hauteur actuelle puisqu'elle a perdu tout son couronnement. On n'aperçoit plus que la partie inférieure d'une ouverture rectangulaire, dont on pourrait penser qu'elle est peut-être contemporaine de la deuxième campagne de construction, correspondant à l'exhaussement de l'abside d'axe en vue de recevoir une voûte en cul-de-four. Effectivement, les piédroits ne sont conservés que sur trois assises, dans le même matériau que celui utilisé pour le contrefort voisin. Les dimensions des blocs semblent également très voisines. Signalons tout de même que les dernières assises supérieures de l'abside attestent, au niveau de cette baie, certains désordres. D'ailleurs, on remarquera que cette ouverture est légèrement décalée par rapport à l'axe central, ce qui paraît plutôt étrange pour la fenêtre d'axe d'un sanctuaire accueillant le maître-autel. Peut-être s'agit-il alors d'un remontage effectué au moment de la pose de la charpente et de la toiture unique sur les deux sanctuaires restants? La raison pourrait en être la volonté de maintenir la ventilation d'une charpente reposant directement sur les murs latéraux. Un même décrochement de la maçonnerie de l'abside d'axe est visible à la base de la charpente dans la partie de l'abside voisine de l'absidiole est. Une autre hypothèse peut être aussi envisagée puisqu'il pourrait s'agir des vestiges d'un système défensif bâti au-dessus de l'édifice entre le XIVe siècle et le XVIe siècle, comme on en rencontre aussi à la cathédrale de Tarbes, à Saint-Jean-Baptiste de Mazères, à l'église de Préchac, à l'abbatiale de Saint-Sever-deRustan, à Beaumarchès, à Vic-en-Bigorre, ... . Enfin, de part et d'autre du contrefort de gauche, à mihauteur, ont été percées deux ouvertures, l'une rectangulaire, l'autre sous un arc légèrement surbaissé,

\footnotetext{
44. La petite ouverture rectangulaire percée dans la partie droite de l'absidiole est plus tardive. Peut-être appartient-elle à l'époque moderne, sans doute au XVIIe siècle.

45. A droite en regardant la fenêtre, on remarque que l'archivolte reposait sur une petite console à tête humaine, aux traits encore légèrement discernables. Les mêmes fenêtres étroites et en plein cintre ont été utilisées tout en haut des murs de la nef de Tasque. Parmi les fenêtres qui y sont conservées, on remarque qu'elles possèdent une archivolte de billettes qui repose sur des consoles. Encore une fois, on peut noter l'importance des similitudes entre les deux chantiers, notamment sur le plan chronologique puisque pour M. Durliat, les fenêtres de Tasque ont pu être réalisées dans la première moitié du XIIe siècle, Durliat 1970 b, 58. De même, l'église romane Sainte-Quitterie, à Aubous en Vic-Bilh, possède une fenêtre axiale de même type. Elle appartient au XIIe siècle : Cabrero-Ravel et alii 2003, 50-51.

46. Voici ce que l'on peut encore apercevoir de ce décor : $1^{\text {er }}$ modillon (à gauche) : imbrications ; 2e modillon : décor trop abîmé ; $3^{\mathrm{e}}$ modillon : un animal dont il reste la moitié inférieure ; $4^{\mathrm{e}}$ modillon : décor trop abîmé ; $5^{\mathrm{e}}$ modillon : un animal dont il reste la partie inférieure ; 6 e modillon : en partie cassé ; 7e modillon : décor trop abîmé ; $8^{\mathrm{e}}$ modillon : voir texte ; 9e modillon : décor trop abîmé.

47. Ce motif apparaît aussi sur un modillon de l'église Saint-Jean-Baptiste de Mazères, à Castelnau-Rivière-Basse, ainsi que sur la partie abattue d'un modillon du chevet de l'église Sainte-Marie d'Audignon, dans les Landes. Cette église, édifiée au début du XIIe siècle, possède un riche décor qui s'inspire directement du grand chantier voisin de Saint-Sever : Cabanot 1978, 167-170. Nous verrons plus loin les liens qui semblent rapprocher l'église de Croute de l'abbatiale de Saint-Sever et des monuments qui ont bénéficié de son rayonnement. Enfin, l'église Sainte-Foy de Morlaàs, en Vic-Bilh, possède un riche décor sculpté. L'un des chapiteaux ornant à l'extérieur la fenêtre sud de l'abside d'axe présente le même décor de fleurons. Pour Jacques Lacoste 2007, 55-66, ce décor a pu être exécuté vers 1120-1125.
} 
vraisemblablement au XVIIe siècle ${ }^{48}$, sans tenir vraiment compte de l'élévation intérieure. D'ailleurs, elles coupent la litre seigneuriale dont on pouvait encore distinguer les armes à la fin du XIXe siècle (fig. 4).

Il s'agit ici d'un élément chronologique important, même si le décor de la litre a totalement disparu et qu'il n'en reste plus, de façon lacunaire, que la bande de plâtre. Des descriptions anciennes présentent les armes visibles sur la litre comme celles de la famille de Sérignac ${ }^{49}$. Malheureusement, les armes de cette maison ne correspondent pas à celles mentionnées dans les descriptions. En effet, ces dernières parlent " $\mathrm{d}$ 'une tour surmontant trois monts nobles », alors que les armes réelles sont « d'or à trois pointes de rocher de sinople, surmontées chacune d'une corneille de sable, becquée et membrée de gueules, celle du milieu plus élevée » (Bourse 2002, 370). Si les rochers de sinople peuvent être identifiés comme des monts, il paraît impossible de confondre une corneille et une tour. Il semble donc difficile de croire qu'un Sérignac ait pu substituer dans ses armes une corneille à une tour, car la corneille est l'emblème de la famille de Sariac dont les Sérignac se sont détachés au XIII siècle (Bourse 2002, 360).

D'après ce que l'on sait, les Sérignac ont succédé à la famille de Mont à la tête de la seigneurie de Lasserrade et donc de Croute en 1634 (Laclaverie 2005, 360-361). Les Mont sont seigneurs de Gellenave, aujourd'hui village de Bouzon-Gellenave, situé à quelques kilomètres au nord-ouest de Croute. Leurs armes sont «d'azur à trois monts d'or ou coupeaux de montagne, posés 2 et 1 » (Bourse 2002, 291). En 1611, Antoine de Mont épouse Françoise de Médrano, fille de Pierre de Médrano, seigneur de Maumusson (Villain 1982, 58). On remarquera que les armes des Médrano sont complexes, «de gueules à une croix tréflée d'or, surmontée en chef d'une colonne d'argent maçonnée de sable, avec une devise en lettres d'or portant ces mots Ave Maria Gracia Plena, rangés en orle autour de la croix et une bordure d'azur chargée de treize tours d'argent maçonnées de sable, crénelées de même et posées deux en chef, quatre sur chaque flanc et trois en pointe » (Bourse 2002, 280). On peut noter que les tours sont un meuble important de leurs armes, d'autant que la colonne maçonnée peut aussi être confondue avec une tour.

Ainsi, il paraît tout à fait possible d'envisager que les armes anciennement visibles sur la litre extérieure de l'église de Lasserrade soient celles de Françoise de Médrano, veuve d'Antoine de Mont, qui aurait ainsi associé aux monts de son époux les colonnes ou tours de ses propres armes. De cette manière, il est plausible de considérer que la litre funéraire a été apposée sur les murs de l'église entre 1611 et, au plus tard, quelques années après 1634, date de la mort d'Antoine de Mont. La difficulté réside dans notre ignorance de la date du décès de son épouse, Françoise de Médrano. En tous les cas, nous pouvons en déduire que les murs extérieurs de l'église ne sont pas postérieurs au milieu du XVII ${ }^{e}$ siècle et que le percement des fenêtres de l'abside d'axe et de l'absidiole est a été réalisé dans la deuxième moitié du siècle, avant 168750 .

Si nous revenons à l'élévation du chevet, nous pouvons à nouveau effectuer de fructueux rapprochements avec l'église Saint-Laurent d'Aignan. En effet, au même moment, on a décidé de construire au-dessus du chœur une voûte, et donc de remanier le chevet : construction de contreforts en pierre de taille, agrandissement de la fenêtre sud agrémentée d'une arcature aveugle, réalisation

\footnotetext{
48. Ces fenêtres aménagées dans les deux sanctuaires ont probablement été percées avant la visite faite à l'église en 1687. Cf. supra, note 18.

49. La famille de Sérignac est originaire du village de Belmont, situé près de Vic-Fezensac, au nord-est de Croute. Entre le XIVe et le XIXe siècle, les membres de la famille de Sérignac, d'abord co-seigneurs de Belmont puis vassaux des comtes d'Armagnac, possédèrent différents titres nobiliaires et certains membres de cette dynastie s'illustrèrent dans les armées royales. Pour en savoir plus : Fontan 2003, 428-429.

50. Je remercie chaleureusement Monsieur Guy Sénac de Monsembernard qui m’a largement fait profiter de sa parfaite connaissance de la généalogie nobiliaire et seigneuriale de la Gascogne centrale. Qu'il trouve ici l'expression de ma gratitude. Notons également que le clocher de l'église de Croute conserve une cloche ancienne. Celle-ci comporte une intéressante inscription : «Sainte Catherine pries pour nous messire Dominique de Sérignac chevalier baron / de Bellemonts Lasserade dame Marie Laurence de Sédillac son épouse / Mr Cousse curé de Pouydraguin et Croute A. 1766 ».
} 
d'une corniche à modillons, encore en place, associés à des métopes ${ }^{51}$, témoignant d'un véritable souci plastique, qui va se vérifier d'ailleurs plus à l'ouest sur le mur sud de la nef avec la construction d'un porche en légère saillie.

Enfin, à Croute, on renforce les murs destinés à recevoir le poids des voûtes en construisant, à l'intérieur des parties droite et semi-circulaire des sanctuaires, une arcature aveugle reposant sur un soubassement continu ${ }^{52}$. On y retrouve d'ailleurs certains des éléments de décor apparus à l'extérieur, notamment les archivoltes de billettes (fig. 7). La même disposition est visible à Aignan, mais seulement dans l'abside d'axe qui a, seule, fait l'objet d'autant d'élégance ${ }^{53}$. Le système du chœur renforcé d'une arcature aveugle pour supporter le poids des voûtes et qui, en même temps, allège les maçonneries intérieures et en rythme l'élévation rencontre, à la fin du XIe siècle et durant tout le siècle suivant, un succès considérable : de chaque côté des Pyrénées, on compte par dizaines les édifices qui ont fait ce choix structurel et esthétique, notamment en Béarn, en Gascogne, en Aragon. Nous verrons plus loin que les rapprochements entre Croute et certains de ces édifices, notamment la chapelle du château de Loarre en Aragon, apparaissent aussi dans le domaine de la sculpture.

Dans un deuxième temps, le chantier s'est également avancé en direction du sud. C'est ici qu'interviennent les nombreux mystères qui entourent la construction mais aussi la disparition de toute la partie méridionale de l'édifice. Avant de faire des conclusions, il convient de procéder par ordre pour essayer de mieux comprendre le déroulement des travaux.

Tout d'abord, on a terminé la construction du chœur au niveau de sa liaison avec le reste de l'édifice : à l'angle nord-est de l'absidiole encore en place, on remarque que le mur droit forme un léger retour évoquant l'existence d'un bras de transept très légèrement saillant, dont le vis-à-vis devait probablement avoir été envisagé de l'autre côté (fig. 8). Ce morceau de bras de transept appartient bien à la deuxième campagne de construction : même appareil de pierre de taille, même matériau, mêmes contreforts rectangulaires épaulant le mur ${ }^{54}$. Malheureusement, presque tout le reste de ce pseudo-bras, surtout le mur-pignon oriental, a disparu, soit totalement détruit à partir de la gauche du contrefort d'angle, soit jamais véritablement réalisé. Seule la première assise verticale est encore en place ${ }^{55}$. Le mur a ensuite été remonté, vraisemblablement au XII siècle, après que la deuxième campagne de travaux, caractérisée par l'emploi d'un bel appareil de pierre de taille, se fut arrêtée pour des raisons inconnues, peut-être liées au contexte historique et religieux du temps ou au coût des matériaux, à leur mise en forme et à leur acheminement. Comme il fallait sans doute terminer au plus tôt cette partie de l'édifice, on eut recours à des matériaux moins coûteux qu'on utilisa pour joindre les deux angles de ce pseudo-bras de transept déjà montés auparavant.

Selon M. Gaborit (Gaborit 1979, 251) ce mur reconstruit appartiendrait à la nef, « laquelle a été probablement tronquée et pourvue de contreforts appareillés ». Une correction s'impose : il ne s'agit pas du mur de la nef, mais plutôt du mur du bras est du transept. De plus, le type d'appareil ne correspond pas à celui utilisé dans la deuxième campagne de travaux de l'église. Il apparaît alors impossible qu'il s'agisse de l'appareil de la nef. En revanche, il est tout à fait plausible que l'on ait remonté ce mur à l'époque médiévale, soit plus tard dans le XII siècle, soit au tout début du XIII siècle. Un élément l'atteste, il s'agit de la petite fenêtre située à gauche du contrefort d'angle, murée d'ailleurs avant la pose de la litre funéraire, et qui est bien dans l'esprit de l'époque romane, petite et fortement ébrasée pour fragiliser le moins possible ce mur, construit, non plus en pierre de taille, mais avec des matériaux qui rappellent le petit appareil allongé caractéristique de la première campagne de

\footnotetext{
51. Elles n'ont pas été utilisées à Croute. En revanche, elles sont présentes dans un autre édifice faisant partie de l'aire géographique proche de Croute. Il s'agit de l'ancienne priorale Sainte-Marie de Maubourguet : Cabanot 1978, 55-60.

52. Ce soubassement mesure 0,40 $\mathrm{m}$ de large dans l'abside d'axe, 0,32 $\mathrm{m}$ dans l'absidiole est.

53. On peut d'ailleurs pousser assez loin les similitudes entre Croute et Aignan puisqu'à Aignan, la banquette placée à la base de $l^{\prime}$ arcature aveugle fait également $0,40 \mathrm{~m}$ de large.

54. On remarque d'ailleurs que la litre funéraire passe sur les contreforts, témoignant donc de leur antériorité et donc de leur contemporanéité avec le chantier.

55. Cette portion verticale est conservée sur quatorze assises. On est sans doute assez loin de la hauteur prévue à l'origine.
} 
la fin du XIe siècle, ce qui paraît démontrer que des problèmes financiers ont conduit le maître d'ouvrage à se séparer de ses tailleurs de pierre pour revenir à une conception technique moins onéreuse et plus grossière. La petite fenêtre bouchée tendrait donc à faire voler en éclats l'hypothèse selon laquelle l'église aurait été en partie détruite par les protestants et reconstruite plus tard. Bien que la litre funéraire qui traverse toute cette portion murale date au plus tard du milieu du XVIIe siècle, il ne semble pas que ce mur ait été reconstruit à ce moment-là. Nous pouvons tout de même supposer que des destructions ont eu lieu car plusieurs sources mentionnent la présence de matériaux près de l'église: Monlezun 1846, 225 relate qu'on remarquait, non loin de l'église actuelle, « une quantité considérable de débris de bâtiment, et un nombre infini de décombres ». Les autres percements, les deux fenêtres et le portail sont bien plus tardifs (fig. 9) ${ }^{56}$.

Justement, l'angle opposé de cette façade d'entrée, là où se trouve le clocher, pose quelques problèmes de compréhension. On peut encore voir une partie de l'élévation primitive appartenant toujours à la deuxième phase de construction : le contrefort, établi dans l'angle, correspond bien à son vis-à-vis, il est construit en moyen appareil de pierre de taille et a été arasé dans sa partie supérieure. Il épaule une portion du mur-pignon du bras de transept, conservé dans la même proportion que de l'autre côté. A nouveau, la litre funéraire est postérieure à ce contrefort.

Le clocher offre un certain nombre de difficultés. En effet, pour tous ceux qui se sont intéressés à l'église de Croute, le clocher est une construction moderne, consécutive au réaménagement de l'église au XVII ${ }^{e}$ siècle ${ }^{57}$. Pourtant, l'examen attentif des maçonneries internes et externes du clocher révèle qu'il se compose de deux parties distinctes et que la construction de son noyau est contemporaine de la deuxième phase de construction de l'église de Croute, même si le «rhabillage » extérieur de l'édifice en petit appareil et moellons liés au mortier peut correspondre à la construction du mur joignant les deux angles de ce bras de transept, au XII e ou au XIIIe siècle ${ }^{58}$. Tout d'abord, lorsqu'on accède au revers du clocher, on remarque que le noyau central, correspondant à l'escalier en vis, est construit de manière soignée et monumentale en moyen et grand appareil de pierre de taille, appareil que l'on a chemisé plus tard pour permettre aux murs de l'escalier de recevoir le poids du clocher. Au dedans, on aperçoit très bien le départ de l'escalier dont les blocs aperçus au dehors forment le parement intérieur.

Ensuite, il est indéniable que cet escalier est contemporain des phases de construction précédentes, non seulement à cause du matériau utilisé, des dimensions des blocs, de la nature des joints, correspondant en tous points à l'appareil de pierre de taille du chevet, mais aussi parce qu'on retrouve sur certaines pierres les mêmes marques lapidaires que celles visibles au chevet, sur l'absidiole est, sur les contreforts qui renforcent cette dernière ainsi que l'abside d'axe, mais aussi dans le chœur, notamment à l'intérieur de ces deux absides (fig. 10). Ces marques lapidaires, qui présentent des affinités avec certaines de celles que l'on rencontre à l'intérieur de l'abside d'axe de la collégiale de

\footnotetext{
${ }^{56}$. Le percement de ces deux fenêtres fut réalisé au XIXe siècle. Au même moment, on perça aussi le portail d'entrée actuel. Dans les notes du curé Lamazouade, ces restaurations sont mentionnées : «au XIXe siècle, la muraille de l'est a été refaite pour y ouvrir une porte en plein cintre surmontée de deux vitraux. L'archivolte repose sur deux corbeaux : celui de droite représentant une figure humaine tenant à la bouche les deux extrémités d'une guirlande, a été sculptée par Beau, tailleur de pierre à Toulouse. Celui de gauche est resté à l'état de simple pierre. Trois moulures concentriques en boudin ornent l'arcade de la porte ». On remarque d'ailleurs que la litre a été fortement endommagée au niveau de ces percements. On peut alors envisager qu'une partie du mur a été remontée à nouveau à ce moment-là.

57. Dès le XIXe siècle, pour l'abbé Cazauran qui visite l'église le 13 octobre 1890, le clocher apparaît comme une construction "quadrangulaire moderne, dominé par une flèche octogonale couverte en ardoise ", puis, plus loin, "à l'angle sud-est, se trouve une porte à linteau droit permettant de monter au clocher moderne placé à l'angle sud-est de l'édifice » : Cazauran 1890, 267. Dans les notes manuscrites prises par le curé Lamazouade, on peut lire : « Une petite tour carrée, à l'est, renferme la cage de l'escalier de pierre en colimaçon et aux marches très usées, dont il ne reste qu'une partie. Cette tour est relativement récente et se termine par un clocher à flèche, à huit pans ». Quant à P. Mesplé, l'abbé Cabanot ou M. Gaborit, ils n'ont même pas signalé sa présence, considérant sans doute qu'il appartenait tout entier au XIXe siècle.

58. A nouveau, les vestiges encore visibles de la litre funéraire interdisent de voir dans ce clocher une construction postérieure au milieu du XVIIe siècle.
} 
Nogaro ${ }^{59}$ apparaissent aussi sur le contrefort extérieur du clocher, preuve de son antériorité par rapport à la métamorphose de la tour d'escalier du début du XIIe siècle en un clocher construit entre le XIIe ou le XIIIe siècle et le milieu du XVIIe siècle.

Que peut-on donc penser de tous ces éléments ? Tout d'abord, l'escalier du clocher a bien été construit en même temps que le reste, sans doute dans le premier quart du XII e siècle. Le type $\mathrm{d}^{\prime}$ appareil, les traces d'outil ${ }^{60}$, les marques lapidaires en font foi. Sa position à l'angle sud-est du bras de transept correspondant peut permettre de penser que l'on avait prévu de construire un clocher audessus de la croisée. Il s'agirait donc d'une nouvelle phase intermédiaire de construction dans le déroulement de cette deuxième campagne de travaux, visant à la fois à agrandir l'édifice vers le sud et à surmonter les parties intérieures d'un couvrement de pierre. En effet, on trouve à l'intérieur de l'église de Croute, mais aussi à l'extérieur, dans le jardin et dans le presbytère, différents indices prouvant, sinon la réalisation de ce voûtement, du moins la volonté de diviser l'espace en trois vaisseaux et de voûter cet espace : intéressons-nous tout d'abord aux supports placés à l'entrée du chœur: de chaque côté de l'abside d'axe, l'arc triomphal devait reposer sur une demi-colonne engagée, posée sur un haut socle et une base attique. Mais, il manque toute la partie supérieure, notamment le chapiteau, le tailloir et l'arc lui-même (fig. 11).

On a longtemps pensé que la moitié supérieure de l'abside d'axe avait disparu après les exactions causées par les protestants à la fin du XVIe siècle. Il faut, à mon avis, envisager une autre hypothèse : l'achèvement des parties hautes de l'abside a pu être réalisé car, au-dessus du plancher actuel, sous la charpente, le mur semi-circulaire de l'abside se poursuit sur quelques centimètres de hauteur et paraît avoir été arasé. Il a donc pu exister un niveau d'ouvertures au-dessus de l'arcature aveugle ainsi qu'une voûte en cul-de-four surplombant le tout, signifiant ainsi que l'arc triomphal reposait sur deux chapiteaux de demi-colonnes ${ }^{61}$. Il paraît tout de même assez étrange que l'on n'ait pas conservé d'autres traces de cet état.

De plus, il est impossible que la destruction des parties hautes du chœur soit le fait des protestants car des traces du décor gothique visible ailleurs dans l'édifice apparaissent clairement à l'endroit des demi-tambours disparus. Cela signifie donc que la disparition de l'élévation supérieure de l'abside est sans doute antérieure au XIVe siècle. Enfin, signalons que les parties murales situées dans le comble possèdent le même décor, ce qui signifie qu'à l'époque gothique, la couverture actuelle était plus élevée mais que les parties hautes de l'arc triomphal étaient déjà tombées. Il reste donc à savoir quel événement a pu conduire à cet état de fait : on peut estimer alors que l'inachèvement du transept et de la nef et donc l'absence de tout système d'épaulement ont causé progressivement l'effondrement de cette voûte qui ne fut jamais remontée au-dessus de l'abside. On se contenta de peindre l'intérieur de l'abside sur toute la hauteur des murs conservés à l'époque gothique avant de procéder à un abaissement du lambris actuel, sans doute au XIXe siècle, lors des remaniements effectués sur la charpente et la toiture.

Du côté sud, vers la nef, on retrouve d'ailleurs la même élévation: socle carré, base attique dont on aperçoit une partie de la mouluration, ainsi qu'un vestige de la demi-colonne engagée dans un dosseret, censée recevoir la retombée de l'arc d'encadrement séparant la croisée du transept du

\footnotetext{
59. Elles sont notamment visibles depuis l'enlèvement des couches d'enduit et de peinture qui recouvraient l'intérieur de l'abside d'axe. On peut y voir un A et un N renversé, ainsi qu'une spirale : Pousthomis-Dalle 1996, 64. A Tasque, où la pierre de taille n'a été que très peu utilisée dans les parties orientales, je n'ai pu retrouver qu'un seul bloc marqué, au signe différent de ceux de Croute. A Aignan, je n'ai pas trouvé de marques lapidaires, ni à l'extérieur, ni à l'intérieur de l'église.

${ }^{60}$. Les traces apparentes sur la pierre attestent l'utilisation d'une laye ou marteau taillant, utilisé avec précision. Les résidus des coups d'outil sont fins et réguliers, conformément à la technique employé à l'extrême fin du XIe siècle ou au XIIe siècle dans les édifices contemporains où l'on fait appel à des tailleurs de pierre compétents.

61. Au-dessus du dernier tambour, et ce, sur les deux supports, on voit la trace d'une couche de mortier sur laquelle reposait au moins un bloc supplémentaire dont la trace d'arrachement se discerne également sous les enduits successifs qui recouvrent le mur.
} 
bras ouest ${ }^{62}$. Ensuite, de l'autre côté, à moitié engagée dans les murs postérieurs qui dessinent le volume sud de l'église, on peut apercevoir la base du pilier d'angle sud-ouest de la croisée, de forme circulaire et présentant une large imposte au milieu de laquelle se trouvait un pilier cruciforme, vraisemblablement agrémenté de demi-colonnes engagées censées recevoir la retombée des grandes arcades et des doubleaux (fig. 12). D'ailleurs, à l'extérieur, on aperçoit une autre partie de ce support, aux dimensions colossales ${ }^{63}$. L'absence $\mathrm{d}^{\prime}$ enduit montre qu'il $^{\prime}$ est entièrement construit en pierre de taille. Malheureusement, son exposition aux intempéries l'a détérioré. On aurait donc eu la volonté de construire une nef de trois vaisseaux dont les travées voûtées étaient séparées, du moins aux angles sud de la croisée du transept ${ }^{64}$, par des piliers cruciformes flanqués de demi-colonnes engagées et posés sur de gros socles circulaires ${ }^{65}$.

Le problème, c'est que ce type de plan et de subdivision de l'espace intérieur en trois vaisseaux n'est pas très compatible avec la présence de la tourelle d'escalier à l'angle sud-est de ce transept, sauf dans le cas d'une nef en léger retrait sur le transept. Pourtant, tous ces éléments que nous venons d'étudier semblent contemporains ${ }^{66}$. Nous sommes donc ici au cœur du problème posé par les vestiges romans de l'église de Croute : mis dans une perspective d'ensemble, ils apparaissent comme étrangers les uns aux autres. De plus, il faut se demander quelle était la teneur du reste du plan: d'après les maigres vestiges encore discernables, on voit un fragment de support, pouvant correspondre au système de retombée des arcs séparant la dernière travée du vaisseau central de la dernière travée du collatéral est ${ }^{67}$, ainsi qu'un mur transversal, orienté ouest-est, situé à l'aplomb du ravin, à une trentaine de mètres au sud. C'est un mur rectiligne en pierre de taille, dont les matériaux et les dimensions des blocs pourraient correspondre à ceux de la partie nord de l'église. Il pourrait peut-être s'agir d'un vestige du soubassement de la façade occidentale, mais en l'absence de tout autre élément corroborant cette hypothèse, il faut se montrer très prudent. Si cette interprétation était juste, on aurait affaire à un édifice de taille plus qu'appréciable par rapport à ce qu'il en reste et à la disparition presque totale de sources le concernant, plus grand que la collégiale de Nogaro, plus imposant que Notre-Dame d'Estang, que Saint-Mamet de Peyrusse-Grande, et que la plupart des édifices religieux gascons contemporains.

En résumé, voici probablement comment se sont déroulées les multiples phases de l'existence de l'église Saint-Barthélemy de Croute: le chantier de construction de l'église a bien été lancé à l'extrême fin du XI' siècle pour se poursuivre dans le premier quart du XII siècle. Malheureusement, des conditions historiques difficiles, liées peut-être à des problèmes financiers ont stoppé net l'œuvre

62. A droite de l'entrée de l'abside, tout a disparu puisque socle, base et support ont été bûchés, laissant apparaitre un dosseret parfaitement lisse.

63. Le support apparaît énorme du fait du niveau du sol du jardin plus bas que celui de l'église. On aperçoit donc une partie des fondations du support. Le socle circulaire mesure 2,20 $\mathrm{m}$ de diamètre sur 1,10 $\mathrm{m}$ de haut. Un des dosserets mesure 0,70 $\mathrm{m}$ de large pour 0,25-0,26 $\mathrm{m}$ de profondeur. Quant au noyau central, il mesure environ 0,88 $\mathrm{m}$ de large.

64. On peut voir sur le plan les vestiges d'un pilier identique au précédent, situé en vis-à-vis de ce dernier, parfaitement dans l'axe du support séparant l'abside d'axe de l'absidiole méridionale. Ainsi, nous aurions affaire à une croisée de transept parfaitement régulière, de 5,75 m de côté. Ces vestiges sont aujourd'hui situés dans la propriété privée que constitue l'ancien presbytère.

65. Ce type de support est courant dans l'architecture romane méridionale aux XIe et XIIe siècles, notamment dans les grands édifices voûtés, comme par exemple à Conques. Les modèles de Croute pourraient être les supports intérieurs de la collégiale de Nogaro, de profil et de structure semblables. Néanmoins, les socles circulaires et les piliers cruciformes de Nogaro sont plus massifs.

${ }^{66}$. Il faut aussi prendre en compte la nature des supports et leur profil. En effet, les piliers placés à l'entrée du chœur - abside d'axe et absidiole sud - possèdent la même structure que le pilier engagé apparaissant sur la face ouest du clocher, face disposée à l'intérieur de l'église aujourd'hui : il s'agit d'un support rectangulaire, d'environ 0,50 $\mathrm{m}$ de hauteur, dont l'extrémité supérieure est agrémenté de deux rainures. En revanche, les vestiges des piliers placés en face, aux angles sud de cette croisée de transept sont totalement différents, constitués d'un socle circulaire sur lequel est posé un pilier cruciforme. Cette différence pourrait être l'indice d'un faible hiatus chronologique dans la conception de l'élévation intérieure de l'église.

67. Sur le plan, on devine la présence d'un conglomérat de blocs situés dans le prolongement du support précédent, en direction de la façade sud, support placé entre deux travées de la nef. L'examen de ces éléments ne permet pas d'être plus catégorique, bien que la maçonnerie paraisse ancienne. 
dans le deuxième quart du siècle, ne permettant pas de réaliser un édifice aussi grandiose et élégant que le plan, l'élévation du chœur, le décor sculpté intérieur et extérieur, les dimensions des supports et les volumes d'ensemble le laissaient présager. A ce moment-là, dans le courant du XIIe siècle, on décida de terminer le chantier à l'économie, en fermant les faces latérales de l'édifice encore inachevées par des maçonneries plus grossières, assez semblables aux murs les plus anciens du chevet. Aujourd'hui murée, la petite fenêtre ébrasée percée près du contrefort nord-est de l'église témoigne de l'ancienneté de cette campagne. On plaça au-dessus de l'abside d'axe et peut-être aussi au-dessus de l'absidiole ouest un plancher, après que les deux voûtes en cul-de-four d'origine se sont effondrées. Seule l'absidiole orientale peut être considérée comme terminée. Le reste de l'édifice, au niveau du transept surtout, ne fut qu'ébauché, son tracé étant encore visible à l'intérieur grâce aux supports qui furent seulement élevés sur quelques dizaines de centimètres de hauteur.

Si l'église a pu subir en 1569 les assauts des protestants, ce fut sans doute de manière négligeable ${ }^{68}$. En effet, on a pu montrer que l'aspect actuel du monument ne résultait pas de ces dégradations, en tous cas pas dans la proportion des $2 / 3$ comme on le pensait généralement, mais plutôt d'un remaniement ancien, très rapproché de la date de commencement de la construction et consécutif à un déroulement assez chaotique de celle-ci. A partir de là, il est possible d'attribuer certains éléments de ce remontage qui a pu avoir lieu entre 1569-1570 et au plus tard 1650, puisque la présence d'une litre funéraire présentant les armes de Françoise de Médrano interdisent d'envisager une datation plus basse que le milieu du XVIIe siècle. L'église, telle qu'elle était visible à ce moment-là, n'a quasiment pas été modifiée, en dépit de quelques aménagements mineurs, réalisés pour la plupart au XIXe siècle (fig. 13).

Néanmoins, la tour d'escalier transformée plus tard en clocher pose encore problème, notamment quand on évoque son raccordement au transept faiblement saillant qu'on avait projeté d'édifier. Ce transept devait posséder une croisée qu'on avait sans doute prévu de surmonter d'un clocher, accessible par la tour d'escalier hors œuvre encore conservée aujourd'hui. On peut donc ici envisager deux postulats : dans un premier temps, on voulait construit une nef à vaisseau unique, peut-être charpentée et située dans le prolongement de la croisée de transept, comme dans l'abbatiale voisine de Tasque, dont on a vu qu'elle possédait de nombreux liens avec Croute. Dans un deuxième temps, après avoir construit le transept en légère saillie et la tourelle d'escalier, on aurait décidé de construire un édifice entièrement voûté, ouvrant sur une nef à trois vaisseaux. Pour ce faire, on se servit de la croisée de plan carrée, de $5,75 \mathrm{~m}$ de côté, destinée à être voûtée et à toujours être surmontée d'un clocher. L'articulation méridionale de la croisée de transept, avec ses piliers cruciformes à demi-colonnes engagées, atteste ce changement de parti. A ce moment-là, la tour devient un élément intégré à l'édifice et raccordé de manière maladroite à la future nef. Reste à savoir comment les constructeurs allaient réussir à insérer harmonieusement cette tourelle d'escalier dans l'élévation de l'église puisque son emprise au sol rend la circulation quelque peu malaisée vers l'absidiole est (fig. 14) ${ }^{69}$. Dans ce cas de figure, la référence locale n'est plus l'abbatiale de Tasque, mais plutôt la collégiale de Nogaro, dont le plan harmonieux pouvait mieux convenir à une petite communauté religieuse accueillant des pèlerins. D'ailleurs, certains des tailleurs de pierre ayant travaillé à la construction de la collégiale ont pu également participer au chantier voisin de Croute. Certaines marques lapidaires, assez voisines entre elles, laissent entrevoir cette hypothèse.

\footnotetext{
${ }^{68}$. Pour infirmer cette hypothèse, on peut aussi arguer du fait que le décor sculpté intérieur est relativement bien conservé, en dépit de quelques dégradations. Si les protestants avaient décidé de ruiner l'édifice, nul doute qu'ils s'en seraient pris aux chapiteaux des arcatures aveugles, particulièrement accessibles.

69. En fait, la réalisation du nouveau plan au sol démontre que la tour d'escalier s'intègre mieux dans l'édifice que le plan de $P$. Mesplé ne le laissait supposer. Remarquons d'ailleurs que du côté ouest, le mur de l'escalier présente des vestiges de supports engagés, une demi-colonne sur dosseret?, pouvant correspondre aux vestiges des autres supports encore discernables à l'intérieur et à l'extérieur de l'édifice.
} 


\section{Un décor sculpté de tradition hispano-languedocienne ${ }^{70}$ :}

L'étude de la sculpture intérieure va nous permettre d'affiner la chronologie de cette deuxième phase de construction de l'église de Croute et de replacer la conception et l'exécution de ce décor dans la production contemporaine. Malgré la présence d'une corniche à modillons au-dessus de l'absidiole orientale et d'une archivolte de billettes autour de la fenêtre qui l'éclaire, on a pu remarquer que l'élévation extérieure de l'édifice était simple et dépouillée, non seulement à cause des multiples avatars subis par le monument, mais aussi par le choix d'un chevet mis en valeur par les matériaux eux-mêmes. Certaines églises romanes du Vic-Bilh, avec lesquelles l'église de Croute présente quelques analogies, possèdent aussi un décor sculpté "peu envahissant mais de qualité, rehaussant les points forts de leur architecture »(Cabrero-Ravel et alii 2003, 11). A l'intérieur, c'est tout le contraire et l'on peut alors juger de l'intérêt d'avoir voûté l'édifice: apporter solidité et monumentalité tout en utilisant une structure intérieure mise en valeur par le décor sculpté, auquel il faut aussi ajouter le décor peint, dont le degré de conservation sous les enduits de chaux est difficile à évaluer aujourd'hui ${ }^{71}$.

Le décor sculpté intérieur se limite donc, à cause des destructions, à l'abside d'axe et à $1^{\prime}$ absidiole est ${ }^{72}$. Placé à différents niveaux, principalement de manière horizontale, il avait été conçu à l'origine pour unifier les trois absides. Dans l'absidiole est, le décor anime et rythme de manière élégante la structure de tout le volume. Une première corniche de billettes forme retour à l'angle nordest du bras de transept pour se prolonger sur les supports de l'arc d'entrée du sanctuaire, constitués de chaque côté de deux colonnes géminées, par l'intermédiaire de bagues de billettes qui forment le départ de la corniche placée au-dessus de l'arcature aveugle. Plus haut, au niveau des chapiteaux d'entrée, la même corniche se déploie, destinée à séparer le mur droit de la naissance de la voûte en cul-de-four et à mettre en valeur la fenêtre qui, comme à l'extérieur, est encadrée par une archivolte de billettes ${ }^{73}$. Enfin, l'arc triomphal est lui-même bordé par un tore cordé accompagné de boules et d'une nouvelle archivolte de deux rangées de billettes (fig. 15) ${ }^{74}$, motif éminemment roman, très en vogue dans la sculpture romane du nord de l'Espagne et du Midi de la France depuis le milieu du XI siècle ${ }^{75}$.

Du point de vue de l'élévation, d'autres édifices régionaux reprennent, dans le premier quart du XIIe siècle, ce schéma qui vise à mettre en valeur le sanctuaire et à en accentuer la composition structurelle par des horizontales qui partagent l'espace. C'est notamment le cas à Saint-Jean-Baptiste de Mazères, en Rivière-Basse, où le chœur à fond plat est divisé en plusieurs niveaux horizontaux par

\footnotetext{
${ }^{70}$. Pour des raisons de commodités, on utilisera cette expression pour désigner la provenance structurelle, iconographique et stylistique des chapiteaux de Croute. Ces deux termes font ainsi référence, dans leur ensemble, au décor sculpté que l'on peut rencontrer sur les chemins de Saint-Jacques et autour de ceux-ci, dans le Nord de l'Espagne et le Midi de la France, et plus précisément au pied des Pyrénées, et ce, dans la première moitié du XIIe siècle.

${ }^{71}$. Cf. supra, note 21 et p. 4 .

72. Comme je l'ai mentionné plus haut, la reconstruction de l'absidiole ouest en 1860 pour en faire une sacristie a permis de rappeler son élévation primitive grâce aux quelques vestiges conservés. En effet, on a pu réutiliser certains éléments de l'arcature aveugle, notamment deux départs d'arcs latéraux en plein cintre, surmontés par une corniche de billettes, un fragment de la banquette, le socle et la base de la colonne. Mais ce sont les seuls éléments en pierre puisque la colonne et le chapiteau sont en plâtre, le décor de ce dernier copiant celui d'un chapiteau ancien de l'église. Quant au tailloir, il est lisse et a été également agrémenté d'un décor de plâtre. L'ensemble, qui n'a aucune valeur scientifique permet tout de même de mieux apprécier l'unité du choeur tripartite au moment de sa construction.

73. La fenêtre repose sur la première corniche.

74. Remarquons aussi la variété des billettes: elles peuvent être de taille différente en fonction de l'emplacement qu'elles occupent. Leur forme peut aussi varier : la corniche inférieure de l'absidiole est constituée de grosses billettes en quart-de-rond, tandis que celles de la corniches supérieures sont planes. Tous ces détails, qui peuvent apparaître comme superflus, témoignent du soin que l'on a apporté à la décoration intérieure du chœur.

75. Les corniches intérieure et extérieure de billettes connaissent un grand succès dans des édifices du dernier quart du XI ${ }^{e}$ siècle situés, près de Croute, aux confins de la Bigorre et du Pardiac, à Saint-Mamet de Peyrusse-Grande, à Sainte-Marie de Maubourguet, à Saint-Orens de Larreule. A chaque fois, la corniche est utilisée pour mettre en valeur le volume du chœur. Remarquons aussi que certaines églises du Vic-Bilh possèdent un décor comparable, des corniches de billettes qui rehaussent les élévations. C'est le cas à Simacourbe et à Sedze-Maubecq, dans la 1ère moitié du XIIe siècle : Cabanot 1978 et Cabrero-Ravel et alii 2003.
} 
des corniches de billettes qui habillent aussi les fenêtres reposant sur la corniche inférieure (Cabanot 1969 b, 1970 a, 67-79 et 1978, 203-208) ainsi que dans l'abside d'axe ou les absidioles de Saint-Nicolas de Nogaro (Durliat 1970 c, 91-110 et Cabanot 1978, 236-242). Mais surtout, l'utilisation à l'entrée du sanctuaire de colonnes géminées ceintes d'un bandeau de billettes se prolongeant à l'intérieur et à l'extérieur de la chapelle rappelle encore plus précisément ces deux édifices ainsi que l'ancienne abbatiale Saint-Jean-Baptiste de Saint-Mont, où l'on retrouve, dans le bras sud du transept, le principe des colonnes jumelles (Cabanot 1970 b, 80-90 et 1978, 229-234). On peut imaginer que dans l'abside d'axe, ce décor devait être encore plus élégant. Malheureusement, et comme on l'a vu plus haut, toute la moitié supérieure est détruite : chapiteaux et tailloirs de l'arc triomphal, archivolte le couronnant, décor intérieur de l'abside ${ }^{76}$, structure des fenêtres, ... . En revanche, dans la moitié inférieure, on observe que, contrairement à l'absidiole est, les arcades aveugles ont été entourées d'une archivolte de billettes.

Posées sur des socles rectangulaires parfois décorés de billettes ou de boules dans l'abside d'axe $\left(\mathrm{n}^{\circ} 10 \text { et } 11\right)^{77}$, les bases comportent généralement des griffes d'angle constituées de simples boules $\left(\mathrm{n}^{\circ} 2,12 \text { et } 14\right)^{78}$, que l'on peut retrouver, au milieu de la scotie ${ }^{79}$, traitées comme des boules suspendues sous l'extrémité inférieure d'une feuille lisse $\left(n^{\circ} 13\right)$ ou des pommes de pin $\left(n^{\circ} 5\right)$. Le motif des boules placées sous une feuille lisse peut aussi apparaître aux angles du socle $\left(n^{\circ} 4,13\right.$ et 19), de même que des volutes en forme de coquille d'escargot ( $\mathrm{n}^{\circ} 7$ et 9 ). Enfin, plus rarement, le décor peut concerner le socle et la base $\left(\mathrm{n}^{\circ} 11\right)$. A nouveau, ce traitement élégant apporté à la partie basse de l'élévation - banquette, socle, base de colonne - est tout à fait caractéristique du début du XIIe siècle ${ }^{80}$. Remarquons enfin que l'autel roman de l'absidiole comporte des colonnettes d'angle dont la base est ornée en son milieu d'une feuille lisse donnant naissance à une boule. Cette similitude de mouluration et de décor avec les autres bases de colonnes atteste la contemporanéité d'exécution de ces éléments et donc du soin apporté à la décoration de l'église ainsi qu'à la réalisation d'une partie de son mobilier liturgique.

Les colonnes monolithes ${ }^{81}$ sont surmontées $d^{\prime} u n$ astragale torique ${ }^{82}$ faisant partie $d u$ chapiteau. Tous les chapiteaux situés à la base des deux arcs aveugles sont à épannelage corinthisant ${ }^{83}$, plus ou moins étirés dans le sens de la hauteur ${ }^{84}$ et surmontés d'un tailloir rectangulaire saillant, aux faces abattues, comportant un décor purement ornemental et disposé au-dessus d'un abaque échancré 85 . Il reste vingt chapiteaux et autant de tailloirs encore en place ${ }^{86}$ dans le chœur de Croute,

\footnotetext{
76. A certains endroits, la corniche inférieure est conservée.

77. Voici les dimensions des socles : dans l'abside : 0,42-0,43 m x 0,34 m; dans l'absidiole : 0,32 m x 0,24 m. Notons que certains socles rectangulaires de l'ancienne église priorale de Madiran comportent une baguette torsadée, comme à Croute.

78. Ces bases sont généralement de deux types, que ce soit dans l'abside d'axe ou dans l'absidiole est: soit des bases élancées dans lesquelles la scotie est haute et concave, placée entre deux tores accompagnés d'une rainure, soit des bases plus aplaties, dans lesquelles la scotie est beaucoup plus réduite, et toujours placées entre deux tores. Notons que le tore supérieur ou inférieur est parfois tressé de manière fine et minutieuse.

79. A Nogaro, la base de la première colonne nord de l'arcature aveugle possède aussi un décor au milieu de la scotie. Il s'agit de petites feuilles à quatre pétales, traitées en relief.

${ }^{80}$. Les bases à boules sont visibles dans beaucoup d'édifices régionaux au XIIe siècle, notamment à Aignan ou à Nogaro. Dans l'ancienne collégiale Sainte-Candide de Jégun, un support de la nef du XIIe siècle possède une base de demi-colonne engagée dont la scotie est ornée de boules : Dubourg-Noves 1970, 228-234.

81. Voici les dimensions des colonnes : dans l'abside : 0,23 $\mathrm{m}$ de diamètre ; dans l'absidiole $0,21 \mathrm{~m}$. Les colonnes de l'arcature aveugle d'Aignan mesurent aussi 0,21 $\mathrm{m}$ de diamètre.

82. Voici les dimensions des astragales: dans l'abside : entre 0,05 et 0,06 $\mathrm{m}$ de haut; dans l'absidiole : 0,05 m. A nouveau, les dimensions des astragales d'Aignan et de Nogaro sont très voisines de celles de Croute.

83. Encore une fois, nous devons évoquer les liens structurels qui existent entre de nombreux édifices régionaux puisqu'en VicBilh tous les chapiteaux prennent modèle sur le type corinthien, que ce soit pour des compositions végétales ou historiées: Cabrero-Ravel et alii 2003, 16-22 et surtout Lacoste 2007.

84. Voici les dimensions des chapiteaux: dans l'abside : 0,45 $\mathrm{m}$ de hauteur, il ne m'a pas été possible de prendre les mesures en largeur; dans l'absidiole : $0,30 \mathrm{~m}$ de haut sur $0,35 \mathrm{~m}$ de large.

85. Voici les dimensions des tailloirs : dans l'abside : 0,20 $\mathrm{m}$ de haut, il ne m'a pas été possible de prendre les mesures en largeur ; dans l'absidiole : la norme varie entre 0,33-0,34 $\mathrm{m}$ de large et 0,51-0,52 $\mathrm{m}$ de long.

${ }^{86}$. Tout l'intérieur du chœur de l'église, notamment les éléments sculptés, est revêtu d'une épaisse couche de badigeon de chaux qui empêche tout examen précis des détails de composition, d'iconographie, de style et de technique des chapiteaux et, dans
} 
répartis comme suit: onze chapiteaux simples dans l'abside d'axe, à la base des arcs en plein cintre aveugles, sept chapiteaux simples occupent le même emplacement dans l'absidiole est et on trouve deux chapiteaux doubles à l'entrée de celle-ci ${ }^{87}$.

L'ensemble du programme décoratif des chapiteaux conservés ne paraît pas obéir à un schéma précis, mais il faut noter la grande variété des thèmes représentés, ce qui n'empêche pas tout de même quelques redites. Il n'y a qu'une faible proportion de chapiteaux historiés, seulement quatre sur vingt, deux dans l'abside ${ }^{88}$ et les deux autres à la retombée de l'arc triomphal de l'absidiole est ${ }^{89}$. Les seize chapiteaux restant peuvent se scinder en deux groupes : le premier comprend des œuvres purement ornementales, végétales et zoomorphes. Cela concerne quinze chapiteaux sur seize ${ }^{90}$. Quant au dernier, il associe l'homme et l'animal dans une composition bien connue qui peut évoquer des tourments infernaux ${ }^{91}$.

Commençons par les chapiteaux décoratifs, les plus nombreux. Dans cette série, on trouve deux sous-groupes. Le premier se rapporte aux corbeilles essentiellement végétales. Elles sont majoritaires puisqu' on en trouve neuf sur quinze ${ }^{92}$. Cette proportion correspond parfaitement aux normes décoratives contemporaines qu'on peut rencontrer dans les édifices romans du Nord de l'Espagne et du Midi de la France. Que ce soit dans les grands chantiers tels Sainte-Foy de Conques, Saint-Sernin de Toulouse, Saint-Sever sur l'Adour, Saint-Isidore de León, Saint-Jacques de Compostelle ou la cathédrale de Jaca, ainsi que dans des édifices plus modestes qui profitent de leur rayonnement, les chapiteaux décoratifs végétaux rencontrent un énorme succès, notamment grâce à leurs possibilités quasi-infinies de déclinaisons possibles ${ }^{93}$. Ils sont souvent majoritaires par rapport aux chapiteaux historiés. A Croute, l'épannelage corinthien permet de mettre l'accent sur la structure du chapiteau : les angles, le dé médian, l'abaque échancré sont propices à une organisation du décor souvent renouvelée, à partir de l'élément de base, la feuille.

On ne rencontre que trois chapiteaux à un seul niveau de feuilles ${ }^{94}$.

- le chapiteau $\mathrm{n}^{\circ} 4$ possède une corbeille tronconique, presque tubulaire aux $2 / 3$ de sa hauteur (fig. 16). Un décor couvrant composé de médaillons circulaires renfermant chacun une petite fleur à quatre pétales permet d'accrocher la lumière. Ce type de composition rappelle tout à fait le modillon de l'absidiole orientale dont il a été question plus haut. Au-dessus, le décor se soumet à la structure de la corbeille et on voit sur les trois faces du chapiteau de grandes feuilles lisses, dont on n'aperçoit que la moitié supérieure, auxquelles sont suspendues des fruits lisses, de forme ovoïde, dont ceux placés aux angles paraissent suspendus aux volutes. Si les deux dés médians latéraux, volumineux et courbes, sont lisses, celui du centre possède un petit motif floral, aux folioles terminées en crossettes ${ }^{95}$. Ce chapiteau apparaît comme un unicum dans la sculpture gasconne contemporaine. Bien qu'il en soit quelque peu éloigné, il semble qu'on puisse le rapprocher des magnifiques séries de palmettes recroquevillées sur elles-mêmes que l'on peut voir à Saint-Sernin (Durliat 1990, 95), notamment dans les parties les plus orientales de la collégiale, motif qui va connaître un véritable succès là où

une moindre mesure, des tailloirs. Il serait particulièrement judicieux de procéder à un nettoyage des parties sculptées, non seulement pour faire apparaître les restes de décor peint, mais aussi pour restituer à la sculpture sa qualité d'origine.

87. Pour la numérotation des chapiteaux, se référer au plan du chœur.

88. Ce sont les chapiteaux $n^{\circ} 6$ et 9 .

89. Ce sont les corbeilles $n^{\circ} 12$ et 20 .

${ }^{90}$. Ce sont les chapiteaux $n^{\circ} 1,2,3,4,5,7,8,10,13,14,15,16,17,18$ et 19.

91. Il s'agit du chapiteau $\mathrm{n}^{\circ} 11$.

92. Ce sont les chapiteaux $\mathrm{n}^{\circ} 1,3,4,5,7,10,14,17$ et 18 .

93. Sur tous ces édifices, on consultera Durliat 1990, véritable ouvrage de référence ainsi que Lacoste 2006, pour une mise au point récente et complète sur la sculpture romane dans le nord de l'Espagne. Enfin, sur les rapports entre les monuments romans situés de part et d'autre des Pyrénées, notamment en Béarn et Aragon, on lira avec profit Lacoste 2007.

94. Ce sont les chapiteaux $n^{\circ} 4,10$ et 17 .

${ }^{95}$. Techniquement, la feuille apparaît comme simplement gravée sur la pierre. Cette impression est d'ailleurs renforcée par l'importante couche de chaux qui a été étalée sur ce chapiteau. 
travaillent certains sculpteurs toulousains, comme dans le chœur de l'église Saint-Jean-Baptiste de Mazères à Castelnau Rivière-Basse (Cabanot 1970 a, 67-79). La seule différence réside dans la qualité très moyenne du chapiteau de Croute, à cause surtout de l'absence de taille en creux qui laisse les feuilles totalement planes.

- les chapiteaux à feuilles lisses, disposées sur une ou deux rangées superposées, ont rencontré un vrai succès à Croute puisqu' on en dénombre cinq sur neuf ${ }^{96}$. Parmi eux, on ne trouve qu'un chapiteau à une seule rangée de feuilles occupant les $2 / 3$ de la hauteur totale de la corbeille ${ }^{97}$. Les feuilles sont minces et déliées, marquées par une fine nervure centrale, assez loin des grosses feuilles lourdes et massives qu'on rencontre à Saint-Sever et qui vont se diffuser dans un certain nombre d'édifices proches, tels Mazères (Cabanot 1970 a, 73). Comme sur l'œuvre précédente, des boules sont accrochées à l'extrémité supérieure de la feuille et en même temps à l'angle supérieur de la corbeille, entre les volutes ${ }^{98}$. Celles-ci, assez grêles, s'enroulent en forme de coquille d'escargot et se dressent au-dessus de hampes fines et élancées ${ }^{99}$. Une feuille lisse lancéolée occupe le dé central, comme pour prolonger le motif principal de la corbeille (fig. 17).

Trois des quatre autres chapiteaux sont assez semblables ${ }^{100}$ : deux rangées de feuilles lisses superposées et disposées en quinconce, une nervure médiane plus ou moins saillante, des boules accrochées aux feuilles ${ }^{101}$. Une influence aragonaise, que nous retrouverons plus loin, apparaît fugacement sur le chapiteau $n^{\circ} 1$. En effet, une tête humaine apparaît sous la boule d'angle de la rangée supérieure. Légèrement décalée par rapport aux boules de la rangée inférieure, elle met en valeur l'axe de symétrie de la corbeille (fig. 18). Ce jeu sur la métamorphose de la boule lisse en une tête humaine rappelle l'une des œuvres les plus marquantes de la cathédrale de Jaca, véritable manifeste de l'évolution technique et structurelle de la composition du chapiteau à l'époque romane. A Croute, si la tête est traitée avec beaucoup moins de finesse, la composition d'ensemble pourrait s'inspirer des recherches menées par le maître de Jaca sur certains des chapiteaux intérieurs de la cathédrale (Durliat 1990, 232, fig. 41). Quant au dernier, le $\mathrm{n}^{\circ} 10$, il offre une composition assez originale : les feuilles les plus hautes, celles qui possèdent encore une fois une boule accrochée à leur extrémité supérieure, deviennent plus étroites et se lient entre elles en se croisant. Dans l'espace ainsi formé vient s'insérer une feuille lisse à la nervure médiane en creux, formant ainsi un intéressant jeu d'ombre et de lumière, malheureusement atténué par l'épaisseur de l'enduit.

A côté des chapiteaux à feuilles lisses, apparaissent des compositions à décor couvrant ${ }^{102}$. Sur les trois, la structure générale est bien connue puisque l'on a deux rangées de feuilles à boules superposées. A l'inverse des œuvres précédentes, les feuilles ne sont plus lisses mais couvertes de minces folioles taillées en creux, symétriquement disposées à partir d'une nervure médiane, comme une feuille de fougère (fig. 19). Parfois, les boules laissent la place à des pommes de pin ${ }^{103}$. L'autre caractéristique de ces trois chapiteaux vient du traitement du ou des dés médians. Contrairement aux compositions précédentes, les dés sont recouverts eux aussi d'un décor floral: petites feuilles lancéolées, palmette dressée à la verticale, petite rosette dans un médaillon. Remarquons aussi que les chapiteaux $\mathrm{n}^{\circ} 7$ et 14 possèdent des séries de petites feuilles taillées en creux disposées entre les hampes des volutes et les feuilles de la rangée supérieure.

C'est un trait que l'on rencontre dans beaucoup d'édifices méridionaux autour de 1100 : à Sainte-Foy de Conques, à Saint-Sernin de Toulouse, dans le cloître de Moissac, à Saint-Sever (Durliat

\footnotetext{
${ }^{96}$. Ce sont les chapiteaux $n^{\circ} 1,5,10,17$ et 18 (fig. 31).

97. Il s'agit du $\mathrm{n}^{\circ} 17$

98. Cette petite attache de la feuille sous les volutes d'angle se retrouve aussi à Nogaro et à Aignan. Ce caractère distinctif, absent par exemple des œuvres influencées à la fois par Saint-Sernin et Saint-Sever, pourrait se révéler être un trait d'atelier ou seulement la marque distincte d'un sculpteur.

99. En revanche, il s'agit là d'une influence directe de Saint-Sever ou des édifices qui s'en inspirent.

${ }^{100}$. Il s'agit des $n^{\circ} 1,5$ et 18 .

101. Sauf pour le chapiteau $n^{\circ} 18$ où les feuilles de la rangée inférieure n’ont pas de boules.

102. Ce sont les chapiteaux $n^{\circ} 3,7$ et 14 .

${ }^{103}$. Comme ici sur le $n^{\circ} 7$, où quelques boules apparaissent au milieu des pommes de pin.
} 
1990), dans la crypte de Saint-Girons d'Hagetmau (Cabanot 1978, 123-127), à Mazères ${ }^{104}$, ... . Enfin, notons que dans l'église de Sedze-Maubecq, en Vic-Bilh, un des chapiteaux de l'abside disposés côté nord est absolument semblable au chapiteau $\mathrm{n}^{\circ} 7$ de Croute (Cabrero-Ravel et alii 2003, 20, fig. 20). Pour l'abbé Cabanot, le décor de cette église béarnaise aurait été exécuté au début du XIIe siècle par l'habile sculpteur de Mazères (Cabanot 1970 a, 78). Voilà qui nous donne des indices chronologique et stylistique intéressants sur la date et les auteurs du décor sculpté de l'église de Croute.

Le deuxième sous-groupe se compose de chapiteaux décorés d'animaux - oiseaux et quadrupèdes principalement - insérés parfois dans des compositions végétales. Le thème des rapaces aux ailes déployées fermement accrochés à l'astragale a été répété trois fois, dans l'abside et dans $l^{\prime}$ absidiole ${ }^{105}$. La composition des deux premiers chapiteaux est rigoureusement symétrique : un oiseau à chaque angle, une aile déployée sur une face latérale, les deux autres se rejoignant sur la face centrale, séparées par un vide correspondant à l'axe de symétrie (fig. 20). Un petit motif floral peut occuper le dé médian ${ }^{106}$. Justement, sur le chapiteau de l'absidiole est, les dés sont recouverts d'un motif caractéristique, à nouveau d'origine hispanique, trois demi-cercles concaves superposés (fig. 21) que l'on peut voir aussi à Jaca (Durliat 1990, 232, fig. 209), dans l'église haute de Loarre (Durliat 1990, fig. 273), à Saint-Isidore de León (Durliat 1990, 365, fig. 380), c'est-à-dire en Aragon et sur le chemin de Saint-Jacques, mais pas dans le Midi de la France, excepté en Gascogne centrale, à Croute, à nouveau sur le chapiteau $\mathrm{n}^{\circ} 12$, mais aussi à Nogaro ${ }^{107}$. Quant au thème de l'aigle aux ailes déployées, $\mathrm{c}^{\prime}$ est un poncif de la sculpture romane de cette région puisqu'on le rencontre partout à Toulouse (Durliat 1990, $113)^{108}$ et à Loarre (Durliat 1990, 270), notamment.

Il semble qu' on puisse attribuer ces trois chapiteaux à deux sculpteurs différents. Le premier aurait réalisé les deux situés dans l'abside d'axe: oiseaux allongés, attitude statique, tête et bec pointus, traitement systématique à base de pointes de diamant du poitrail et des ailes, serres fines. Le deuxième a su mieux utiliser les dimensions du chapiteau, plus ramassé, pour réaliser sa composition. L'oiseau y apparaît mieux proportionné, semblant véritablement prendre son envol, les ailes constituées de plumes en "plis repassés» légèrement concaves conférant à l'oiseau un certain mouvement dynamique. Si la tête a souffert, les serres ont été bien traitées, en forte saillie et $\mathrm{s}^{\prime}$ accrochant fermement à l'astragale ${ }^{109}$. L'artiste a su faire alterner plages lisses sur les pattes, plis repassés pour les plumes et duvet écailleux sur le poitrail. On aperçoit encore le petit animal qu'il tient dans sa gueule.

Les trois chapiteaux décoratifs restant sont tous situés dans l'absidiole orientale et sont parmi les plus réussis de tous les chapiteaux de l'église. Le premier associe des oiseaux picoreurs adossés et affrontés, emprisonnés dans un feuillage touffu' ${ }^{110}$. A nouveau, la composition est très équilibrée malgré l'enchevêtrement des rinceaux qui donnent naissance à des pommes de pin ou des fruits grenus qui se déploient dans tous les sens et qui occupent le moindre espace vide (fig. 22). Les pattes des oiseaux semblent disparaître dans le feuillage et se confondre avec les rinceaux végétaux. On pourra aussi apprécier la qualité technique de l'ensemble, le sculpteur jouant sur la superposition des

104. En revanche, si la composition d'ensemble apparaît aussi à Nogaro et à Aignan, ainsi que le dé médian décoré, le motif des feuilles sous les hampes n'y est pas représenté.

105. Ce sont les chapiteaux $n^{\circ} 2,8$ et 13 .

106. Sur les $n^{\circ} 2$ et 8 .

107. Ce motif apparaît sur le dé médian central d'un chapiteau de l'arcature aveugle de la travée droite de l'absidiole nord.

108. Notons d'ailleurs que ce thème apparaît dans les tribunes des bras de transept, sans doute autour de 1100, notamment dans l'entourage de Bernard Gilduin.

109. Une grande partie de ce chapiteau est recouvert de peinture de couleur rouge. Ce qui semble suggérer que les chapiteaux étaient peints, en harmonie avec les peintures murales que l'on aperçoit encore, masquées sous les enduits. Il s'agit vraisemblablement de peintures réalisées à l'époque gothique, contemporaines de la réalisation du saint Christophe portant l'Enfant Jésus récemment découvert dans une arcature aveugle de l'abside d'axe. Cf. supra, p. 4.

${ }^{110}$. Il s'agit du chapiteau $n^{\circ} 16$. A nouveau, nous rencontrons une composition semblable en Vic-Bilh, sur le chapiteau de droite de la fenêtre d'axe de l'église Saint-Orens d'Escurès, datée du deuxième quart du XIIe siècle : Cabrero-Ravel et alii 2003, 18, fig. 14 et 56-57. 
surfaces et le relief au niveau des différentes parties du corps des oiseaux. Le traitement très fin des oiseaux rappelle le chapiteau précédent du rapace aux ailes déployées, tandis qu'apparaît un élément nouveau, témoignant encore une fois de l'influence de la sculpture romane aragonaise. Il s'agit du fameux «piton» de Jaca, que l'on trouve aussi plus loin, à León (Durliat 1990, 358-375) et à Compostelle, où ce motif est d'ailleurs peut-être né, puisqu'on le rencontre à la fois dans les parties orientales de la cathédrale que l'on peut attribuer à l'évêque Diego Pelaez, mais aussi dans les campagnes de construction et de décoration réalisées sous Diego Gelmirez durant le premier quart du XIIe siècle (Durliat 1990, 204-217 et 310-324). Côté français, le piton a été aussi utilisé en Gascogne centrale, dans l'église de Saint-Mont (Cabanot 1970 b, $80-90$ et 1978, 229-234), à Aignan (Cabanot 1978, 26-27), en Béarn, notamment à Morlaás et à Simacourbe (Cabanot 1978, 37-38 et 43, Lassère 1989 dir., 488-493 et 586-587, Cabrero-Ravel et alii 2003 et Lacoste 2007, 55-66), en Bigorre, dans l'église de Bénac située au sud de Tarbes (Cabanot 1978, 27-28) et en Comminges, dans l'ancienne collégiale de SaintGaudens Durliat 1990, 298-303). On peut donc à nouveau noter l'importance du piémont central des Pyrénées françaises dans la diffusion de formules venant du versant sud. D'ailleurs, le thème luimême, la composition générale semblent issus de ces ateliers de sculpteurs aragonais, notamment ceux de Loarre.

Le deuxième chapiteau reprend aussi un thème visible à Jaca et à Loarre mais de façon plus conventionnelle ${ }^{111}$. Sur une structure corinthienne dont les feuilles ont disparu, le décor se trouve divisé en deux. Solidement agrippés à l'astragale, trois lions sont disposés en frise, le dernier, à droite, par manque de place, est obligé de rejeter sa tête vers l'arrière, de façon assez malhabile. Sur le dé médian central, deux oiseaux sont juchés sur un arbuste au tronc cordé et entrecroisent leur tête. On les retrouve aussi sur la face latérale de gauche (fig. 23). Il s'agit encore une fois de la copie d'œuvres réalisées par l'atelier du «maître de Jaca » dans la cathédrale aragonaise (Durliat 1990, 234), reprises quelques temps plus tard dans l'église haute de Loarre (Durliat 1990, 280). Le traitement des oiseaux coïncide avec celui des deux chapiteaux précédents et pourraient être de la même main. La représentation des lions, notamment pour celui de droite qui est le seul à avoir gardé sa gueule, s'éloigne un peu du style du «lion souriant» de Saint-Sever - mis à part pour les pattes traitées comme des serres d'oiseau - en particulier au niveau de la gueule, toujours largement ouverte mais plus aplatie, comme on peut le voir à Loarre112.

Enfin, la troisième corbeille associe les oiseaux et les lions dans une composition toujours décorative mais qui pourrait posséder un arrière-plan symbolique ${ }^{113}$. Les faces latérales sont occupées par deux oiseaux en vol, dont les extrémités des ailes occupent les dés médians. Avec leurs serres et leur bec, elles s'agrippent fermement à un quadrupède qui semble surgir du fond de la corbeille et dont on ne voit que le buste (fig. 24). Le traitement stylistique d'ensemble évoque tout à fait les œuvres précédentes. On pourra apprécier également l'aisance du sculpteur, notamment dans le domaine technique, car il utilise des coups d'outils qui suggèrent de différentes manières l'aspect des corps des animaux ${ }^{114}$. D'ailleurs, la gueule de l'animal est surmontée d'une tresse cordée en guise de crinière. Elle est aussi visible sur les lions du chapiteau précédent. Il s'agit bien donc d'œuvres que l'on peut attribuer au même sculpteur.

\footnotetext{
111. Il s'agit du chapiteau $n^{\circ} 15$.

112. Les chapiteaux de félins que l'on peut trouver à Nogaro ou à Aignan s'éloignent en revanche quelque peu de la manière du sculpteur de Croute. De même, les lions de Croute n'offrent que peu de liens avec les animaux du chapiteau de droite du portail de Mazères, dont on trouve la copie à Sedze-Maubecq sur le chapiteau de gauche de l'arc triomphal. Ils paraissent en effet l'œuvre d'un sculpteur au style original. Enfin, nous sommes loin aussi du style de l'atelier du maître de la Porte des Comtes de Saint-Sernin de Toulouse, dont on trouve la trace en Bigorre, en Gascogne et en Béarn, notamment à Saint-Sever-de-Rustan, à Mazères et dans la cathédrale de Lescar. Cela révèle la présence à Croute d'artistes aux personnalités et aux origines diverses. ${ }^{113}$. Il s'agit du chapiteau $n^{\circ} 19$.

114. Le sculpteur associe de manière heureuse le méplat, la taille en creux, le haut-relief atteignant presque la ronde-bosse au niveau des pattes du lion, presque totalement détachées du bloc. Cela a d'ailleurs entraîné la perte de sa patte gauche. La variété technique fait apparaître trous de trépan, fines incisions sur le plumage des oiseaux et guillochage minutieux sur la gueule du félin, mêlés à un attaque vigoureuse de la pierre qui permet de dégager progressivement le volume des trois animaux.
} 
Le chapiteau $\mathrm{n}^{\circ} 11$, faisant intervenir l'homme et l'animal, est malheureusement assez détérioré, de sorte qu'il n'est pas possible de l'étudier en détail ${ }^{115}$. Néanmoins, le thème est parfaitement identifiable et appartient encore une fois à la sphère $d$ 'influence des sculpteurs de Croute. Deux lions affrontés, disposés debout sur les deux faces latérales, rejoignent leur tête à l'angle. Malgré leur disparition, on peut penser que les gueules étaient largement ouvertes et commençaient de dévorer un homme, disposé tête en bas, par ses membres inférieurs. Il tente d'ailleurs d'échapper à l'étreinte mortelle des deux félins en s'agrippant à leur cou (fig. 25). On reconnaît là un thème très en vogue dans la sculpture romane méridionale, notamment dans l'atelier du maître de la Porte des Comtes qui va largement l'utiliser à Saint-Sernin de Toulouse mais aussi dans un certain nombre d'édifices du piémont pyrénéen dans lesquels on peut assurer sa présence. A Toulouse, le thème est souvent décliné car le sculpteur change la nature des animaux et la position du damné : on peut trouver quatre lions debout sur leur arrière-train, rejoignant leurs têtes à l'angle, les deux animaux de la face principale emprisonnant dans leurs pattes une tête humaine (Durliat 1990, 93-94). Le plus souvent, ce sont des dragons qui dévorent par la tête un homme assis qui essaie de s'en libérer, comme on peut le voir à la Porte des comtes et dans la tribune du bras sud. Cette dernière composition apparait comme une signature de l'atelier toulousain puisqu'on la retrouve dans deux édifices gascon et bigourdan où ont travaillé des sculpteurs issus de cet atelier de Saint-Sernin. Il s'agit encore une fois de l'église de Mazères (Cabanot 1970 a, 80-90 et 1978, 229-234), mais aussi de l'ancienne abbatiale de Saint-Sever de Rustan, sur le chapiteau situé à l'angle sud-est de la croisée du transept (Cabanot 1978, 209-210). En revanche, la déclinaison réalisée à Croute se voit aussi dans ces deux derniers édifices : à Mazères, comme à Saint-Sever, deux lions antithétiques achève d'engloutir un personnage dont la tête seule émerge encore de leur gueule ${ }^{116}$. Simplement, à Croute, les animaux sont debout sur leurs pattes, comme sur l'un des chapiteaux de l'absidiole est, et le personnage est dévoré par ses membres inférieurs. On évite donc à Croute la copie servile qui pourrait confiner au plagiat en se libérant du schéma établi tout en restant fidèle à la signification de l'image ${ }^{117}$. Malheureusement, du point de vue du style, le mauvais état de conservation de l'œuvre ne permet pas d'attribuer cette œuvre directement à un sculpteur toulousain de passage à Croute ou au sculpteur qui a réalisé certains des chapiteaux précédents ${ }^{118}$, lequel aurait $\mathrm{pu}$, de façon détournée, avoir connaissance de ces thèmes décoratifs si chers aux sculpteurs toulousains.

On pourrait d'ailleurs insérer cette dernière scène dans une réflexion plus profonde incluant les deux chapiteaux historiés de l'abside d'axe. Le premier ${ }^{119}$ illustre le Nouveau Testament par l'intermédiaire de l'Apocalypse de Jean, dans un schéma présent durant toute l'époque médiévale (fig. 26). Sur la face centrale du chapiteau, deux anges nimbés, aux ailes repliées vers l'arrière et se tenant aux angles, portent dans leurs mains un médaillon perlé120 au centre duquel se trouve l'Agnus Dei à la croix dressée. Le message iconographique étant concentré sur la face principale, les deux faces latérales sont purement ornementales puisqu'elles sont recouvertes de deux rangées superposées de feuilles à boules, motif récurrent à Croute ${ }^{121}$.

Quelle pourrait être l'origine de la présence de ce motif à Croute? Encore une fois, comme l'avait d'ailleurs supposé l'abbé Cabanot (Cabanot 1978, 35), il faut se tourner vers les édifices construits dans le nord de l'Espagne sur le chemin de Saint-Jacques. Le modèle prestigieux du portail de l'Agneau à Saint-Isidore de Leon (Durliat 1990, 376-380) a pu inciter l'un des sculpteurs de Croute à

\footnotetext{
115. Il est à la fois cassé à l'angle sur une certaine hauteur et recouvert d'une épaisse couche d'enduit.

116. A Saint-Sever de Rustan, il s'agit du chapiteau situé à l'angle nord-ouest de la croisée de transept.

117. Pour Cabanot 1978, 35, il pourrait s'agir d'un numéro d'acrobates. Je serai plus enclin à pencher dans le sens du supplice infernal, non seulement parce qu'il s'agit d'un thème cher à l'atelier du maître de la Porte des Comtes mais aussi parce que cette évocation des tourments infernaux pourrait s'opposer à d'autres chapiteaux historiés du chœur.

118. Je pense notamment aux chapiteaux $\mathrm{n}^{\circ} 13,16,15$ et 19.

119. Il s'agit du chapiteau $\mathrm{n}^{\circ} 6$.

120. La moitié inférieure du médaillon a disparu.

${ }^{121}$. Les feuilles de la face latérale de droite comporte un décor couvrant dont sont dépourvues les feuilles de l'autre côté. Est-ce volontaire ou bien n'on-t-elles pas été terminées?
} 
insérer cette image du triomphe du Christ dans l'abside d'axe. En effet l'artiste de Gascogne centrale en a repris le schéma général, le nimbe perlé, l'attitude de l'agneau. Seules ont changé les poses des anges, parfaitement soumis à Croute au cadre structurel imposé par la corbeille. On retrouve d'ailleurs une œuvre similaire au portail de la cathédrale Sainte-Marie d'Oloron, lui aussi d'influence espagnole (Lacoste 2006, 67 et surtout 2007, 93-114). En effet, la clef de la troisième voussure est ornée de l'Agneau divin, symbolisant le triomphe du Christ (Allègre 1978, 292-295). Une autre source pourrait également être envisagée lorsqu'on évoque la sculpture languedocienne dont on a pu voir qu'elle avait influencé la sculpture de notre église gasconne. Bien que ce soit surtout Saint-Sernin qui permette de faire des rapprochements avec Croute, l'achèvement du cloître de Moissac en 1100 a pu influencer le sculpteur du chapiteau de Croute puisqu'une composition similaire, de grande qualité, peut se voir sur la face ouest du tailloir qui surmonte le chapiteaux des trois jeunes Hébreux dans la fournaise (Cazes et alii 2001, 224-225). Même si la composition est différente, on retrouve néanmoins à Croute le médaillon perlé de Moissac.

Bien que l'abbé Cabanot ait déclaré sans ordre la disposition des différents chapiteaux de l'église (Cabanot 1978, 35), on remarque au contraire que l'emplacement de chapiteau a fait l'objet d'une véritable réflexion puisqu'il est parfaitement placé dans l'axe de symétrie de l'abside d'axe, en plein milieu de l'arcature aveugle ${ }^{122}$, face à l'autel. Cela dénote la volonté de mettre en valeur le caractère sacré de la messe et notamment la célébration de l'eucharistie par le décor, comme c'est déjà le cas depuis l'époque paléochrétienne ${ }^{123}$. En revanche, du point de vue du style, on s'éloigne à la fois de l'Espagne et de Toulouse pour se rapprocher d'un atelier qu'à présent nous n'avons fait qu'évoquer, celui de Saint-Sever-sur-l'Adour, qui a connu d'ailleurs un véritable rayonnement. Le traitement des plissés, surtout, évoque de manière très précise les dernières œuvres de qualité de l'abbatiale landaise, situées dans les travées les plus occidentales de la nef. Les anges sont habillés de vêtements amples, formant de larges plis concentriques sur les épaules, les bras, le haut des cuisses, les genoux (fig. 26). Ce style très particulier, que l'on retrouve aussi sur certains chapiteaux de la crypte Saint-Girons d'Hagetmau, caractérise des œuvres appartenant à la fin du premier quart du XII siècle $^{124}$. Notons d'ailleurs que certains des personnages peints du cycle de saint Laurent, récemment découvert dans l'absidiole nord de l'ancienne collégiale de Nogaro, dévoilent les mêmes plissés circulaires, notamment au niveau des articulations, que les anges de ce chapiteau de Croute. Le rapprochement entre ces deux œuvres est particulièrement éclairant: d'une part, les peintures de Nogaro ayant été exécutées dans le premier quart du siècle, elles constituent un repère chronologique non négligeable dans l'étude du décor sculpté de Croute, d'autre part, elles attestent des rapports étroits noués entre peintres et sculpteurs dans les domaines iconographique et surtout stylistique, permettant aux uns et aux autres de s'influencer mutuellement (Airiau 1997, 270-273 et Ducourau et alii 2000, 81-94).

Enfin, remarquons aussi que sur le plan iconographique, ce chapiteau est le témoin d'une réflexion précise sur les liens qui existent entre décor, architecture et liturgie. Cela révèle le soin apporté à l'organisation ornementale de l'église de Croute qui, de ce point de vue, apparait comme assez originale dans le paysage monumental local. En effet, cette volonté de copier les programmes iconographiques complexes des grands monuments contemporains est la plupart du temps absente des autres monuments proches, notamment ceux du Vic-Bilh, en dépit des nombreux liens qui peuvent exister entre les églises romanes de cette région et l'église de Croute.

\footnotetext{
122. On peut d'ailleurs remarquer l'originalité des arcatures aveugles des deux sanctuaires de Croute, en nombre impair, avec un support dans l'axe placé sous la fenêtre alors que dans la plupart des autres édifices contemporains, les arcatures sont toujours en nombre pair, laissant vide l'espace centrale de cette structure architecturale. Ce nombre impair des colonnes se voit aussi, en Condomois, dans l'église de Mouchan, voir Durliat 1970 d, 124-130.

123. Je mentionnerai simplement en guise de rappel la présence, en mosaïques, de l'Agneau divin sur la voûte surmontant l'autel de l'église Saint-Vital de Ravenne, achevée vers le milieu du VIe siècle.

124. A propos de Saint-Sever, voir Cabanot 1969, 3-35 et 1978, 118-120. Pour Hagetmau, lire Cabanot 1978, 123-127 et 1987, 207209.
} 
Le deuxième chapiteau historié de l'abside d'axe pourrait être associé au précédent ${ }^{125}$. Il représente le roi David, ancêtre du Christ, entouré de ses musiciens disposés autour de lui sur les trois faces du chapiteau (fig. 27). David, l'une des figures centrales de l'Ancien Testament, pourrait annoncer ici la naissance du Christ dans le Nouveau Testament, le chapiteau de l'Agnus Dei rappelant de manière glorieuse la Résurrection du Fils de l'Homme après la Passion, dont la célébration de l'eucharistie sur le maître-autel constitue le point d'orgue. Rappelons aussi que l'emplacement du chapiteau au sein de l'arcature aveugle peut ne pas être fortuit. En effet, le chapiteau est placé, si l'on suit l'orientation classique, côté sud, en tout cas à droite de l'autel lorsque le prêtre est face à lui, c'està-dire du côté de l'épître, à l'endroit où on lit les passages de l'Ancien Testament, notamment les psaumes. De même, si l'on pense que l'église de Croute abritait une communauté religieuse, le chapiteau révèle alors un sens supplémentaire lorsque l'on songe à l'importance de la musique et des chants dans les chapitres réguliers et séculiers. On voit donc que les liens entre l'emplacement de ces deux chapiteaux et le déroulement de la liturgie ne sont pas inopinés.

A nouveau, ce thème témoigne des rapports étroits entre la sculpture romane gasconne et l'oeuvre aragonaise. En effet, le thème de David et ses musiciens est présent dans la cathédrale de Jaca sur un chapiteau que l'on peut considérer comme l'un des plus beaux du sculpteur principal de la cathédrale (Durliat 1990, 248-249) ${ }^{126}$. Cet épisode a aussi connu un certain succès à Moissac et dans le premier atelier du cloître de la Daurade (Durliat 1990, 130 et 162-163) mais la composition du chapiteau de Croute permet d'attester sa filiation aragonaise. Comme l'a remarqué J. Cabanot (Cabanot 1978, 35), on peut tout d'abord rapprocher le chapiteau de Croute d'un chapiteau de SaintMont (Cabanot 1970 b, 80-90 et 1978, 234, Durliat 1990, 306-307), conçu sur le même canon : au centre de la face principale, le roi, assis sur un trône mais paraissant debout, semble jouer de la viole, tenant l'instrument dans sa main gauche, l'archet dans la main droite. Autour de lui, on aperçoit deux têtes de félins représentant probablement son trône ${ }^{127}$, alors qu'à Saint-Mont, il s'agissait de deux montants verticaux bien visibles ${ }^{128}$. Ensuite, à Croute comme à Saint-Mont, le reste de la face principale est organisé de la même façon et de manière très régulière: sous des volutes placées très haut et n'arrivant pas jusqu'aux angles, on voit deux bustes de personnages jouant d'un instrument, leurs têtes placées au même niveau que celle du roi. Ils paraissent souffler dans une flûte à bec. Aux angles, deux autres personnages disposés en pied jouent de la flûte de Pan. Enfin, sur les faces latérales deux musiciens, également debout, jouent d'un cor qu'ils tiennent à l'horizontale.

La composition, parfaitement symétrique, un peu monotone et comprenant sept individus semble bien loin de l'élégant désordre apparent du chapiteau de Jaca qui mêle pas moins de onze personnages. A Croute, le sculpteur qui ne bénéficie pas des mêmes compétences artistiques n'a su placer que des personnages debout. Il faut sans doute voir dans les deux bustes qui flanquent le roi une tentative de copier l'élégante association de personnages debout et assis de Jaca. Du point de vue du style, le sculpteur de Croute plagie le maître de Jaca : il utilise les grandes écharpes jetées sur les épaules ou sur les bras ainsi que les tuniques pendant en demi-cercles concentriques sur la poitrine ${ }^{129}$.

Ces drapés d'influence antique, attestant la connaissance directe de chapiteaux aragonais réalisés par le sculpteur principal de la cathédrale de Jaca et ses compagnons, se rencontrent également en Vic-Bilh, dans les églises de Saint-Orens d'Escurès, notamment sur le chapiteau de gauche de la fenêtre axiale de l'abside où l'on voit deux anges portant un objet non identifié (CabreroRavel et alii 2003, 56-57), sur le chapiteau extérieur de droite du portail méridional de Saint-JeanBaptiste de Diusse (Cabrero-Ravel et alii 2003, 27, fig. 27 et 54-55), dans le chœur de l'église Sainte-Foy de Morlaàs (Cabrero-Ravel et alii 2003, 19, fig. 17, 31, fig. 31, 67 et Lacoste 2007, 55-66), ... . Cet élément de style rapproche également et surtout Croute de Saint-Mont, ce qui montre que la Gascogne centrale

\footnotetext{
125. Il s'agit du chapiteau $\mathrm{n}^{\circ} 9$.

126. On peut citer aussi un autre chapiteau tout à fait intéressant dans Simon 1980, 239-248.

${ }^{127}$. Ce détail accentue la proximité avec Jaca puisque dans la cathédrale aragonaise, ce sont aussi deux petites têtes de félins qui semblent sortir du cadre.

128. Le montant de droite a disparu mais une tête léonine est encore discernable à l'extrémité supérieure du montant de gauche.

129. Comme je l'ai signalé plus haut à maintes reprises, l'épaisseur de la couche d'enduit empêche tout examen précis de la corbeille. C'est particulièrement visible sur cette œuvre.
} 
n'a pas échappé à l'influence de la sculpture romane que l'on trouve de l'autre côté des Pyrénées ${ }^{130}$. En tous cas, ces deux chapiteaux témoignent à la fois de la connaissance des grands modèles mais aussi de la difficulté qu'ont les sculpteurs de moindre envergure à atteindre la qualité des œuvres qu'ils cherchent à imiter.

Intéressons-nous enfin aux deux chapiteaux placés à la retombée de l'arc d'entrée de la chapelle est ${ }^{131}$. Si le chapiteau de droite est très mutilé, comme nous le verrons un peu plus loin, celui de gauche est en revanche parfaitement clair: il s'agit à la fois de l'Adoration des Mages et de l'Annonce aux Bergers regroupé sur un même support. C'est une composition plus complexe qui, au plan iconographique, associe deux épisodes précis du Nouveau Testament et au plan structurel, pour la première fois dans l'édifice, unit le tailloir à la corbeille (fig. 28).

La corbeille, en partie dirigée vers les fidèles, représente l'Adoration des Mages : sur la face centrale, les trois rois, placés l'un devant l'autre et se dirigeant vers la gauche, se rendent auprès de la Vierge à l'Enfant, placée sur la face latérale de gauche. Sur la corbeille de droite est représentée l'Annonce aux Bergers : à l'angle, sous la volute, un ange en vol fait signe de la main à un berger placé à sa droite. A l'angle et sur une partie de face latérale de droite, on devine le troupeau, figuré par quatre animaux. Le reste de la face est occupé par un personnage qui paraît assis, s'appuyant sur son bâton. Il est richement vêtu et porte une couronne. Il pourrait s'agir de la représentation du roi Hérode, muni de son sceptre et attendant le retour des trois rois. Ainsi, le sculpteur aurait essayé d'organiser un véritable petit cycle iconographique autour de la naissance de l'Enfant ${ }^{132}$.

Ce sont exactement les deux mêmes scènes qui sont placées à un endroit identique dans l'église de Mazères, tout près de Croute ${ }^{133}$. Comme c'était le cas dans l'abside d'axe, on peut noter l'importance liturgique de ces deux thèmes. En effet, la face latérale de gauche, tournée vers les fidèles, porte l'image de la Vierge à l'Enfant. Cette image glorieuse révèle la naissance du Christ dont on annonce le futur sacrifice sur le chapiteau central de l'arcature située dans l'abside. Puis, la convergence des rois vers la Vierge, les présents qu'ils apportent à la mère et à l'enfant rappellent également aux fidèles l'importance de la cérémonie de l'offertoire, au début de la messe, et des présents offerts par les fidèles à la communauté ou au prêtre (Cabanot 1969, 417-418).

Pour une fois, le tailloir participe à la scène : une frise d'angelots, aux ailes déployés, forme une couronne céleste au-dessus des rois mages et du berger pour renforcer l'importance des scènes. A nouveau, on peut rapprocher cette frise d'anges de représentations ayant pu servir de modèles. Si la formule conquoise des anges "cravatés d'ailes ${ }^{134}$ ", paraît trop lointaine pour avoir servi de référence ${ }^{135}$, on peut penser ici à la frise d'angelots située sur les quatre côtés d'une imposte du rondpoint du déambulatoire de Saint-Sernin (Durliat 1990, 97) ainsi qu'aux mêmes anges situés sur le tailloir d'un chapiteau de l'église haute de Loarre (Durliat 1990, 276). Mais c'est surtout le chapiteau de Mazères consacré à l'adoration des Mages qui sert de prototype puisqu'il possède la même cohorte $\mathrm{d}$ 'anges sur le tailloir. Il est donc particulièrement singulier de noter l'importance des liens entre les sculpteurs de Mazères et ceux de Croute ${ }^{136}$.

\footnotetext{
130. Nous pouvons aussi rapprocher nos deux chapiteaux gascons du chapiteau de droite du portail méridional de l'église de Simacourbe. Rappelons d'ailleurs que le chapiteau de gauche représente Daniel entre les lions, les deux corbeilles constituant alors un mini-cycle préfigurant le Christ : Cabrero-Ravel et alii, 22, fig. 22, 79.

131. Ce sont les chapiteaux $n^{\circ} 12$ et 20 .

132. Ce détail iconographique apparaît aussi de manière moins franche sur le chapiteau de gauche de l'arc triomphal de l'église d'Audignon, près de Saint-Sever. Encore une fois, les liens entre l'église de Croute et la sculpture de la Gascogne landaise semblent forts : Cabanot 1978, 169.

133. Le roi Hérode n'est pas représenté à Mazères. Le thème est également présent à l'entrée du chœur de la cathédrale de Lescar et de l'église de la Sainte-Croix, à Oloron, voir Lacoste 2007.

134. Selon l'heureuse formule de Jacques Bousquet.

135. Voir Durliat 1990, 66-67. Ce motif qui appartient au milieu du XIe siècle connaîtra une fortune considérable dans l'atelier du maître de l'abbé Bégon, au début du siècle suivant.

${ }^{136}$. S'agit-il d'un même sculpteur ? On peut le supposer même si l'impossibilité de procéder à un examen plus précis du style empêche de se montrer plus catégorique.
} 
De l'autre côté de l'arc triomphal, le chapiteau a été très abîmé. La face latérale de droite et les faces centrales de ce chapiteau double ne sont plus identifiables. Seule la face latérale de gauche est bien conservée. On y voit un ange tenir une épée de la main droite et prendre par le bras gauche le bras droit d'Adam qui cache sa nudité de sa main gauche (fig. 29). Il s'agit donc de l'expulsion $\mathrm{d}^{\prime}$ Adam et Eve du Paradis après le Péché originel ${ }^{137}$. Au plan stylistique, les maigres éléments encore visibles permettent de penser que le même sculpteur a réalisé ces deux chapiteaux : même palmette taillée en creux sur le dé médian de gauche, dimensions identiques des personnages, mêmes coiffures volumineuses en forme de casque, mêmes ourlets perlés placés sur les extrémités des vêtements ${ }^{138}$.

D'un point de vue iconographique, la portée de ce chapiteau et de son vis-à-vis témoigne d'une véritable réflexion. En effet, alors qu'à Mazères, on avait mis l'accent sur le sacrifice d'Isaac annonçant le sacrifice du Christ auprès duquel les mages apportent leurs présents sur le chapiteau voisin, le commanditaire et le sculpteur de Croute décident d'opposer l'Eve primitive et la Nouvelle Eve, la Vierge, offerte à la vue des fidèles. Quelle pourrait être la raison de ce choix iconographique? Encore une fois, nous devons nous tourner vers Toulouse et l'Aragon. A Toulouse, on a choisi sur deux chapiteaux de la Porte Miègeville d'opposer Eve au moment de l'expulsion du Paradis et la Vierge de l'Annonciation et de la Visitation ${ }^{139}$. En Aragon, dans la cathédrale de Jaca, le maître sculpteur décide, dans une composition d'une grande portée théologique, d'opposer une parodie du péché originel, par l'intermédiaire d'une guenon ou d'un singe portant quelque chose à sa bouche et d'une femme aux serpents, à la Vierge de l'Annonciation, représentée sur la face centrale du chapiteau (Durliat 1990, 236-237).

En même temps, nous devons rapprocher ce chapiteau de l'un de ceux présents à Mazères. En effet, le chapiteau de droite de la fenêtre d'axe propose au visiteur la vision du châtiment du péché originel, c'est-à-dire l'expulsion d'Adam et Eve du Paradis terrestre. On peut donc aussi placer ce chapiteau historié de droite de l'arc triomphal de l'absidiole orientale de Croute à l'origine d'une réflexion $\mathrm{d}^{\prime}$ ensemble sur le thème du salut, dont l'aboutissement, en passant par le chapiteau de l'Epiphanie, est constitué par le chapiteau axial de l'arcature de l'abside, offrant l'image de la Résurrection. Enfin, on se doit d'envisager que les chapiteaux placés à la retombée de l'arc triomphal de l'abside d'axe devaient être historiés, ainsi qu'à l'entrée de l'absidiole ouest; on aurait donc pu avoir une véritable réflexion iconographique basée sur le thème classique de l'opposition entre les deux Testaments, comme le laissent supposer les œuvres encore conservées. On ne peut donc que regretter la destruction d'une partie de l'édifice et l'absence du décor sculpté correspondant.

Si l'étude des chapiteaux ne suffisait pas à démontrer la qualité de leur décor ainsi que leur appartenance à ce large courant issu des grands chantiers contemporains situés sur le chemin de Saint-Jacques, on pourrait alors évoquer les tailloirs, au riche décor et à l'exécution pleine de sûreté. Ces vingt tailloirs, dix-neuf si l'on excepte la frise d'anges, sont essentiellement végétaux et un seul est revêtu de billettes ${ }^{140}$. Un autre ne possède que deux petites gueules d'animaux aux angles, le reste des faces étant parfaitement lisse ${ }^{141}$, comme s'il n'avait pas été fini. Parmi les compositions végétales, un seul tailloir copie une organisation du décor visible sur la corbeille d'un chapiteau ${ }^{142}$. Il s'agit du motif

\footnotetext{
${ }^{137}$. On peut encore apercevoir, me semble-t-il, les contours de la figure d'Eve, levant la main pour croquer la pomme. Sur la face latérale de droite, il pourrait s'agir d'un autre ange gardant l'autre entrée du paradis.

138. Le dé médian de droite, encore conservé, possède les mêmes demi-cercles concaves que sur le dé médian central du chapiteau situé en face.

139. D'ailleurs, on peut justifier l'origine toulousaine de ce thème dans le domaine de l'iconographie par des rapprochements stylistiques. En effet, les coiffures en forme de casque dont je parle plus haut, utilisées pour l'ange et Adam, copient celles que les sculpteurs de la Porte Miègeville ont réalisées sur différents personnages ornant les chapiteaux du portail : notamment l'ange qui expulse Adam du Paradis et le personnage qui est placé sur la face latérale de gauche de la même corbeille, les anges du chapiteau de l'Annonciation et les soldats du chapiteau du Massacre des Innocents.

${ }^{140}$. Il s'agit du tailloir du chapiteau $\mathrm{n}^{\circ} 20$.

${ }^{141}$. Il s'agit du tailloir du chapiteau $\mathrm{n}^{\circ} 4$.

${ }^{142}$. Il s'agit du tailloir du chapiteau $\mathrm{n}^{\circ} 9$ qui reprend le décor du chapiteau $\mathrm{n}^{\circ} 4$
} 
de la palmette recroquevillée sur elle-même et disposée dans un réseau de rinceaux végétaux disposés sur deux niveaux superposés, les tiges se nouant les unes les autres. L'influence toulousaine est encore une fois parfaitement décelable ici (Durliat 1990, 87-100), mais les petites feuilles de Croute ont perdu la souplesse et l'épanouissement en éventail des palmettes toulousaines.

Le motif le plus courant est néanmoins celui de la palmette circonscrite, placée dans des médaillons liés les uns aux autres par une petite attache ${ }^{143}$. Les palmettes, qui naissent toujours des extrémités des rinceaux, peuvent être soit aplaties, soit largement épanouies, la taille en creux permettant de jouer avec la lumière, le cœur de la feuille étant creusé et les folioles latérales ouvertes vers l'extérieur. La plupart du temps, les palmettes naissent à partir d'un pédoncule triangulaire saillant qui donne en même temps à l'encadrement végétal la forme d'un cœur renversé144. Il s'agit là encore une fois d'un motif caractéristique de la sculpture romane du chemin de Saint-Jacques de Compostelle, dont les plus beaux exemples sont notamment à Saint-Sernin (Durliat 1990, 89), au Panthéon des Rois de Saint-Isidore de León (Durliat 1990, 183-196), à Loarre (Durliat 1990, 261-281). Parfois, le sculpteur introduit dans les écoinçons de petits motifs géométriques losangés qui attestent

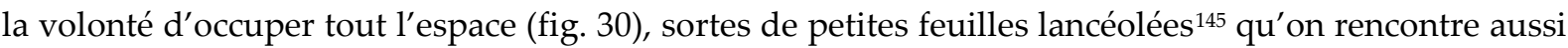
à Moissac ${ }^{146}$. Même si le pédoncule n'apparaît pas ${ }^{147}$, le dessin est toujours aussi ferme, le cadre peut se diviser en deux registres concentriques ${ }^{148}$ et les jeux d'ombre et de lumière sont rehaussés par l'utilisation vigoureuse du coup de trépan qui témoigne d'une technique pleinement maîtrisée (fig. 31).

L'autre motif employé est celui de la feuille épanouie, de type circulaire, placée dans un médaillon de même profil ${ }^{149}$. Les feuilles, taillées en creux, sont disposées en frise, les médaillons étant souvent constitués de deux cadres concentriques, comme dans la série précédente. Parfois, de grands lobes scandent les extrémités des médaillons, comme si on avait voulu en faire le cœur d'une large feuille ${ }^{150}$. Les feuilles sont toutes un peu différentes: les pétales peuvent être entièrement lisses, délicatement ourlées, marquées par une nervure médiane en relief ou en creux, parfois accompagnées de motifs géométriques situées aux angles du tailloir ou de palmettes à trois lobes situées dans les écoinçons ${ }^{151}$. Très souvent les deux angles saillants du tailloir sont décorés d'une large feuille profondément creusée mettant en valeur la structure du tailloir.

Parmi ces tailloirs, un seul associe le végétal et l'animal, à la manière des compositions espagnoles ${ }^{152}$. Les deux angles du tailloir sont habités par une gueule de lion qui crache ou vomit des rinceaux végétaux qui forment l'encadrement de palmettes ourlées, les plus réussies de l'église. C'est donc encore une fois la preuve de la diffusion de compositions décoratives naissant en Aragon ou en León vers la Gascogne centrale et l'autre versant des Pyrénées. Enfin, le tailloir du chapiteau $n^{\circ} 6$ symbolise les diverses influences visibles dans l'église de Croute. En effet, on a abandonné les palmettes et les rosettes pour une variation sur les palmettes grêles à crossettes et les enroulements de demi-palmettes qui évoquent directement le chantier de Saint-Sever (fig. 32) ${ }^{153}$.

\footnotetext{
${ }^{143}$. Il s'agit des tailloirs des chapiteaux $\mathrm{n}^{\circ} 3,10,14,15,17$ et 18 .

144. Notamment sur les tailloirs des chapiteaux $\mathrm{n}^{\circ} 14$ et 15 .

${ }^{145}$. Le petit losange est creux sur le tailloir du chapiteau ${ }^{\circ} 14$, plein sur celui du chapiteau $n^{\circ} 15$.

146. De nombreux tailloirs végétaux du cloître possèdent cet élément distinctif.

147. Comme sur les tailloirs des chapiteaux $\mathrm{n}^{\circ} 17$ et 18.

148. Comme c'est le cas sur certains tailloirs du cloître de Moissac : Durliat 1990, 149-155.

149. Ce sont les tailloirs des chapiteaux $\mathrm{n}^{\circ} 1,5,11,16$ et 19 .

${ }^{150}$. Comme sur les tailloirs des chapiteaux $\mathrm{n}^{\circ} 1$ et 5 .

151. On conserve quelques chapiteaux de la salle capitulaire de l'abbaye de Moissac construite dans le dernier quart du XIe siècle, voir Durliat 1990, 121.

152. Il s'agit du tailloir du chapiteau ${ }^{\circ} 13$.

153. Ce sont les rapprochements précédents avec la grande abbaye landaise mis en évidence plus haut qui justifient à nouveau ces liens. Néanmoins, ce motif ornemental se rencontre partout au même moment, de Saint-Sever à Compostelle, en passant par le cloître de Moissac : Durliat, 1990 et Lacoste 2007.
} 


\section{Conclusion :}

L'église de Croute, par son plan, son élévation, l'ambition portée au projet de sa partie aujourd'hui disparue, l'utilisation successive de matériaux différents, la qualité de son programme sculpté, apparaît comme un monument roman majeur de Gascogne centrale. Si la partie la plus ancienne du chevet est caractéristique des manières de construire à la fin du XIe siècle dans toute la région, la poursuite du chantier et l'élévation définitive du chœur dans le premier quart du XIIe siècle témoigne de la diffusion des formes à la mode dans les domaines de l'architecture et de la sculpture.

Au plan architectural, la marche du chantier révèle la volonté de donner aux reliques que l'église devait probablement conserver un écrin en rapport avec leur statut : après avoir commencé un chevet classique, pareil à de nombreux édifices contemporains régionaux, on a délibérément choisi de copier les grands monuments contemporains qu'on était en train d'élever de part et d'autres des Pyrénées : recours à des tailleurs de pierre, construction d'un chevet tripartite rehaussé de corniches à modillons et de fenêtres ornées, voûtement de toutes les parties intérieures, structuration des volumes intérieurs par des arcatures aveugles plaquées contre les murs des chapelles et utilisation systématique de chapiteaux visant à embellir et à scander les espaces sacrés. Malheureusement, des événements inconnus aujourd'hui ont stoppé net la construction: ruine des voûtes d'une grande partie du chœur, inachèvement du transept et de la nef, fermeture des murs en retour grâce à des maçonneries irrégulières prouvant la détermination à terminer au plus vite un chantier sans doute trop coûteux.

Justement, la connaissance des grands édifices romans situés de part et d'autre des Pyrénées, la capacité technique à en reproduire le plan, l'élévation et le voûtement ainsi que l'élaboration du décor sculpté du chœur de Croute démontrent la mobilité importante des maîtres d'œuvre, des tailleurs de pierre, des artistes et des formes architecturales et décoratives sur le chemin de SaintJacques de Compostelle ${ }^{154}$. En effet, les chapiteaux, les tailloirs, et de manière moins importante, les bases, les socles des colonnes et les corniches intérieure et extérieure, apparaissent comme un véritable abrégé des formes décoratives du temps. Surtout, on remarque que la Gascogne occidentale, mais aussi la Bigorre, le Vic-Bilh, le Béarn et la Gascogne landaise sont un véritable carrefour géographique et artistique entre les terres du Midi toulousain, où se concentre une partie essentielle de l'activité des architectes et des sculpteurs autour de 1100, et le Nord de l'Espagne, notamment l'Aragon qu'il est facile d'atteindre par les différents cols pyrénéens ${ }^{155}$.

L'ouverture de grands chantiers espagnols dans le dernier quart du XIe siècle, tels le Panthéon des rois et la collégiale de Saint-Isidore de Leon, la cathédrale de Compostelle, la cathédrale de Jaca ou la chapelle castrale de Loarre, entre autres, ont permis aux sculpteurs de bénéficier d'un véritable réservoir de formes et de motifs qu'ils utilisèrent ensuite dans les différents endroits où ils ont travaillé. De même, l'activité artistique à Sainte-Foy de Conques, à Saint-Sernin de Toulouse, dans le cloître de Moissac ou dans l'abbatiale gasconne de Saint-Sever facilita la rencontre des sculpteurs, l'échange de leur œuvres qui se sont transformées au gré des partages.

L'autre intérêt de cette étude est de redonner à l'église de Croute la place qui est la sienne dans la production contemporaine. En effet, depuis Jean Cabanot (Cabanot 1970 b, $80-90$ et 1978, 229-

\footnotetext{
154. A ce propos, on consultera un court article de synthèse basé sur quelques grands monuments régionaux et leur contribution à l'épanouissement de l'art roman des deux côtés de la frontière espagnole, dans Balagna 2004 b, 10-13.

155. Certains chercheurs tendent actuellement à minimiser ou à nier le fait que les artistes et les formes décoratives puissent se déplacer en fonction de l'évolution de la commande architecturale. On lira donc avec profit mais aussi avec circonspection Barral i Altet 2006.
} 
234), dont les idées furent reprises par M. Durliat (Durliat, 1990, 303-307), l'abbatiale de Saint-Mont passe pour être l'un des foyers artistiques majeurs de la Gascogne centrale autour de 1100 en raison des liens unissant les chapiteaux de l'église avec des édifices espagnols comme Fromista et Jaca. Mais l'étude de ce décor, qui se résume à quelques pièces plus ou moins bien conservées, semble montrer une circulation unilatérale des sculpteurs et des œuvres. Quant aux œuvres conservées dans l'église de Mazères, en Rivière-Basse (Cabanot 1969, 409-435, 1970 a, 67-79 et 1978, 203-208), construite dans le premier quart du XIIe siècle, dont la qualité et la variété expriment le talent et l'imagination de leurs exécutants, elles permettent également d'apprécier l'importance géographique de la Gascogne dans la transmission des formes romanes. A Mazères, les sculpteurs qui ont travaillé à la décoration du sanctuaire venaient majoritairement de deux édifices majeurs, Saint-Sernin de Toulouse et SaintSever-sur-l'Adour. On va d'ailleurs retrouver certains d'entre eux dans plusieurs petites églises béarnaises qui profitent de toute cette production sculptée.

A Croute, en revanche, il semble que l'on soit dans un véritable creuset artistique au sein duquel se sont exprimées toutes les sensibilités esthétiques contemporaines. On peut d'ailleurs dénombrer plusieurs sculpteurs qui se différencient par leur technique, les motifs qu'ils utilisent, les influences qu'ils reçoivent. Au même moment qu'ailleurs, c'est-à-dire autour des années 1125, les sculpteurs de Croute affirment leur connaissance des grands chantiers du temps, ceux du Midi de la France et ceux du Nord de l'Espagne. Comme on a pu le voir, deux, trois voire quatre mains ont dû réaliser toute l'œuvre sculptée. De formation distincte, d'origines diverses, peut-être aussi de langue ou d'idiome différents ${ }^{156}$, ces artistes se sont retrouvés dans un seul et même lieu et ont mis en commun leur talent et leur compétences au service de commanditaires désireux de dépasser en nombre et en qualité les autres monuments gascons, voire d'égaler les édifices les plus prestigieux. En effet, le nombre important de chapiteaux, la qualité et la variété des thèmes réalisés, la conception et l'exécution, même partielle, d'un véritable programme iconographique confirmant la connaissance précise des thèmes principaux qui pénètrent la sensibilité religieuse à l'époque romane, rangent l'église de Croute dans la catégorie des monuments majeurs de la Gascogne au XIIe siècle.

Si cet excès d'ambition a peut-être conduit à l'arrêt brutal du programme envisagé et à la dispersion des artistes employés sur le site, dont la présence de certains d'entre eux semble avérée tout autour de Croute, nous devons tout de même constater que notre église s'impose comme un lien déterminant entre les deux versants de ce côté-ci des Pyrénées et représente aussi un point d'ancrage indispensable dans la compréhension des pérégrinations des artistes et dans l'élaboration des formes décoratives dans cette partie du Midi de la France au XIIe siècle.

156. Comme le faisait remarquer pertinemment l'abbé Cabanot 1969, 409-435. 


\section{SOURCES}

\section{Sources manuscrites :}

\section{Archives départementales du Gers:}

Cazauran 1890 : CAZAURAN (J.-M.), Le diocèse d'Auch, ou monographies de toutes les églises paroissiales du Gers, 1865-1899, t. VI, p. 267.

Dossier archéologique Croute, commune de Lasserrade, canton de Plaisance.

Enquête de 1840, arrondissement de Mirande, f f $^{\circ} 696$.

Série B. 350.

Série G. 6, f $\mathrm{f}^{\circ} 29$.

Série G. $8, \mathrm{f}^{\circ} 52$.

Série G. 9 , $\mathrm{f}^{\circ} 34$.

Série G. 223, Verbal de Cossi, 1562-1563, p. 72 : recueil des dîmes du chapitre d'Auch.

Série G. 482, Procès-verbal de réception des réparations des églises du diocèse d'Auch, 1687.

Série H. 8 (Tasque).

Série V. 201.

Série 3E 4100, 1687, f 275 (Me Dupuy, notaire à Auch).

Bibliothèque Municipale d'Auch:

Ms. 72, Louis Daignan du Sendat, p. 325.

Service Départemental de l'Architecture:

Commune de Lasserrade, église de Croute, dossier de restauration.

\section{Sources imprimées :}

Bourgeat 1934 : BOURGEAT (C.), Trois pouillés inédits de l'ancien diocèse d'Auch (XVI', XVIIe, XVIII siècles), Bulletin de la Société Archéologique du Gers (désormais cité B.S.A.G.), 1934, p. 250-288 (p. 279).

Bourgeat 1967 : BOURGEAT (C.), Pouillé inédit de l'ancien diocèse d'Auch, B.S.A.G., 1967, p. 70-101, 251-295, 365-407, 536-573.

Breuils 1889 : BREUILS (A.), Enquête de 1546, Revue de Gascogne, 1889, p. 73-82 (p. 74, note 2).

Breuils 1892 : BREUILS (A.), Églises et paroisses d'Armagnac, Éauzan, Gabardan et Albret, d'après une enquête de 1546, Auch, 1892.

Breuils 1901 : BREUILS (A.), Quatre pouillés du diocèse d'Auch, des XIVee et XVe siècles, B.S.A.G., 1901, p. 181-194 (p. 185).

Brugèles 1746: de BRUGÈLES (Dom L.-Cl.), Chroniques ecclésiastiques du diocèse d'Auch, Toulouse, 1746, p. 65 et 389 .

Lacave-Laplagne-Barris 1899 : LACAVE-LAPLAGNE-BARRIS (L.), Cartulaires du chapitre de l'église métropolitaine Sainte-Marie d'Auch, Archives Historiques de la Gascogne, Paris-Auch, 1899.

Monlezun 1846 : MONLEZUN (J.-J.), Histoire de la Gascogne, 6 volumes, Auch, 1846, t. 1, p. 225-226. 
Saint-Blanquat 1972 : de SAINT-BLANQUAT (O.), Pouillés des provinces d'Auch, de Narbonne et de Toulouse, dans Recueil des historiens de la France publié par l'Académie des Inscriptions et Belles-Lettres, Pouillés, t. X, 1ère partie, Paris, 1972.

Samaran 1953 : SAMARAN (C.), Le plus ancien cartulaire de Saint-Mont (Gers), (XIe-XIIIe siècles), Paris, 1953, p. 43-44.

\section{Sources graphiques}

Archives départementales du Gers:

- Carte de Cassini, Armagnac et Pardiac. 


\section{BIBLIOGRAPHIE}

Airiau 1997 : AIRIAU (C.), Les peintures médiévales de Saint-Nicolas de Nogaro, Bulletin de la Société Archéologique du Gers, 1997, p. 270-273.

Allègre 1978 : ALLĖGRE (V.), Pyrénées romanes, Zodiaque, La Pierre-qui-Vire, 1978.

Ayrens 1911 : d'AYRENS, (M.), Tasque, notes historiques et archéologiques, Auch, 1911.

Balagna 2000 : BALAGNA (C.), L'architecture gothique religieuse en Gascogne centrale, thèse Nouveau régime, Université de Toulouse-Le Mirail, 2000, 6 vol.

Balagna 2004 a : BALAGNA (C.), A la redécouverte d'un important édifice médiéval de Gascogne centrale : l'ancienne abbaye de La Case-Dieu (Gers), M.S.A.M.F., t. LXIV, 2004, p. 63-78.

Balagna 2004 b : BALAGNA (C.), La circulation des images et des sculpteurs sur le chemin de SaintJacques de Compostelle à l'époque romane, Patrimoine Midi-Pyrénées, n4, juillet-septembre 2004, p. 1013.

Barral i Altet 2006 : BARRAL I ALTET (X.), Contre l'art roman ? essai sur un passé réinventé, Paris, 2006.

Bourse 2002 : BOURSE (R.), Armorial de la Gascogne gersoise, Société Archéologique du Gers, Auch, 2002.

Breuils 1915 : BREUILS (A.), Histoire de Nogaro, B.S.A.G., 1915, p. 110-128.

Cabanot 1969 a : CABANOT (J.), Les chapiteaux romans de l'abbatiale de Saint-Sever (collatéraux et parties hautes du chœur et de la nef), Bulletin de la Société de Borda, n 333, 1969, p. 3-35.

Cabanot 1969 b : CABANOT (J.), L'église Saint-Jean de Mazères et le problème des origines de la sculpture romane dans le sud-ouest de la France, Bulletin de la Société de Borda, n 336, 1969, p. 409-435.

Cabanot 1970 a : CABANOT (J.), L'église Saint-Jean de Mazères, Congrès Archéologique de France, Gascogne 1970, Paris, 1970, p. 67-79.

Cabanot 1970 b : CABANOT (J.), L'église Saint-Jean-Baptiste de Saint-Mont, Congrès Archéologique de France, Gascogne 1970, Paris, 1970, p. 80-90.

Cabanot 1978 : CABANOT (J.), Gascogne romane, Zodiaque, La Pierre-qui-Vire, 1978.

Cabanot 1987 : CABANOT (J.), Les débuts de la sculpture romane dans le Sud-Ouest de la France, Paris, 1987.

Cabrero-Ravel et alii 2003 : CABRERO-RAVEL (L.), GARLAND, (E.), et LASSÈRE, (J.-L.), Églises romanes en Vic-Bilh, Pau, 2003.

Canéto 1870 : CANÉTO (F.), Les églises romanes de la Gascogne, Revue de Gascogne, 1870, p. 345-360 (spécialement p. 347-360).

Cazes et alii 2001 : CAZES (Q.) et SCELLÈS (M.), Le cloître de Moissac, éd. Sud-Ouest, 2001.

Cénac-Moncaut 1857: CÉNAC-MONCAUT (J.-J.), Voyage archéologique et historique dans les anciens comtés d'Astarac et de Pardiac, Paris, 1857.

Dubourg-Noves 1970 : DUBOURG-NOVES (P.), Sainte-Candide de Jégun, Congrès Archéologique de France, Gascogne 1970, Paris, 1970, p. 228-234.

Ducourau et alii 2000 : DUCOURAU (B.) et STOUFFS (J.-M.), Fresques de l'église Saint-Nicolas de Nogaro, Actes de la 21e Journée des Archéologues Gersois, (Vic-Fezensac 1999), Auch, 2000, p. 81-94.

Durliat 1970 a : DURLIAT (M.), L'église de Peyrusse-Grande, Congrès Archéologique de France, Gascogne 1970, Paris, 1970, p. 43-54.

Durliat 1970 b : DURLIAT (M.), Tasque, Congrès Archéologique de France, Gascogne 1970, Paris, 1970, p. 55-66.

Durliat 1970 c : DURLIAT (M.), Eglise de Nogaro, Congrès Archéologique de France, Gascogne 1970, Paris, 1970, p. 91-110.

Durliat 1970 d : DURLIAT (M.), L'église de Mouchan, Congrès Archéologique de France, Gascogne 1970, Paris, 1970, p. 124-130. 
Durliat 1990 : DURLIAT (M.), La sculpture romane de la route de Saint-Jacques. De Conques à Compostelle, Mont-de-Marsan, 1990.

Fontan 2003 : FONTAN (J.-P.), Belmont, Communes du département du Gers, Arrondissement d'Auch, t. 1, Société Archéologique et Historique du Gers, Auch, 2003, p. 428-429.

Gaborit 1979: GABORIT (M.), Les constructions de petit appareil au début de l'art roman dans les édifices religieux de la France du Sud-Ouest, thèse de doctorat de $3^{\mathrm{e}}$ cycle, Université de Bordeaux III, 1979, 4 vol.

Laclaverie et alii 2002 : LACLAVERIE (J.-M.), et LAGORS (A.), Un village disparu, un castelnau méconnu : Lasserrade, B.S.A.G., 2002, p. 154-169.

Laclaverie 2005 : LACLAVERIE (J.-M.), Lasserrade, Communes du département du Gers, Arrondissement de Mirande, t. III, Société Archéologique du Gers, 2005, p. 360-361.

Lacoste 1976: LACOSTE (J.), Sainte-Foy de Morlaàs, Les Amis des Églises Anciennes du Béarn, Jurançon, 1976.

Lacoste 2006 : LACOSTE (J.), Les maîtres de la sculpture romane dans l'Espagne du pèlerinage à Compostelle, éd. Sud-Ouest, 2006.

Lacoste 2007 : LACOSTE (J.), Les grandes æuvres de la sculpture romane en Béarn, éd. Sud-Ouest, 2007.

Maroix 2004 : MAROIX (V.), Saint-Pierre de Tasque (Gers), mémoire de maîtrise, Université de Pau et des Pays de l'Adour, 2004.

Mesplé 1966 : MESPLÉ (P.), L'église de Maubourguet, Gens et choses de Bigorre, Actes du XXIIe Congrès d'études de la Fédération des Sociétés Académiques et Savantes de Languedoc-Pyrénées-Gascogne, Bagnères-de-Bigorre, 1966, p. 57-74.

Mesplé 1971 : MESPLÉ (P.), Les plans des églises romanes du Gers, Bulletin archéologique du Comité des Travaux historiques et scientifiques, nouvelle série, $\mathrm{n}^{\circ}$ 7, année 1971, p. 75-130.

Polge 1967: POLGE (H.), Lasserrade, église Sainte-Christine de Croute, Dictionnaire des églises de France, tome IIIa, Paris, 1967, p. 69.

Pousthomis-Dalle 1996 : POUSTHOMIS-DALLE (N.), Saint-Nicolas de Nogaro (Gers) : redécouverte du décor sculpté de l'abside, Archéologie du Midi Médiéval, t. XIV, 1996, p. 63-68.

Rouja 1995-1997 : ROUJA (S.), Étude archéologique monumentale du prieuré Saint-Orens d'Auch, mémoire de maîtrise, Université de Toulouse-Le Mirail, 1995-1997, 2 vol.

Simon 1980 : SIMON (S.), David et ses musiciennes : iconographie d'un chapiteau de Jaca, Cahiers de Saint-Michel de Cuxa, n 11, 1980, p. 239-248.

Lassère 1989 dir.: LASSÈRE (J.-L.), Vic-Bilh, Morlaàs, Montanérès, Pyrénées-Atlantiques, inventaire topographique, ouvrage collectif, Inventaire général des monuments et des richesses artistiques de la France, Paris, 1989.

Villain 1982 : VILLAIN (J.), La France moderne, grand dictionnaire généalogique, historique et biographique, Montpellier, 1911, rééd. Laffitte, Marseille, 1982. 


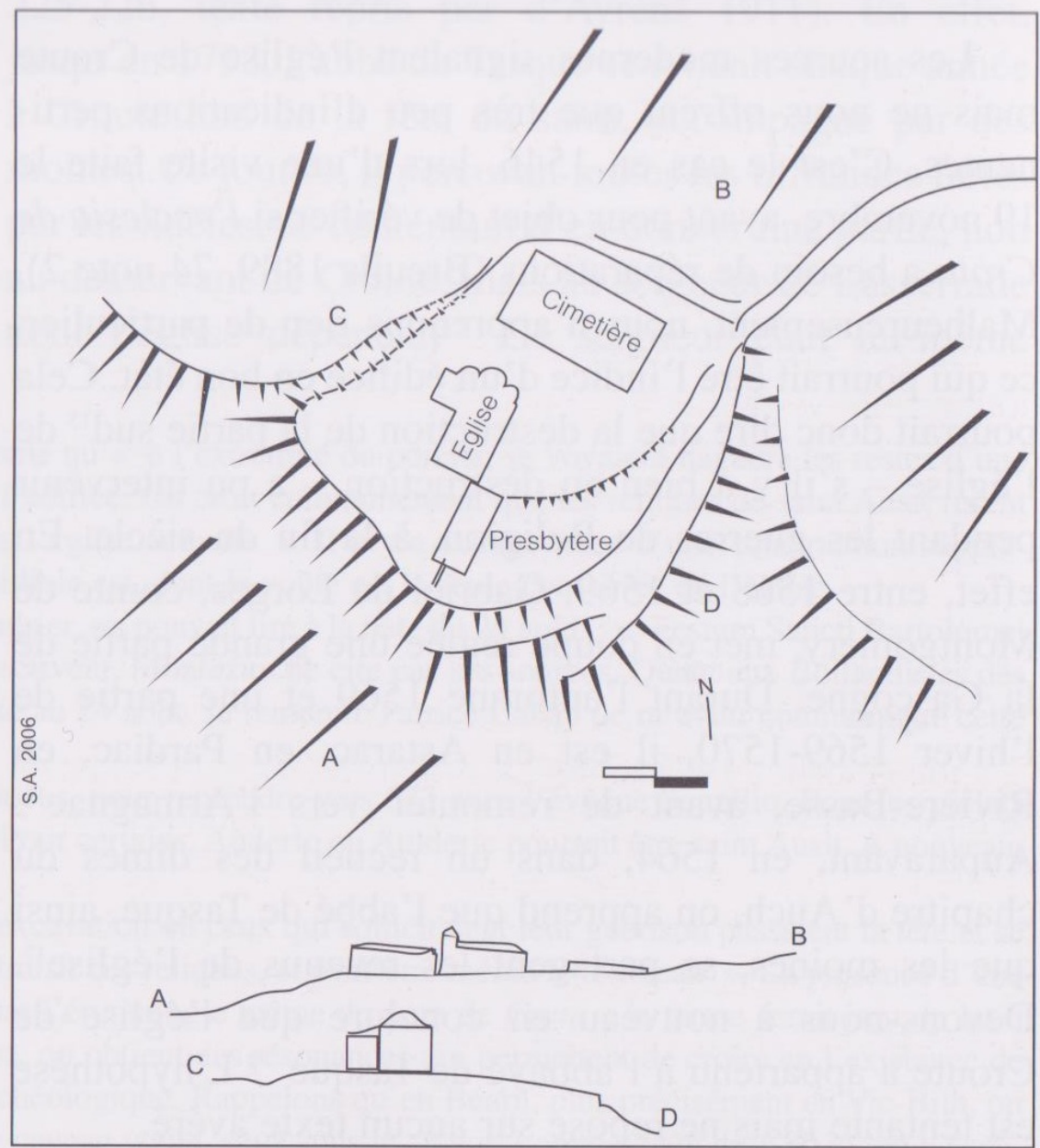

Fig. 1 : Vue en plan et coupes de la plate-forme supportant l'église de Croute. Cette plate-forme est entourée au sud et à l'est de hauts talus qui accentuent la pente naturelle, et à l'ouest d'un fossé partiellement comblé qui s'élargit en direction de la vallée. Il est vraisemblable que cette structure correspond à l'emprise médiévale du prieuré et de ses bâtiments annexes disparus. Le champ à l'ouest du fossé a livré quelques fragments de panse de poterie médiévale en kaolin à dégraissant sableux, semblable à celle que l'on retrouve en Bigorre et Rivière-Basse (datation probable : $\mathrm{X}^{\mathrm{e}}-\mathrm{XII}^{\mathrm{e}}$ siècles). 


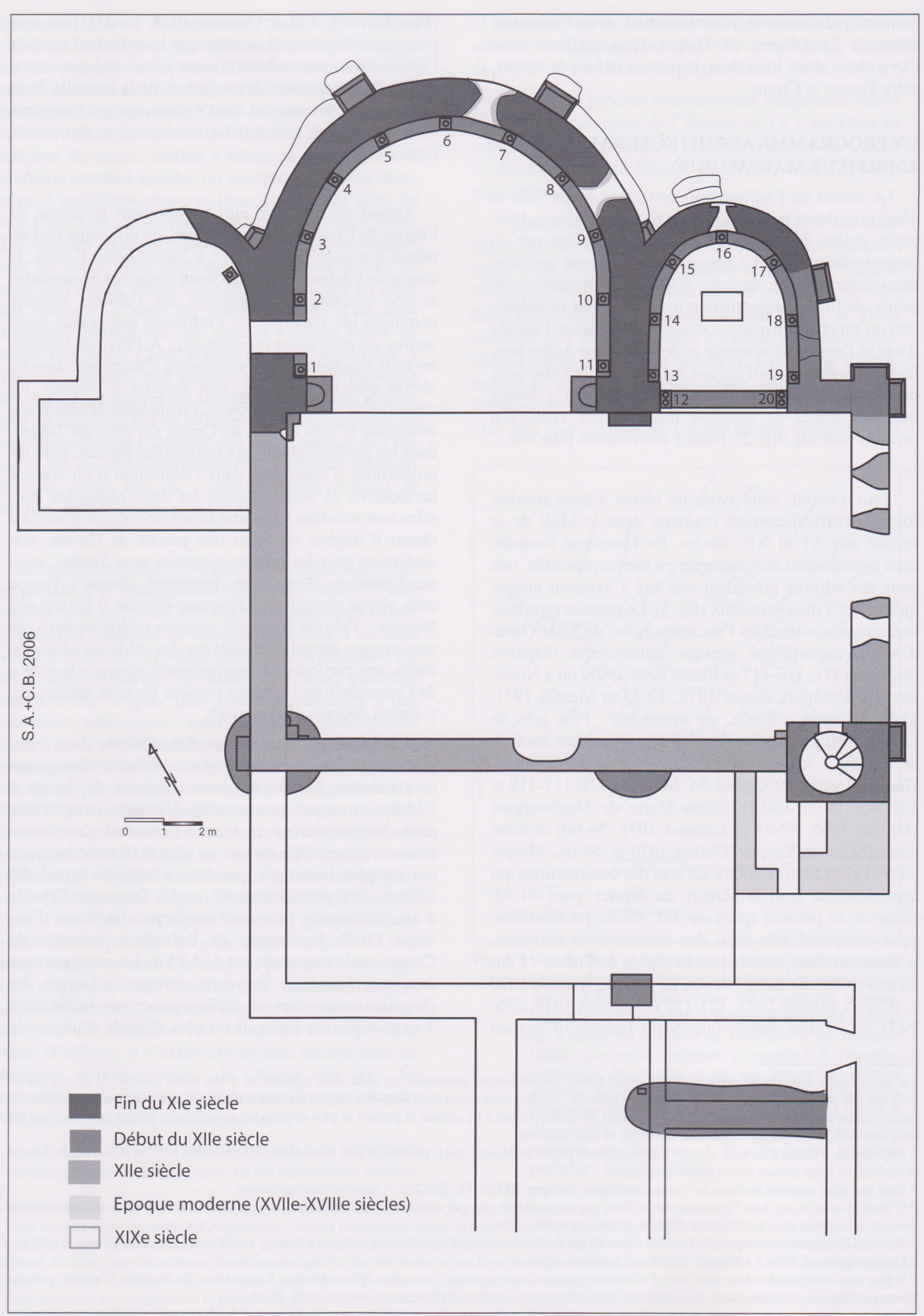

Fig. 2 : Plan général de l'église Saint-Barthélemy de Croute avec numérotation des chapiteaux. 


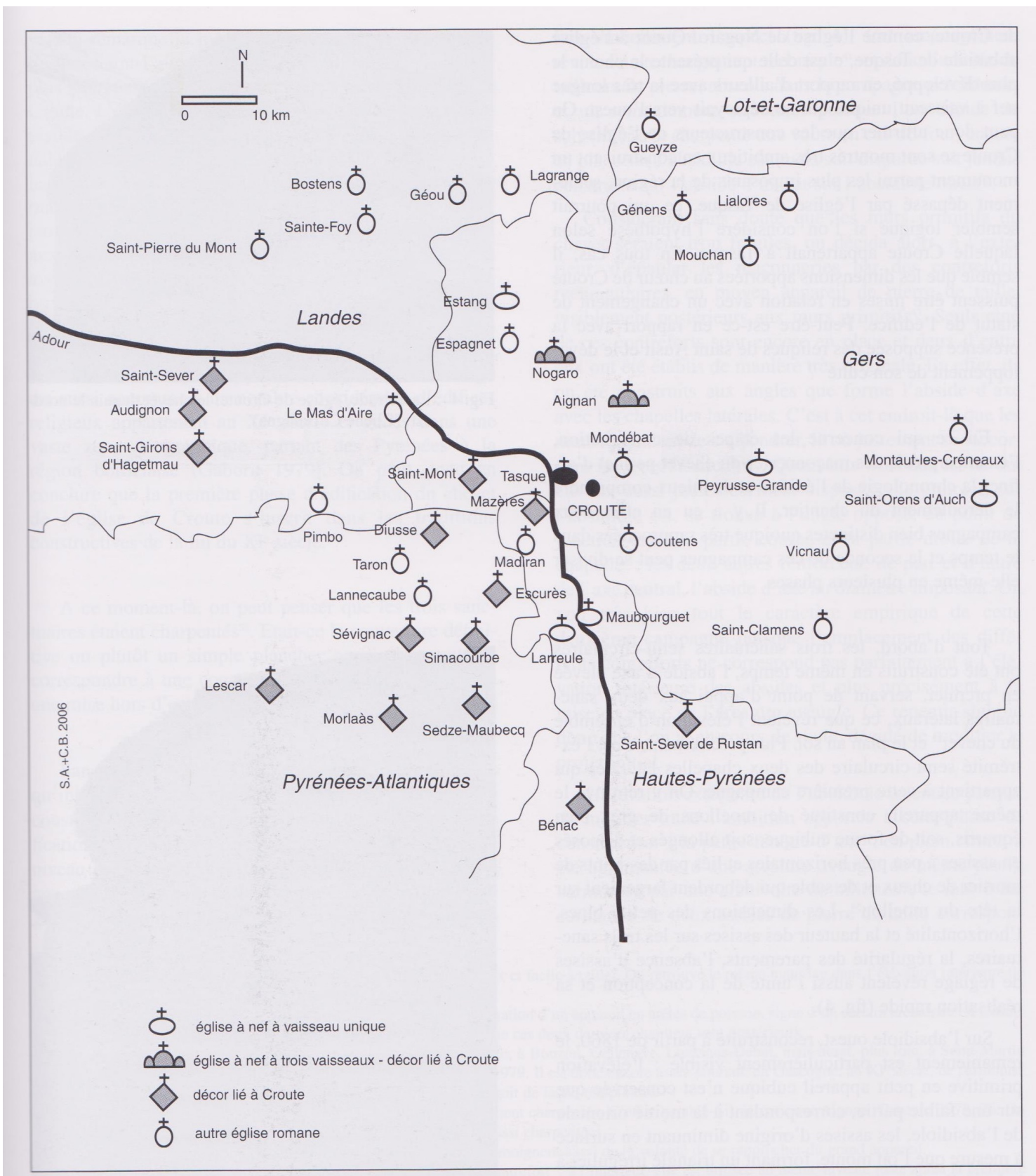

Fig. 3 : L'église romane de Croute dans son environnement monumental. 


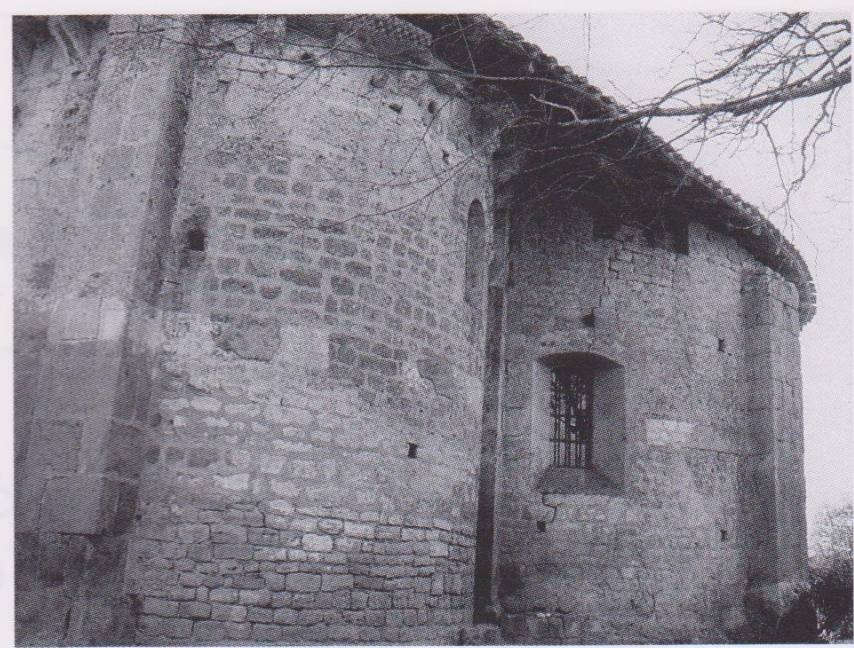

Fig. 4 : Lasserrade, église de Croute, le chevet depuis le nordest. (Cliché C. Balagna)

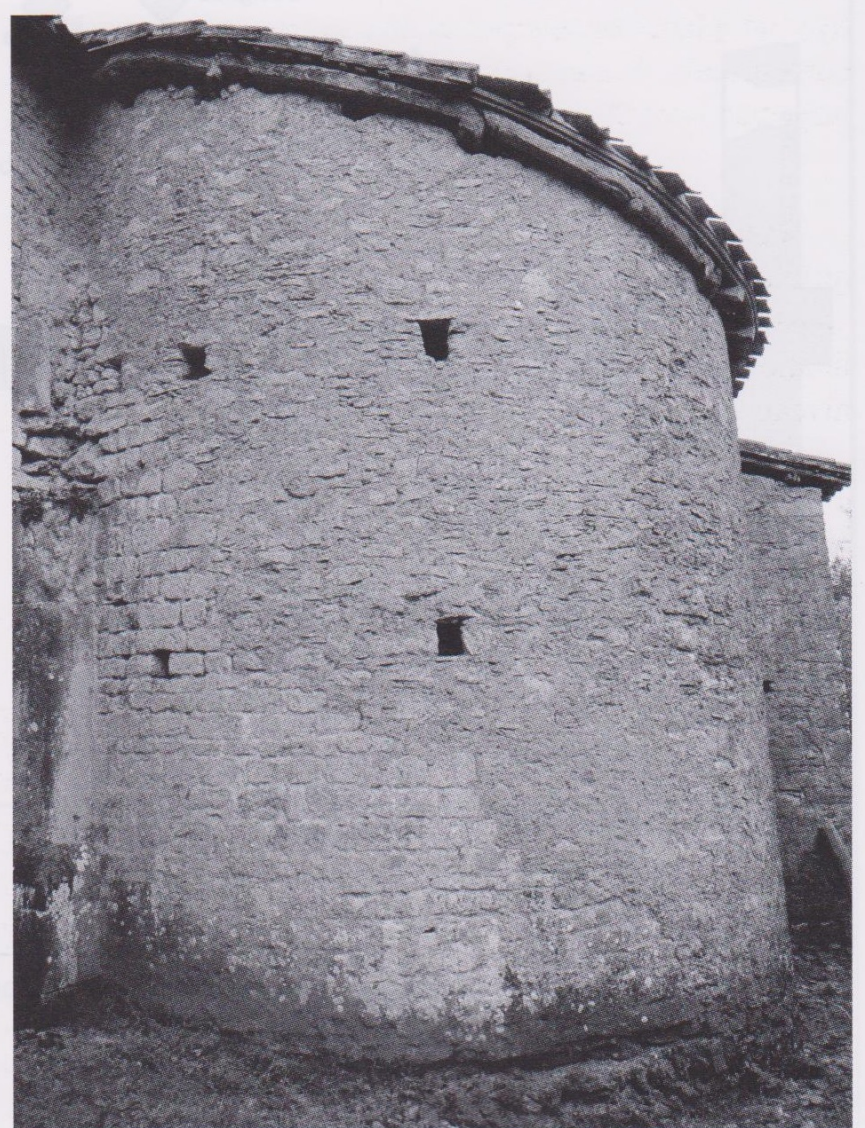

Fig. 5 : Lasserrade, église de Croute, vue extérieure de la sacristie actuelle. (Cliché C. Balagna) 



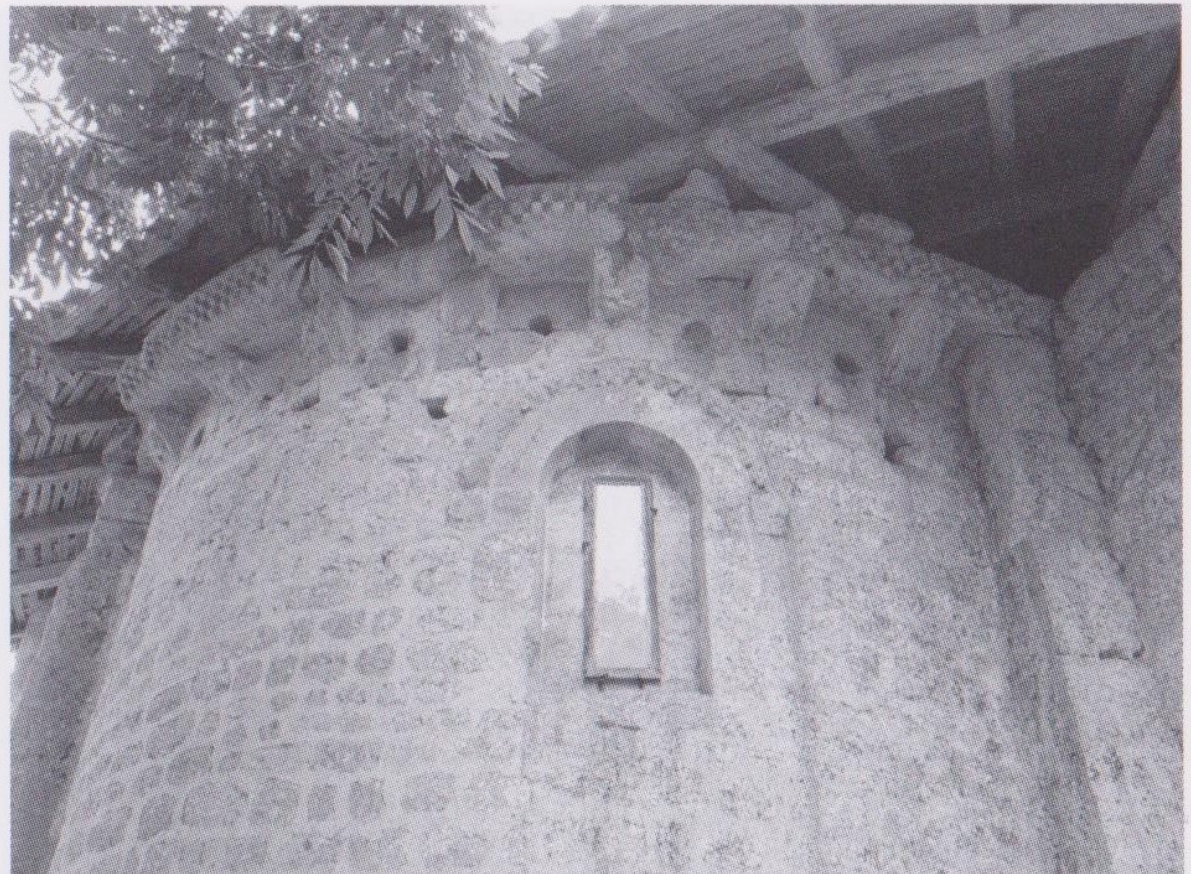

Fig. 6 : Lasserrade, église de Croute, détail de l'élévation du chevet. (Cliché C. Balagna)

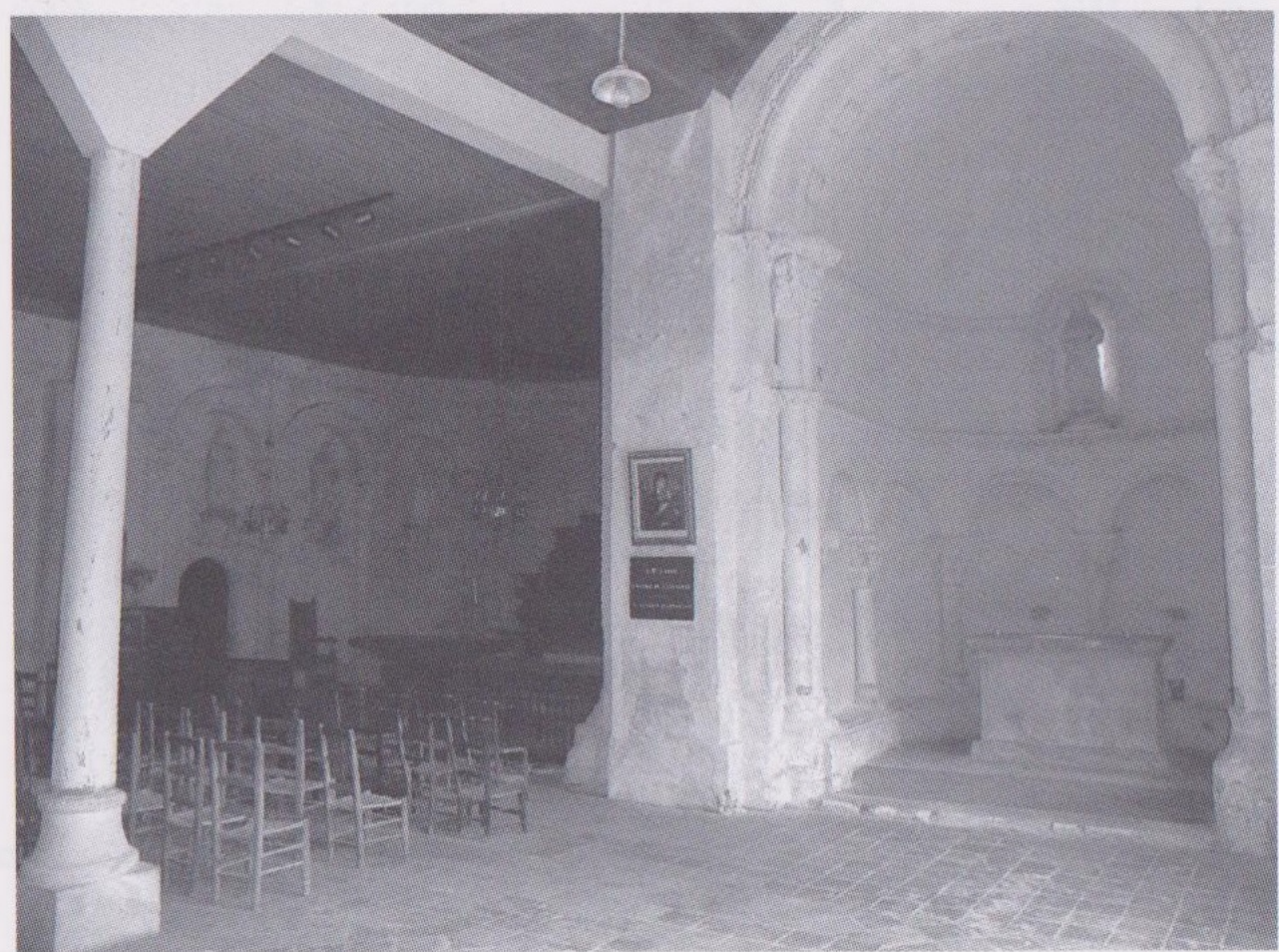

Fig. 7 : Lasserrade, église de Croute, vue intérieure du choeur. (Cliché C. Balagna) 


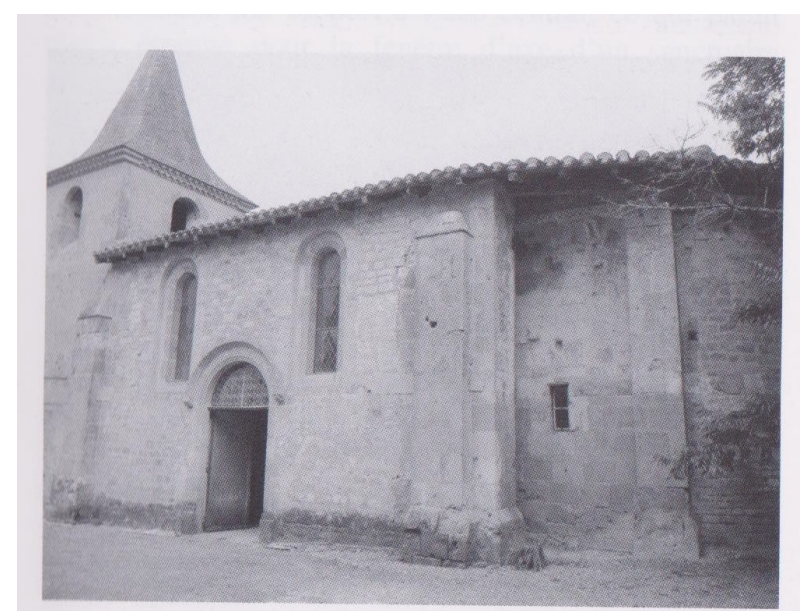

Fig. 8 : Lasserrade, église de Croute, l'église depuis l'angle nord-est. (Cliché C. Balagna)

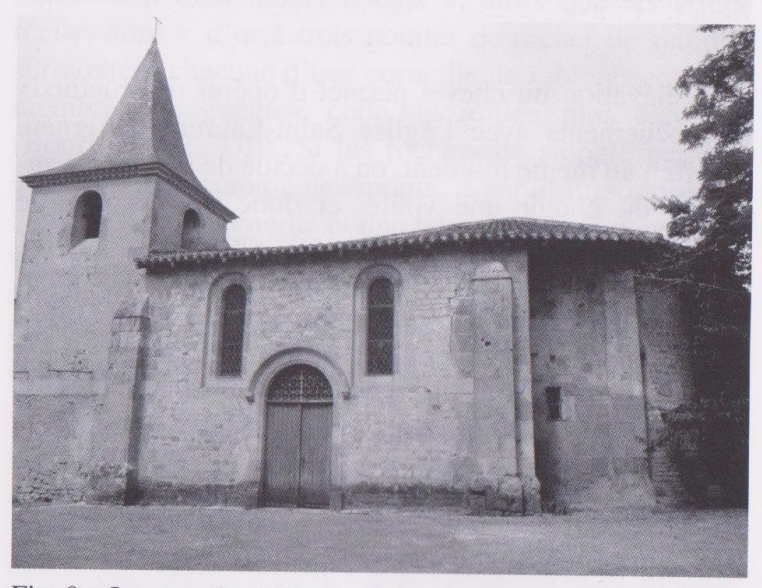

Fig. 9 : Lasserrade, église de Croute, vue générale depuis l'est. (Cliché C. Balagna)

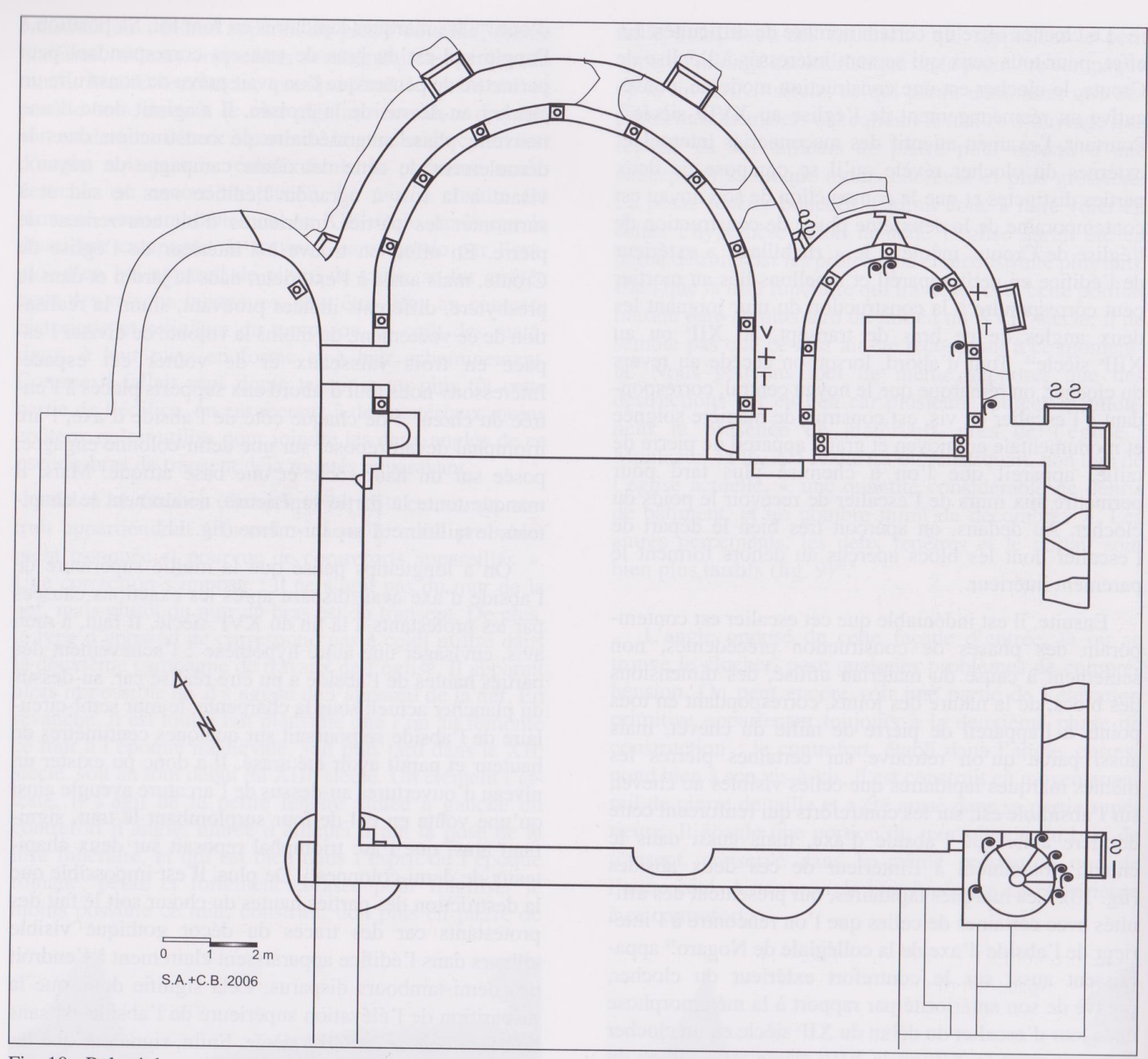

Fig. 10 : Relevé des marques lapidaires de l'église de Croute. 


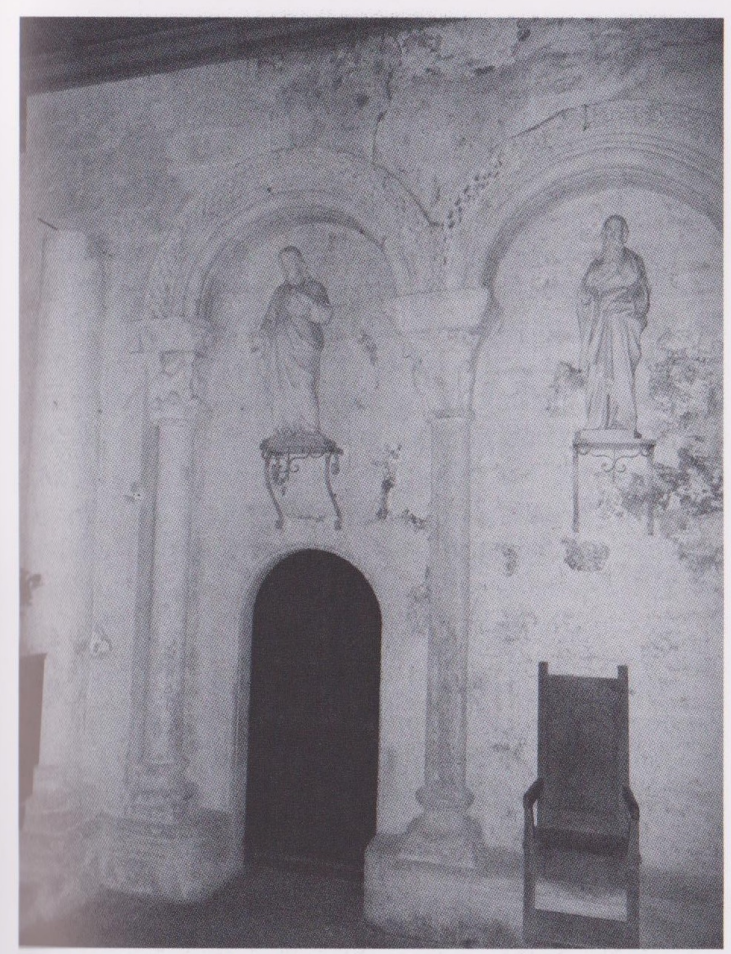

Fig. 11 : Lasserrade, église de Croute, détail de l'élévation intérieure de l'abside. (Cliché C. Balagna)

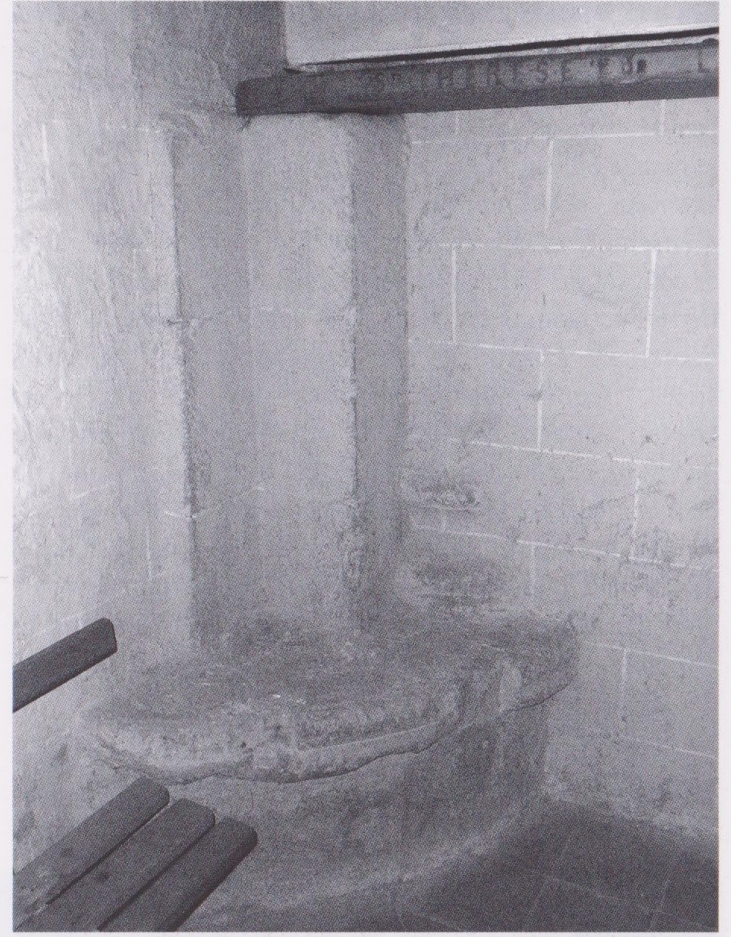

Fig. 12 : Lasserrade, église de Croute, vestiges du pilier sudouest de l'église. (Cliché C. Balagna)

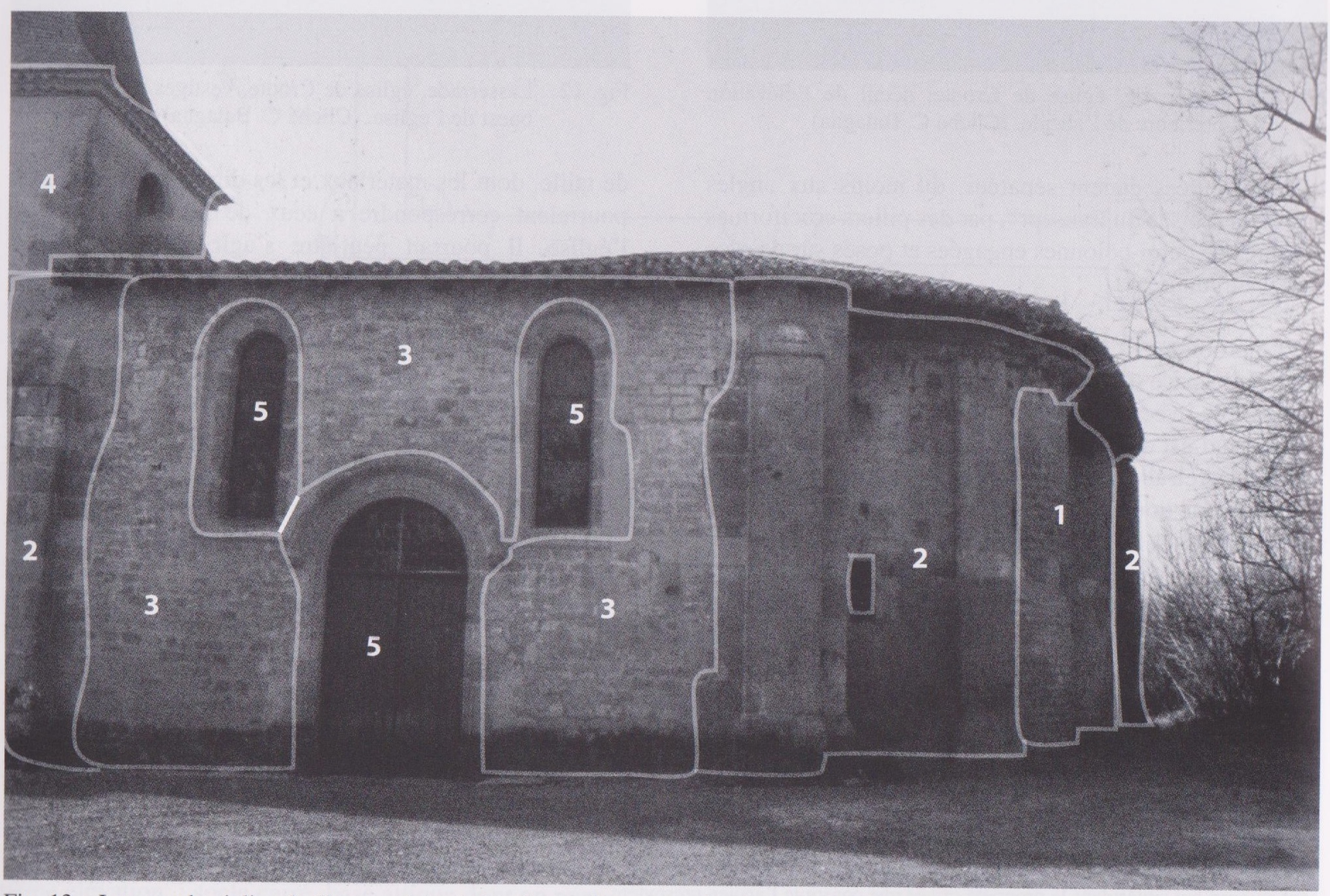

Fig. 13 : Lasserrade, église de Croute, résumé des phases de construction à partir de l'élévation orientale. $1:$ Roman $1:$ petits blocs de grès et calcaire disposés en lits réguliers (chevet, fin $\mathrm{XI}^{\circ} \mathrm{s}$.). 2 : Roman $2:$ moyen et grand appareil de grès et calcaire (contreforts, modillons, absidiole, début $\mathrm{XII}^{\circ} \mathrm{s}$.). 3 : Roman $3:$ petit appareil de grès et calcaire. Fenêtre romane occultée (nef, courant $\mathrm{XII}^{\circ}$ ou XIII' ${ }^{\circ}$ s.). 4 : époque moderne : reprise d'ouvertures et du clocher en calcaire (linteaux, chaînages) et blocage. XVII ${ }^{\circ}$ s. 5 : époque contemporaine : reprise d'ouvertures en grès et calcaire mouluré. XIX` siècle. 


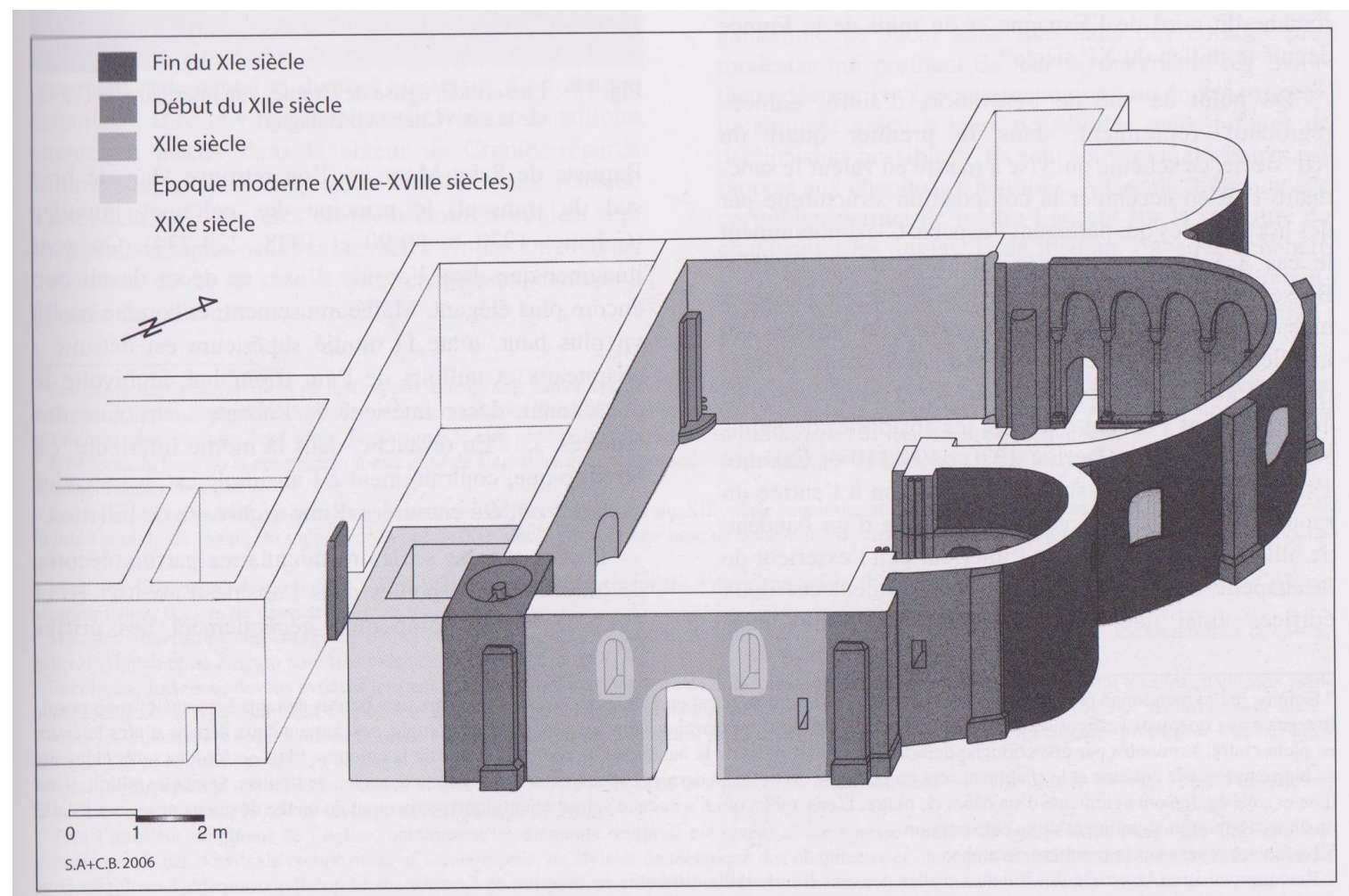

Fig. 14 : Chronologie relative des campagnes de construction de l'église de Croute.

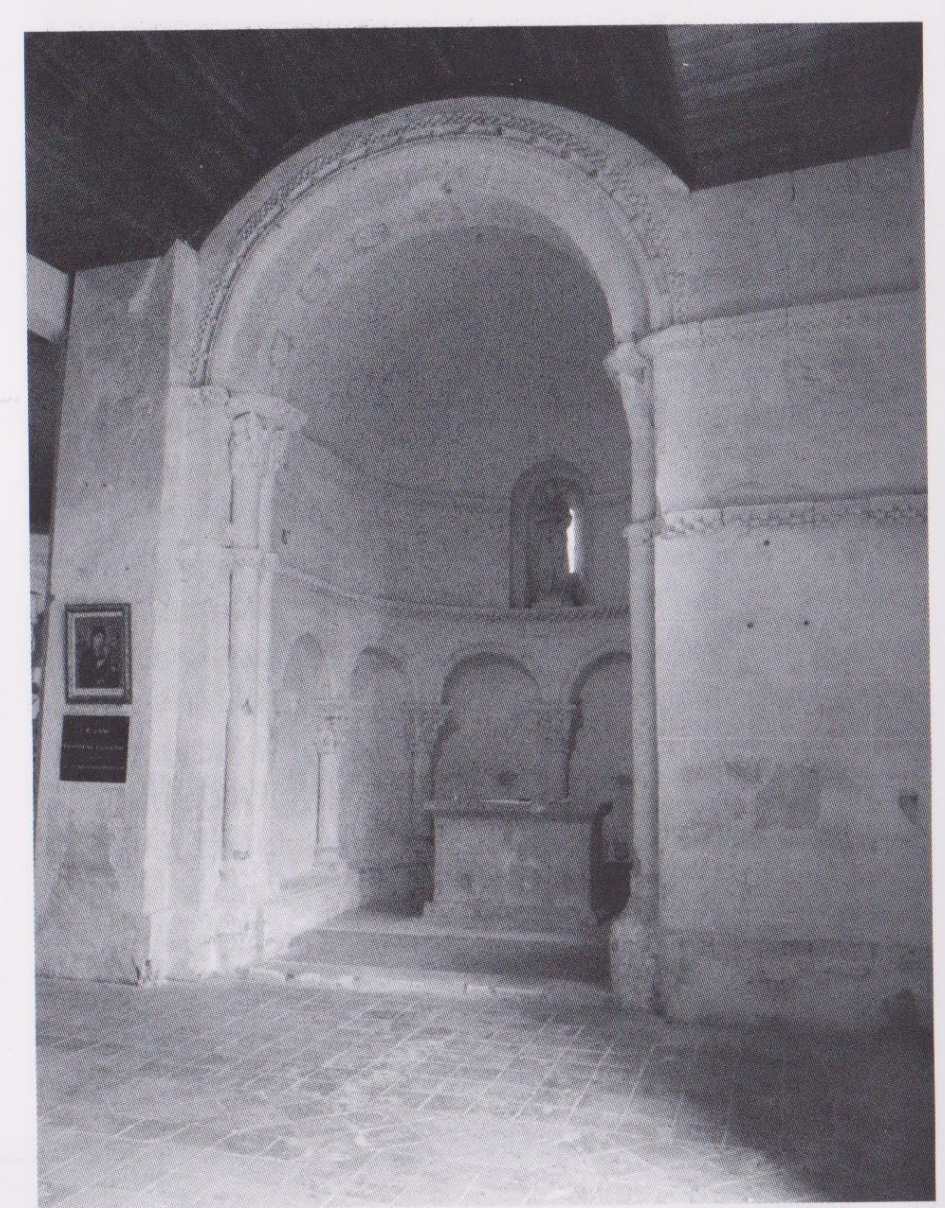

Fig. 15 : Lasserrade, église de Croute, vue intérieure de l'absidiole est. (Cliché C. Balagna) 


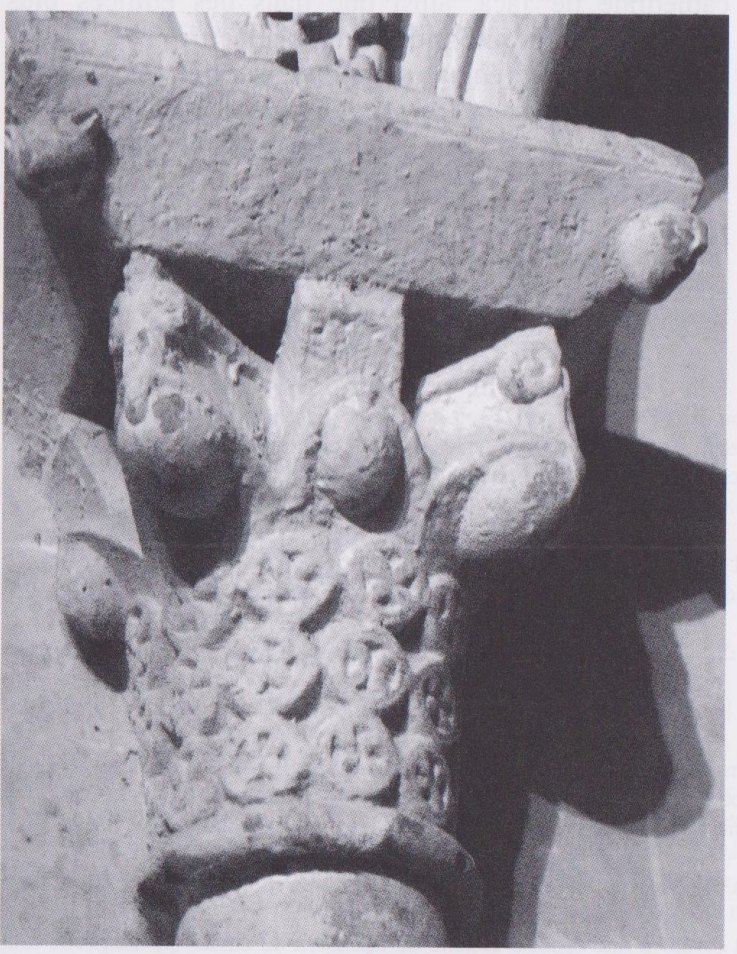

Fig. 16 : Lasserrade, église de Croute, chapiteau n ${ }^{\circ} 4$. (Cliché C. Balagna)

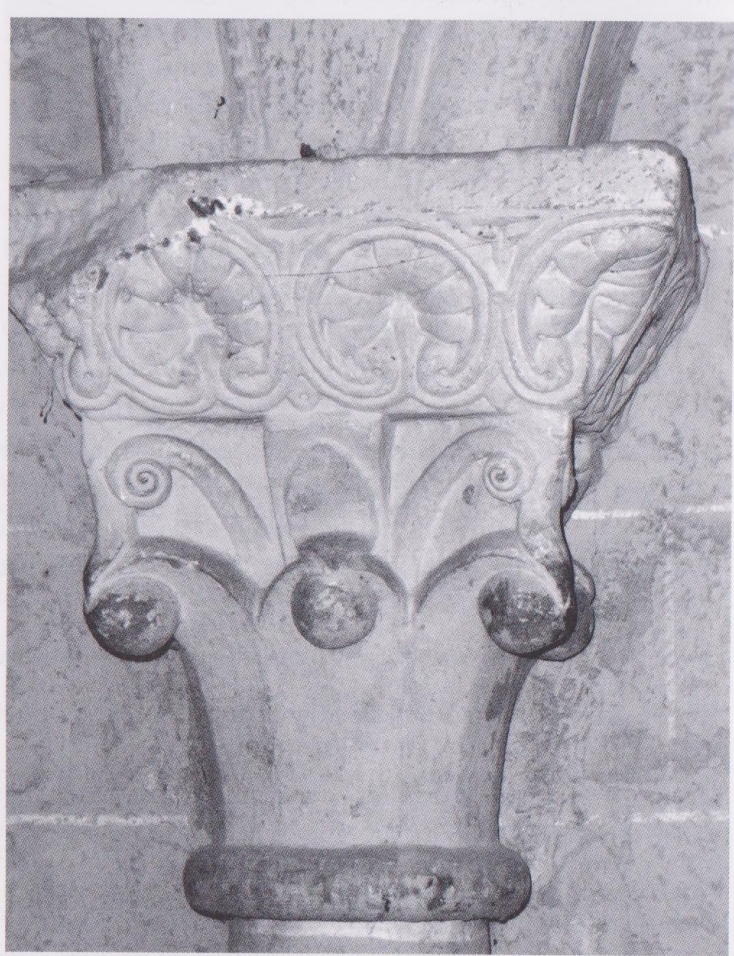

Fig. 17 : Lasserrade, église de Croute, chapiteau n 17. (Cliché C. Balagna)

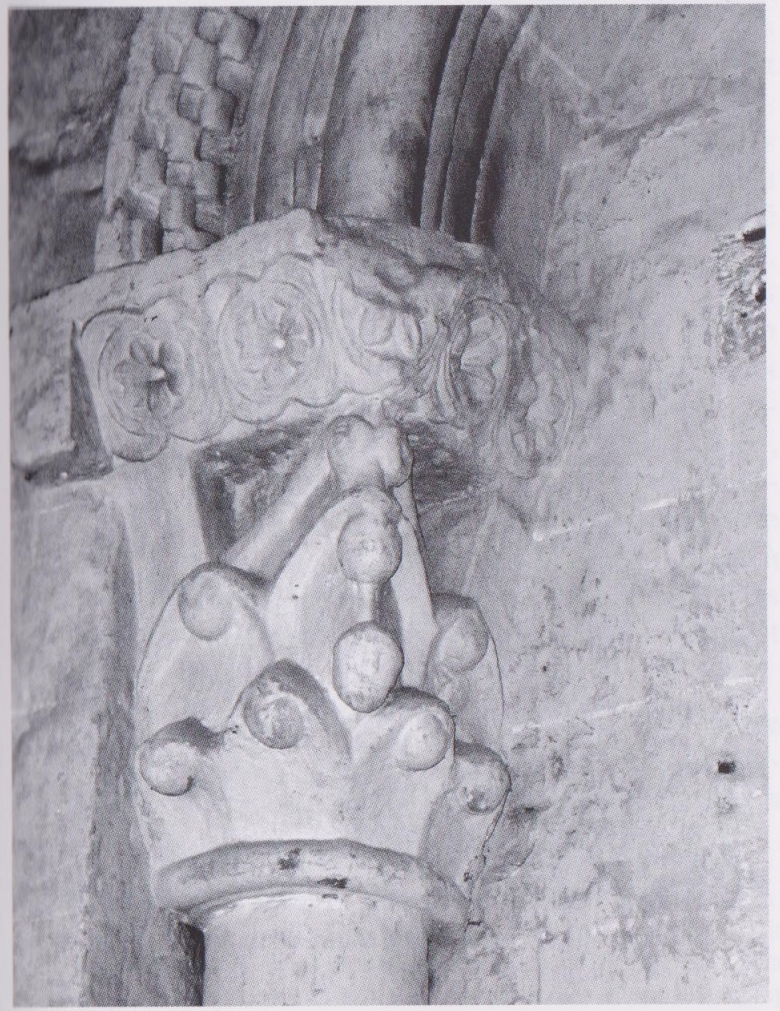

Fig. 18 : Lasserrade, église de Croute, chapiteau ${ }^{\circ}{ }^{\circ}$. (Cliché C. Balagna)

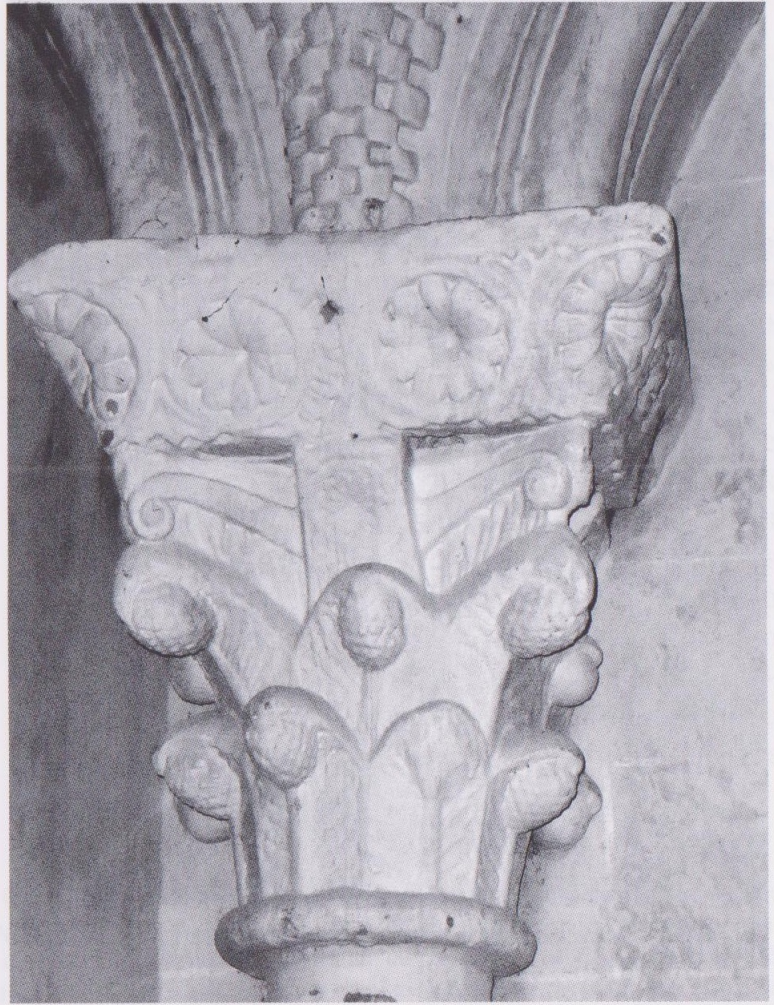

Fig. 19 : Lasserrade, église de Croute, chapiteau n 7 . (Cliché C. Balagna) 


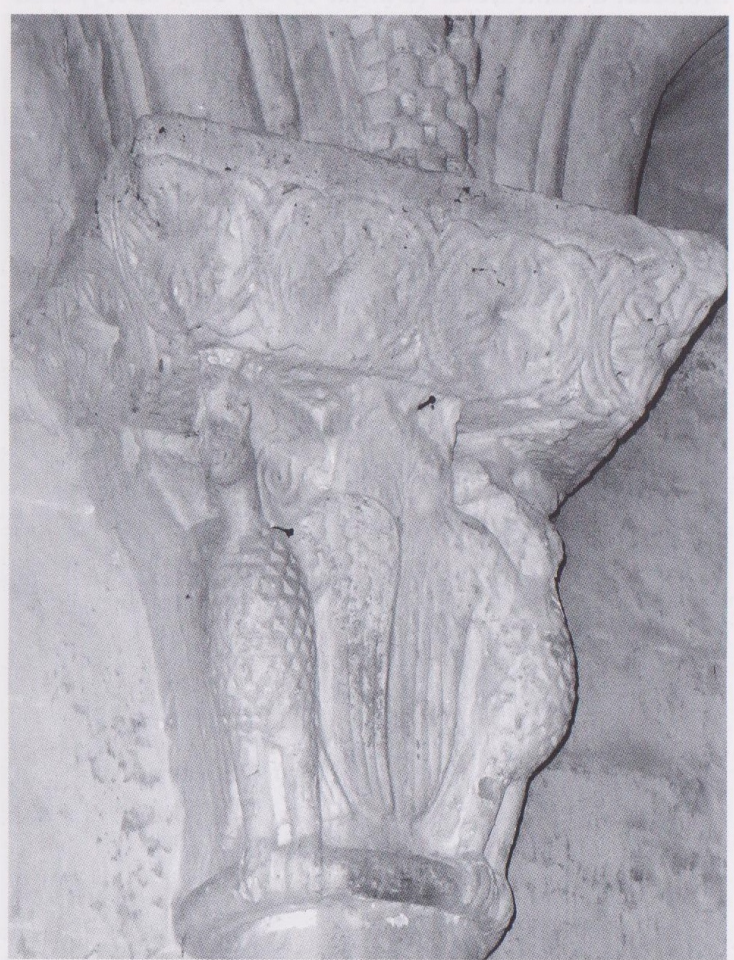

Fig. 20 : Lasserrade, église de Croute, chapiteau $n^{\circ} 2$. (Cliché C. Balagna)

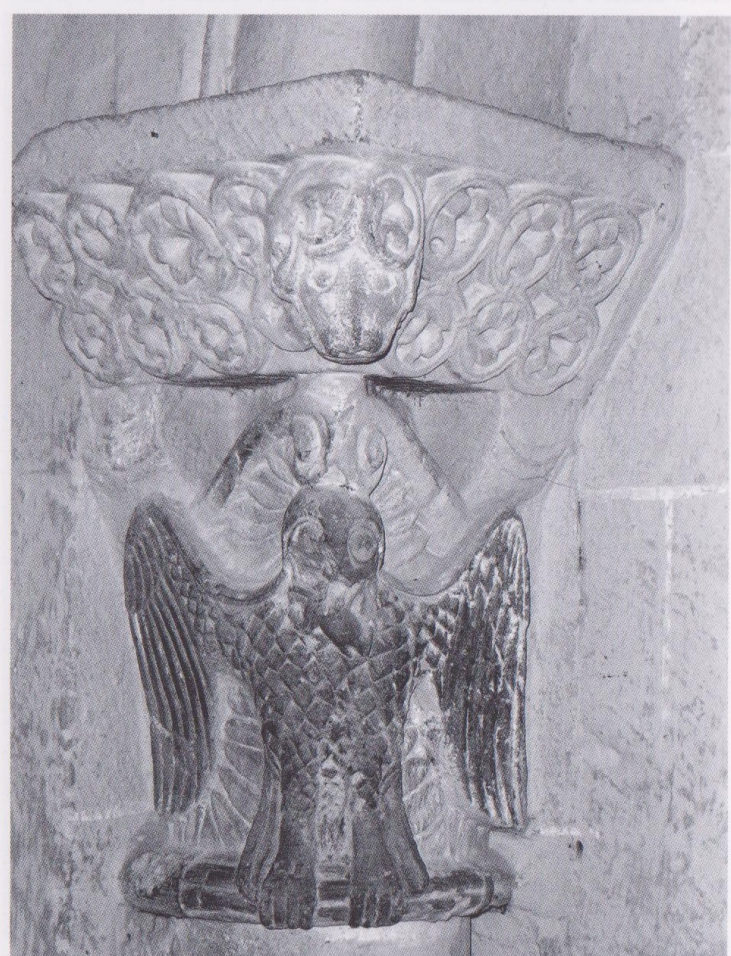

Fig. 21 : Lasserrade, église de Croute, chapiteau n 13. (Cliché C. Balagna)

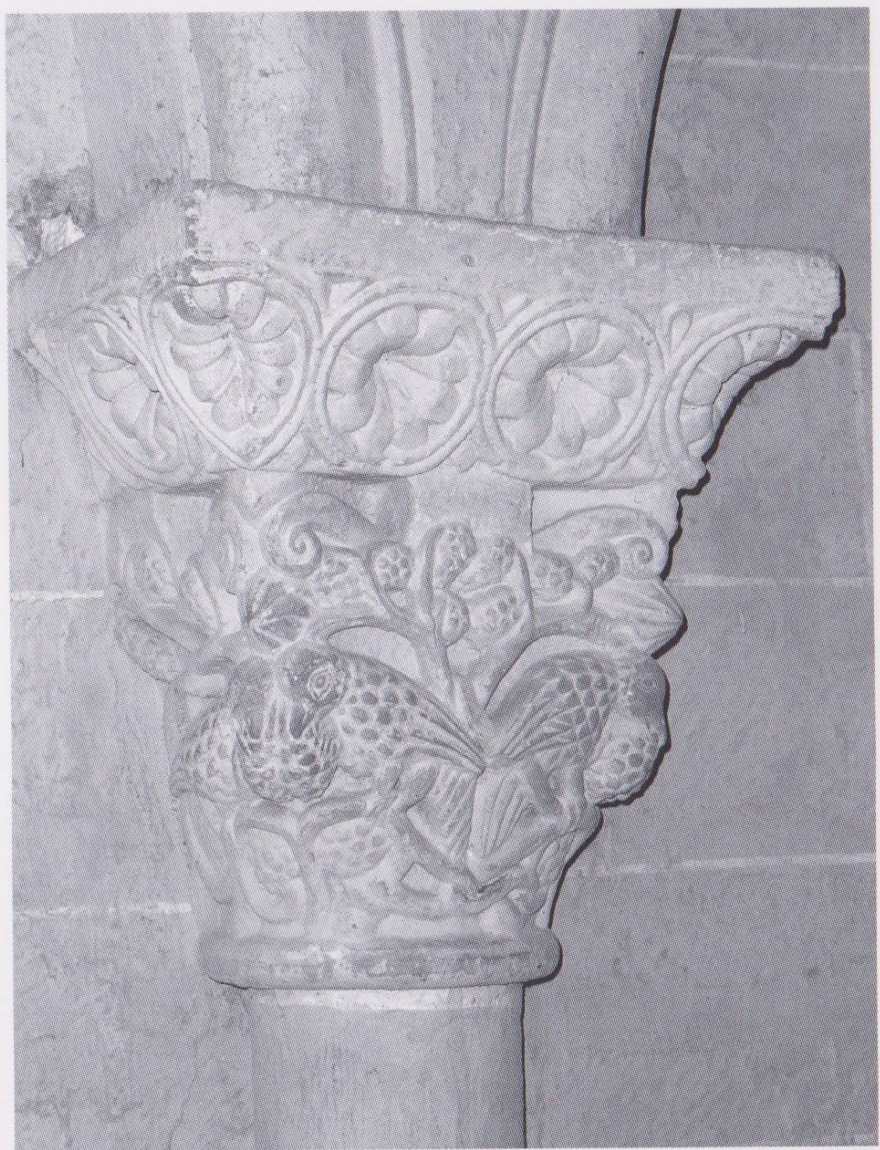

Fig. 22 : Lasserrade, église de Croute, chapiteau n 16. (Cliché C. Balagna) 


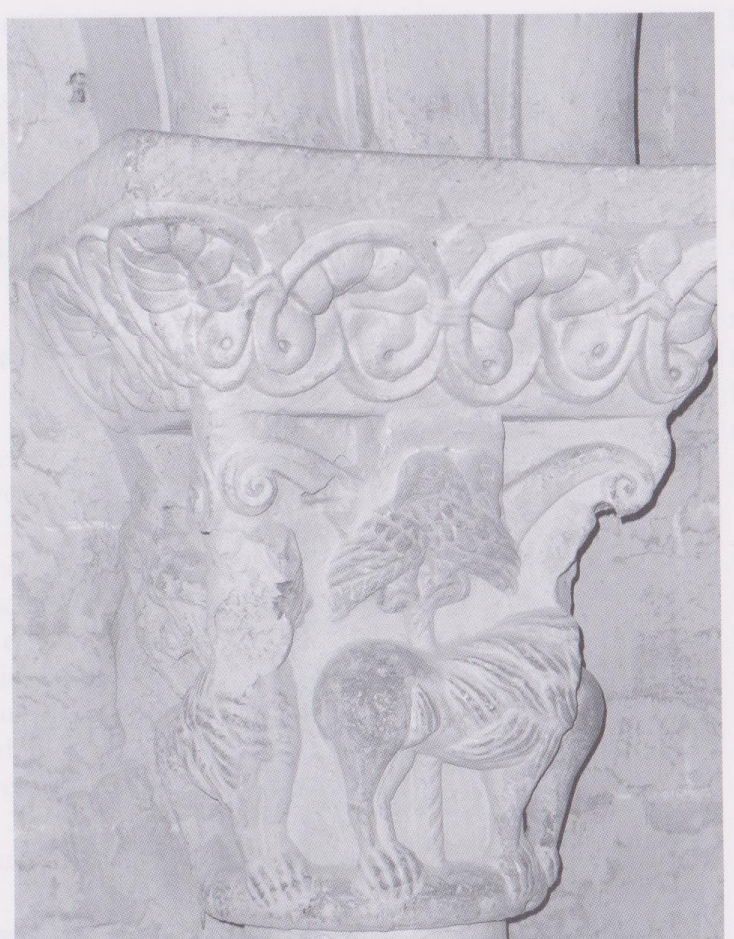

Fig. 23 : Lasserrade, église de Croute, chapiteau n 15 . (Cliché C. Balagna)

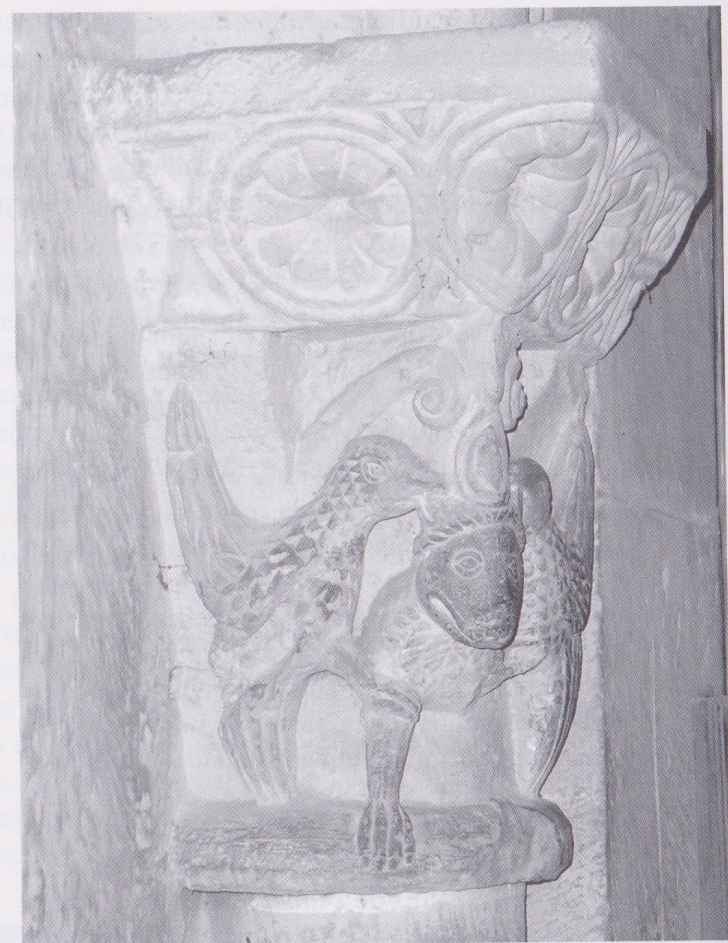

Fig. 24 : Lasserrade, église de Croute, chapiteau n ${ }^{\circ}$ 19. (Cliché C. Balagna)

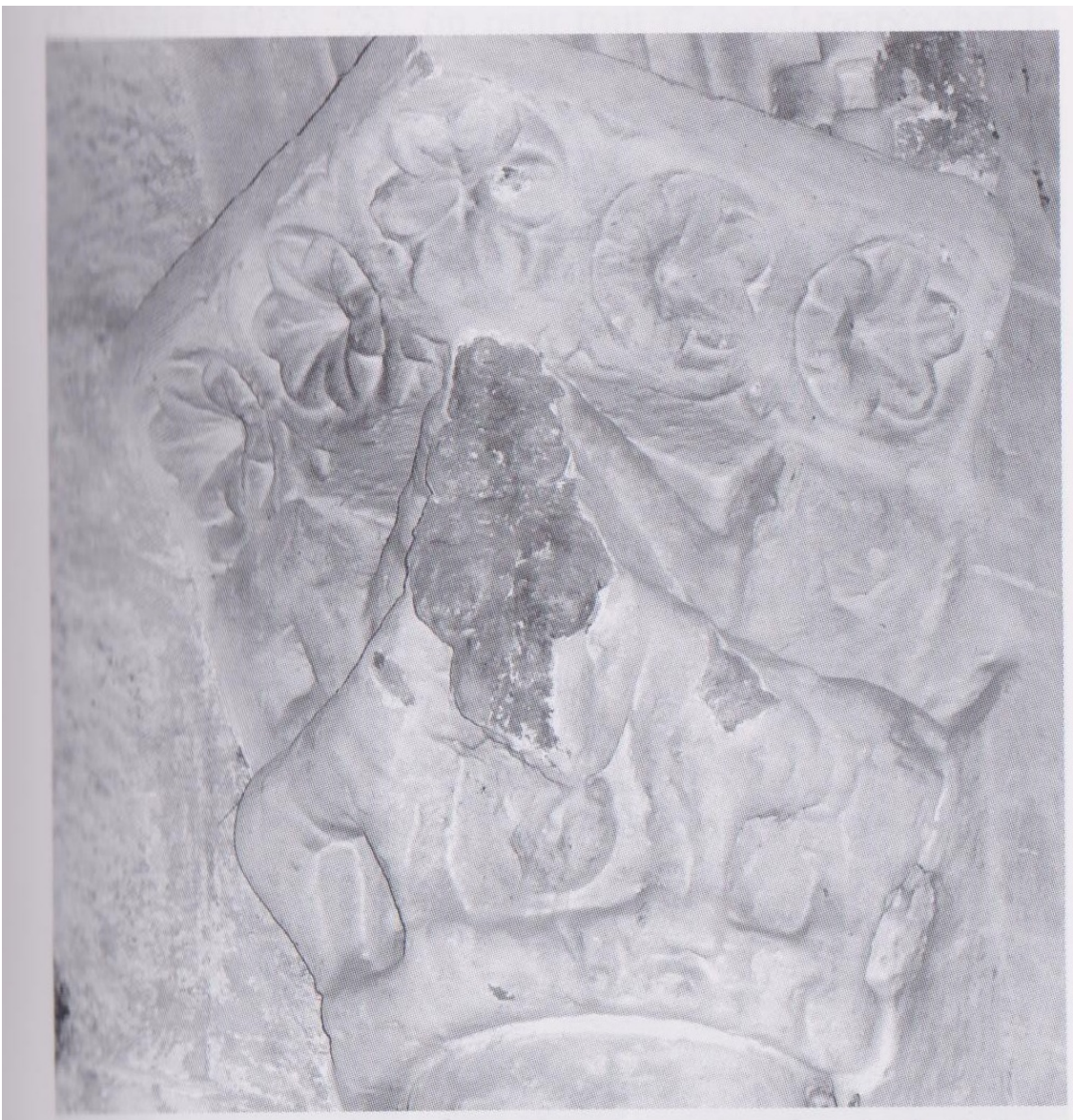

Fig. 25 : Lasserrade, église de Croute, chapiteau n ${ }^{\circ} 11$. (Cliché C. Balagna) 


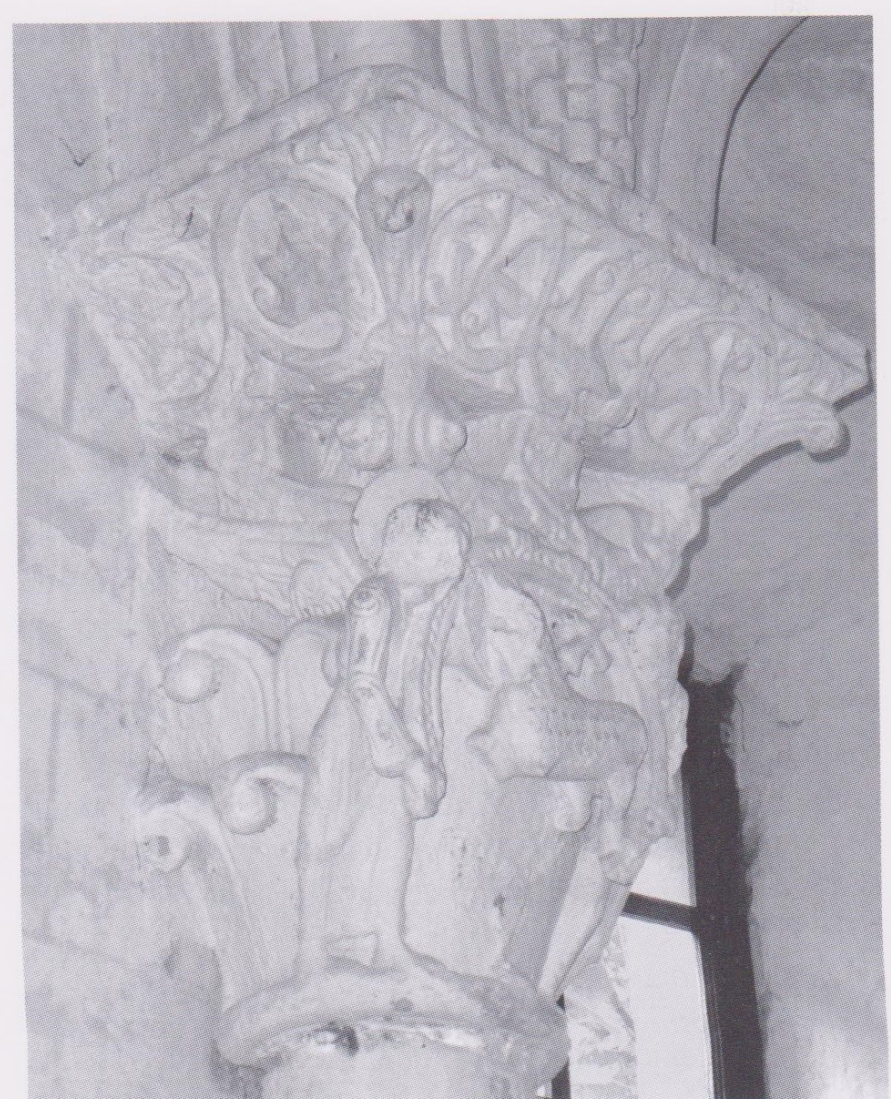

Fig. 26 : Lasserrade, église de Croute, chapiteau nº 6. (Cliché C. Balagna)

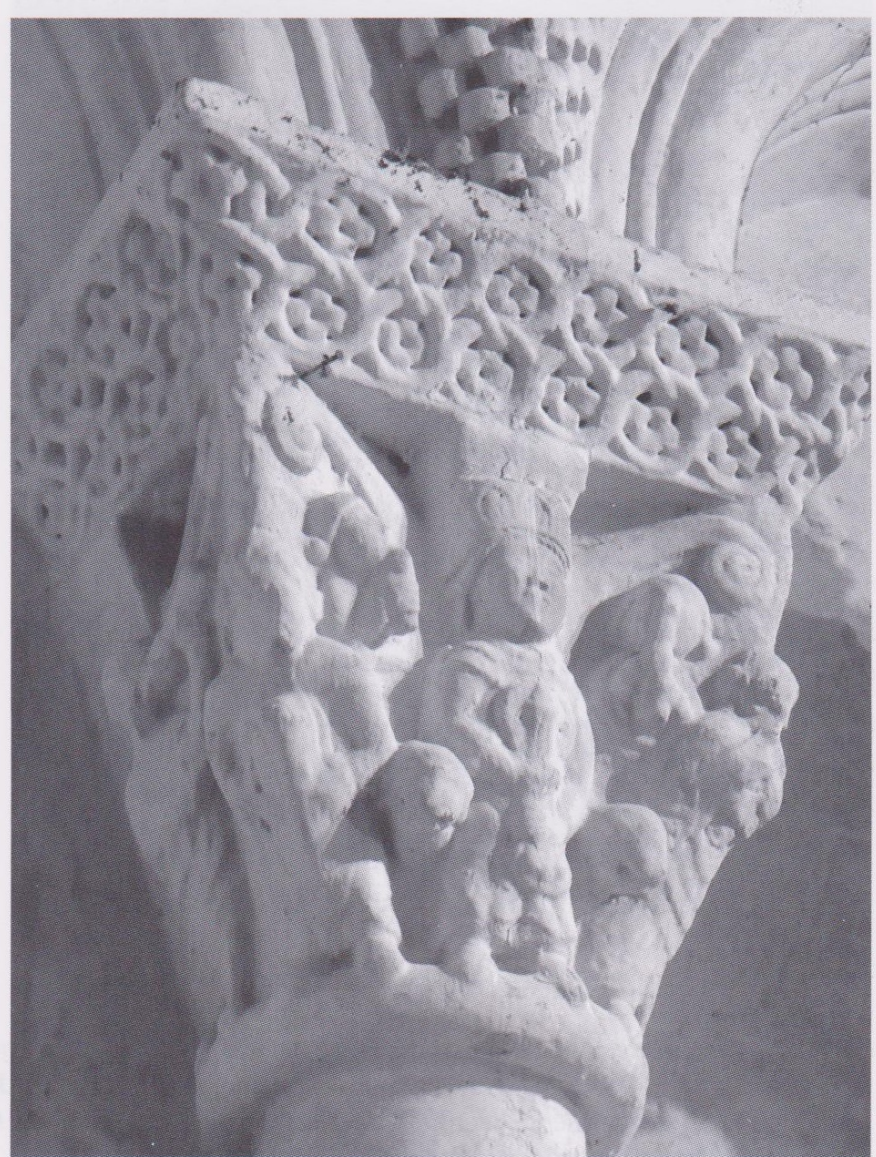

Fig. 27 : Lasserrade, église de Croute, chapiteau n 9. (Cliché C. Balagna) 


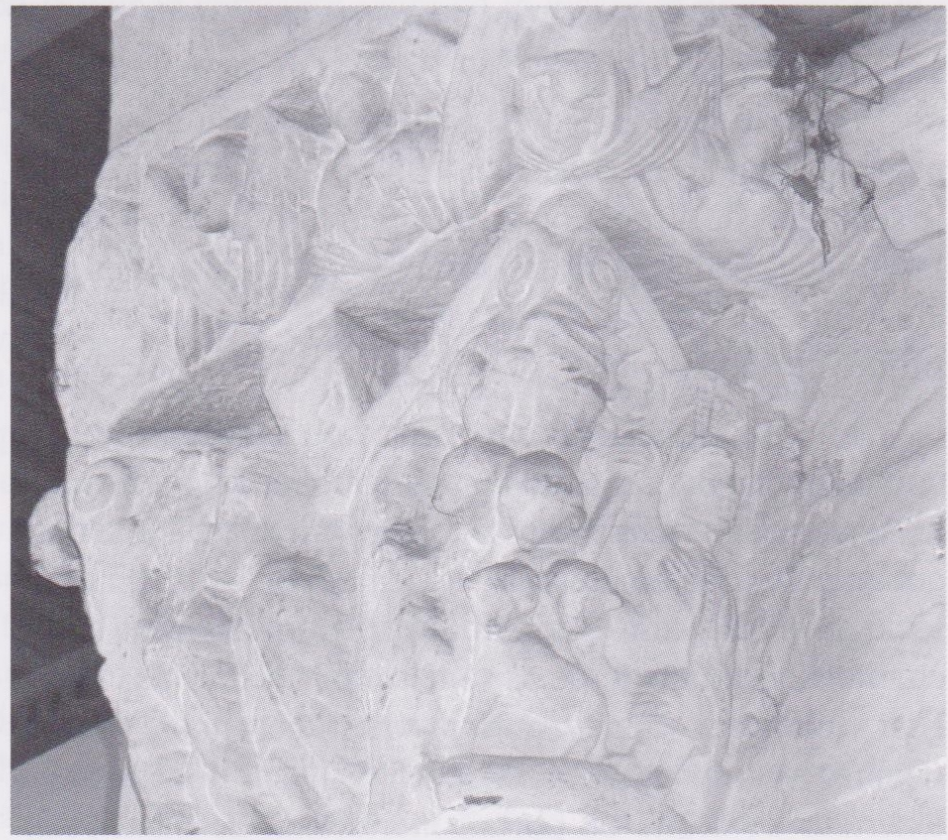

Fig. 28 : Lasserrade, église de Croute, chapiteau n 12. (Cliché C. Balagna)

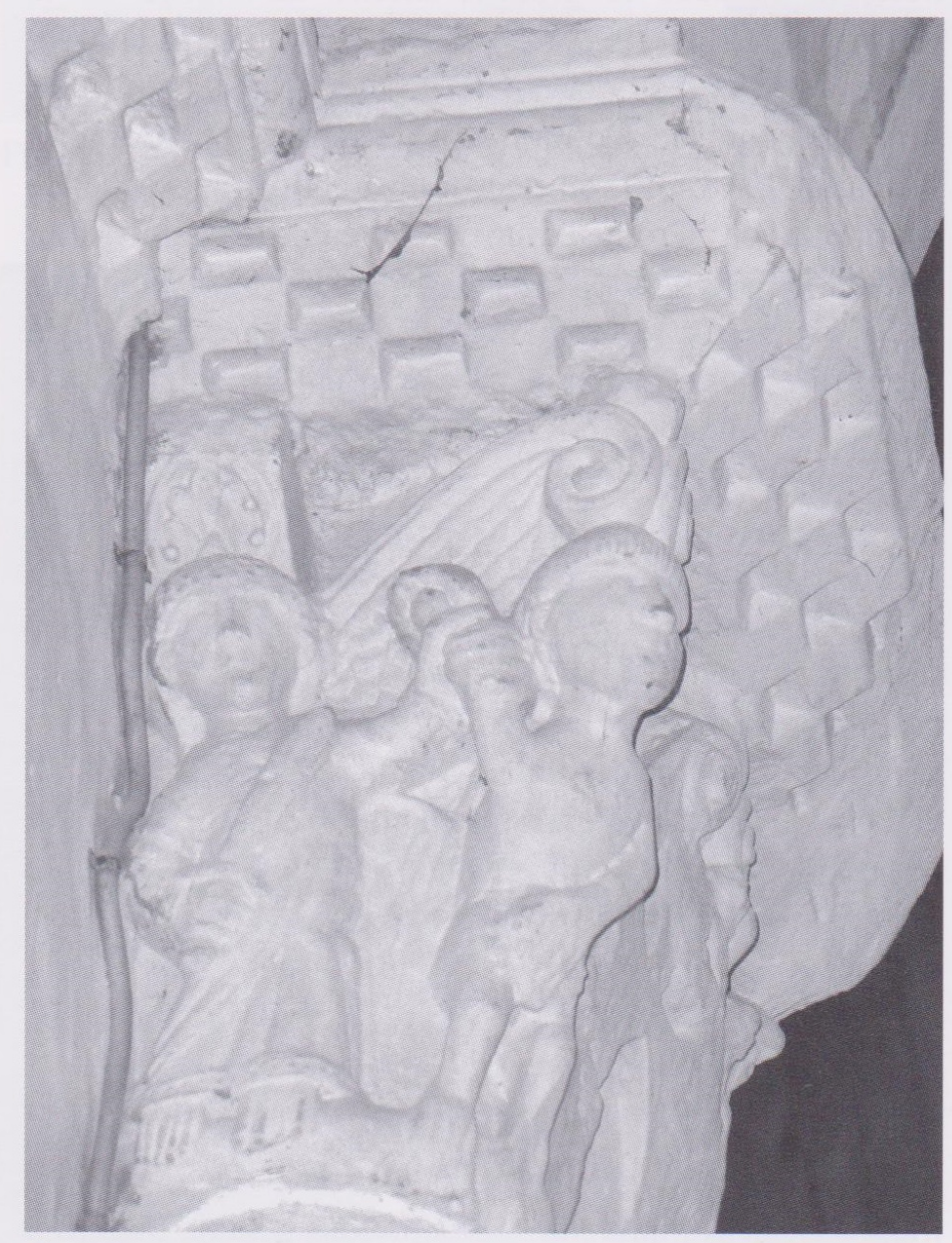

Fig. 29 : Lasserrade, église de Croute, chapiteau n 20. (Cliché C. Balagna) 


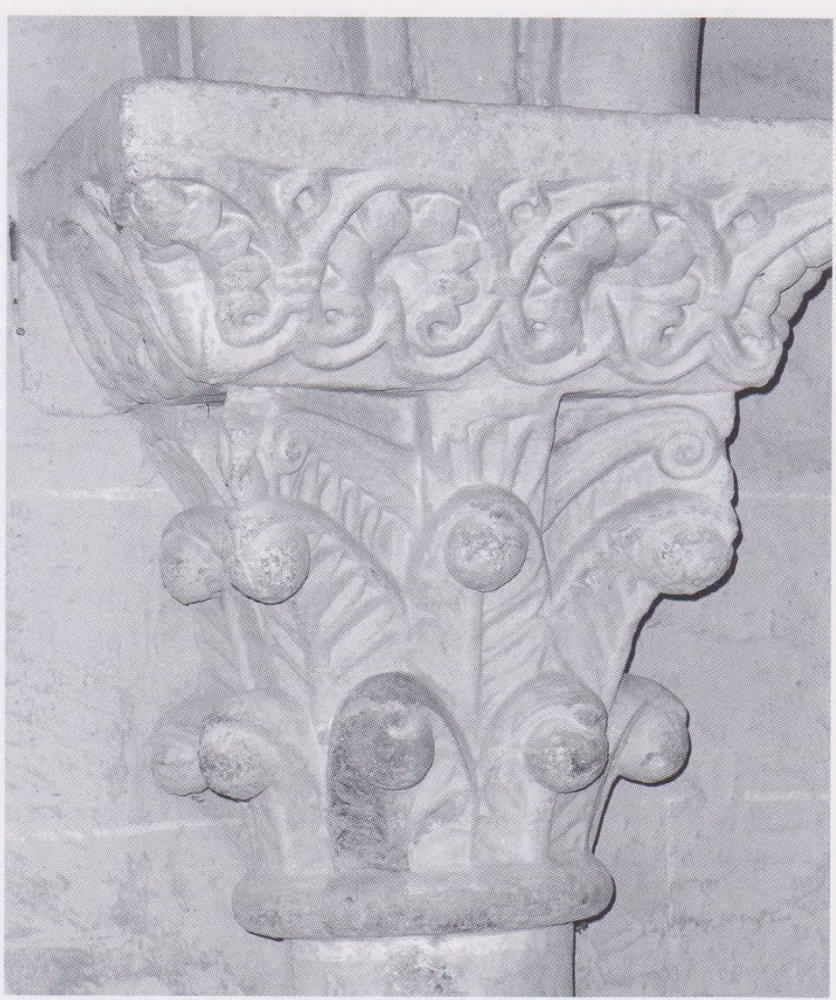

Fig. 30 : Lasserrade, église de Croute, chapiteau n ${ }^{\circ}$ 14, détail. (Cliché C. Balagna)

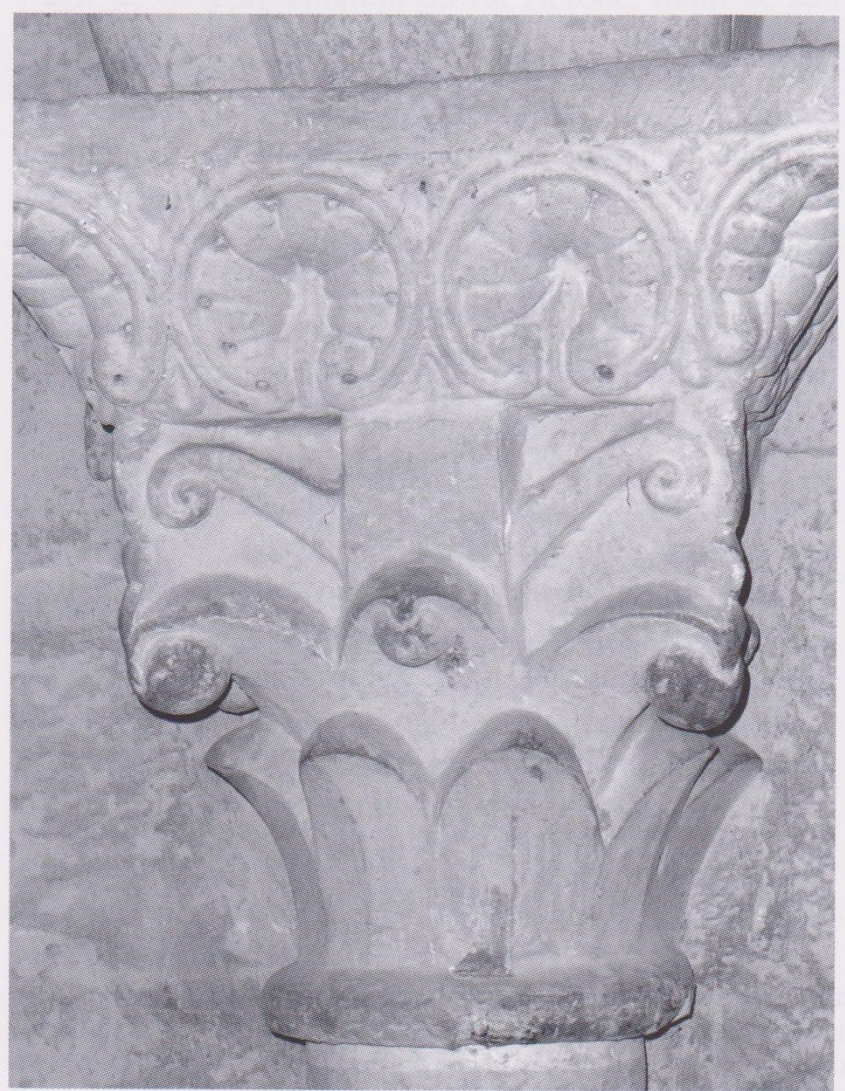

Fig. 31 : Lasserrade, église de Croute, chapiteau n ${ }^{\circ}$ 18. (Cliché C. Balagna) 